\title{
Life stories of selected adults with learning disabilities: How they come to understand and choose to reveal their disabilities
}

Christine M. Sampson

West Virginia University

Follow this and additional works at: https://researchrepository.wvu.edu/etd

\section{Recommended Citation}

Sampson, Christine M., "Life stories of selected adults with learning disabilities: How they come to understand and choose to reveal their disabilities" (2009). Graduate Theses, Dissertations, and Problem Reports. 4526.

https://researchrepository.wvu.edu/etd/4526

This Dissertation is protected by copyright and/or related rights. It has been brought to you by the The Research Repository @ WVU with permission from the rights-holder(s). You are free to use this Dissertation in any way that is permitted by the copyright and related rights legislation that applies to your use. For other uses you must obtain permission from the rights-holder(s) directly, unless additional rights are indicated by a Creative Commons license in the record and/ or on the work itself. This Dissertation has been accepted for inclusion in WVU Graduate Theses, Dissertations, and Problem Reports collection by an authorized administrator of The Research Repository @ WVU.

For more information, please contact researchrepository@mail.wvu.edu. 
Life Stories of Selected Adults with Learning Disabilities:

How They Come to Understand and Choose to Reveal Their Disabilities

Christine M. Sampson

\author{
Dissertation submitted to the \\ College of Human Resources and Education \\ at West Virginia University \\ in partial fulfillment of the requirements \\ for the degree of
}

Doctor of Education

in

Special Education

\author{
Barbara Ludlow, Ed.D., Chair \\ Helen Hazi, Ph.D. \\ David Hoppey, Ph.D. \\ Richard Walls, Ph.D. \\ Diane Woodrum, Ed.D. \\ Department of Special Education \\ Morgantown, West Virginia \\ 2009
}

Keywords: Qualitative Research; Young Adults; Self-Disclosure (Individuals);

Learning Disabilities 


\begin{abstract}
Life Stories of Selected Adults with Learning Disabilities:

How They Come to Understand and Choose to Reveal Their Disabilities
\end{abstract}

Christine M. Sampson

Adults with learning disabilities continue to be impacted by their disabilities throughout their lives. Once they exit formal education, the disclosure of the disability becomes a personal choice. Previous research proposes that although the effects of disabilities are present in the workplace, individuals with learning disabilities are hesitant to disclose their disabilities or request accommodations. Ten adults with learning disabilities were interviewed for this qualitative study to determine how individuals with learning disabilities come to understand and disclose their disabilities. The results suggest that the understanding of what a learning disability means is based upon several factors including the words and actions of others, special education placement, and self-evaluation. Most adults in this study fully- or partiallydisclose their learning disabilities to a variety of people and for an assortment of reasons. They use self-presentation strategies such as covering or passing to minimize or conceal the effects of the learning disability. Demystification and selfdetermination assist with a positive understanding of the learning disability and successful adjustment in adulthood. 
Dedication

To my parents, Michael and Margaret Kulenich, who taught me that we not only learn from formal schooling but from each experience and person that we encounter. I have learned so much.

I love you. 


\section{Acknowledgements}

A thank you does not seem enough to express my gratitude to those who have supported me in this journey. First, I am appreciative to the members of my doctoral committee--Drs. Walls, Hoppey, and Woodrum, and especially Drs. Hazi and Ludlow-for your participation in the process. Your time and guidance have been very helpful as I planned my program, presented my research ideas, and completed the research. Dr. Hazi, your wise words and encouragement for the "birth of this baby" have motivated me to complete what I started; thank you. Dr. Ludlow, your commitment to me over the many years has been remarkable, and I am ever grateful to you for your availability to answer my questions, and to refocus and reassure me. A special thanks goes to Dr. Gabe Nardi. I chose to attend WVU because of our initial meeting over 30 years ago. Throughout the years, your passion for full acceptance of individuals with disabilities has inspired me to become an advocate for social justice as well.

Thank you to my friends and coworkers for your inspiration and patience. Dr. Keely Camden-the discussions as we drove to WVU together are some of the best parts of my graduate education. Whether we were disagreeing over the gel pen or debating ideas about education, there was never a dull moment. Your friendship is invaluable to me. Jerry Schultze, Traci Tuttle, Heather Taylor, and Kathy Steber-I am blessed to work with a staff that made this process easier for me by handling the unexpected "surprises" in the learning center on a daily basis.

I am fortunate to have a family that provides me with unconditional love. Matt, thanks for accepting the times when I could not attend one of your games or watch a 
movie with you because I had to drive to Morgantown or complete class work. You are an amazing son! Bill, I could not have had a better partner in this adventure. You willingness listen to my stories, drive me to my interviews, take care of all of the household chores, and tolerate me when I did not get enough sleep are only a few of the ways that you made my life easier so that I could complete this dissertation. I am so grateful that you are my wonderful husband, and I love you.

Finally, thank you to the adults with learning disabilities who are the participants in this research. Your willingness to share your lives with me was one of the most powerful and unforgettable learning experiences of my life. 


\section{TABLE OF CONTENTS}

Abstract ii

Dedication iii

Acknowledgements iv

Table of Contents $\quad$ vi

List of Tables $\quad$ ix

Chapter One - Introduction 1

Statement of Problem 1

Definition of Terms 2

Purpose of Study $\quad 4$

Research Questions 5

$\begin{array}{ll}\text { Chapter Two - Review of the Literature } & 6\end{array}$

$\begin{array}{ll}\text { Learning Disabilities } & 6\end{array}$

$\begin{array}{ll}\text { Adults with Learning Disabilities } & 7\end{array}$

$\begin{array}{lr}\text { Academic Impact } & 9\end{array}$

$\begin{array}{ll}\text { Vocational Impact } & 12\end{array}$

$\begin{array}{ll}\text { Social Impact } & 13\end{array}$

$\begin{array}{ll}\text { Stigma and Self-Presentational Strategies } & 16\end{array}$

Self-Disclosure $\quad 20$

Self-Determination $\quad 23$

$\begin{array}{ll}\text { Chapter Three - Method } & 27\end{array}$

Introduction of the Researcher 28

Participants $\quad 30$

$\begin{array}{ll}\text { Procedure } & 31\end{array}$

$\begin{array}{ll}\text { Data Collection } & 32\end{array}$

Data Analysis 33 
$\begin{array}{ll}\text { Chapter Four - Results } & 37\end{array}$

Interview Summaries $\quad 39$

Cassie 39

George 42

Heather 48

Henry $\quad 54$

$\begin{array}{ll}\text { Nanci } & 60\end{array}$

$\begin{array}{ll}\text { Pete } & 66\end{array}$

$\begin{array}{ll}\text { Richard } & 70\end{array}$

$\begin{array}{ll}\text { Stan } & 74\end{array}$

Steve 78

Vincent $\quad 83$

$\begin{array}{ll}\text { Composite Summary } & 88\end{array}$

Theme One - Reactions of Others 88

Words of Others 88

Actions of Others 90

Theme Two - Reaction to Self 93

Self-Comparison to Others 94

$\begin{array}{ll}\text { Self-Evaluation } & 96\end{array}$

Theme Three - Impact of Support Systems 99

Impact of Individuals 100

Impact of Placement 103

Theme Four - Changes Throughout the Lifespan 106

Impact of Disability 106

Perceptions of the Learning Disability Label as Stigma 112

Theme Five - Disclosure Decisions 113 
Type of Disclosure 113

To Whom the Disability is Disclosed 117

Purpose of Disclosure 121

Theme Six - Management Techniques 124

Withdrawal 124

$\begin{array}{ll}\text { Covering } & 124\end{array}$

Passing 125

$\begin{array}{ll}\text { Role Acceptance } & 127\end{array}$

Confrontation and Breakthrough 128

$\begin{array}{ll}\text { Chapter Five - Discussion } & 130\end{array}$

Understanding the Learning Disability 130

Disability Disclosure 143

$\begin{array}{ll}\text { Management Strategies } & 147\end{array}$

$\begin{array}{ll}\text { Recommendations } & 149\end{array}$

Limitations of the Study 154

Implications for Future Research 155

$\begin{array}{ll}\text { Conclusion } & 156\end{array}$

$\begin{array}{ll}\text { References } & 157\end{array}$

$\begin{array}{ll}\text { Appendix A } & 163\end{array}$

$\begin{array}{ll}\text { Appendix B } & 166\end{array}$

$\begin{array}{ll}\text { Appendix C } & 169\end{array}$ 


\section{LIST OF TABLES}

Table 1. Relationship of Themes and Subcategories to Research Questions 


\section{CHAPTER ONE}

Introduction

This study researched adults with learning disabilities, their choices to disclose their learning disabilities, and the self-presentational strategies that they use to cope with the effects of their learning disabilities. Through an analysis of interviews, an understanding of the lived experiences of selected adults with learning disabilities emerged. Chapter One includes the statement of the problem, the purpose of the study, the research questions, and the definition of terms.

\section{Statement of the Problem}

Adults with learning disabilities are becoming more visible in today's society. What was once viewed as a disability of children has now become a lifespan disability. The misconception that previously existed that persons with learning disabilities would be cured or the learning disabilities outgrown before adulthood is no longer accepted (Gerber, 2003). This is not the reality, and research in the area of adults with learning disabilities, while limited, is increasing (Patton \& Polloway, 1992). As Price, Gerber, and Mulligan (2003) state, "The question to be answered in the days ahead-one not grappled with yet on the adult agenda-is whether an adult must have learning disabilities in adulthood if he or she was identified as learning disabled during his or her school-age years" (p. 357). Although the interest level of researchers in adults with learning disabilities has increased, few researchers such as Higgins, Raskind, Goldberg, and Herman (2002), McNulty (2003), and Reiff, Gerber, and Ginsberg (1997) have chosen to describe the lived experiences of adults with learning disabilities. The results of this research suggest: 1) Adults with learning 
disabilities go through stages as they develop an understanding of their learning disabilities (Higgins et al., 2002), 2) The life stories of adults with learning disabilities parallel the plot development of a narrative (McNulty, 2003), and 3) Successful adults have the self-awareness to reframe their lives to accommodate their disabilities (Reiff, et al., 1997). Other researchers have investigated the difficulties that adults with learning disabilities encounter or continue to encounter. This research indicates that many adults with learning disabilities experience academic and social difficulties similar to those they experienced in childhood (White, 1985), and they often face problems with obtaining and keeping suitable work (White, 1983; 1985). Although the protection of the rights of individuals with disabilities is being supported with laws such as the Americans with Disabilities Act, many adults with learning disabilities are unaware of their rights or choose to remain silent about their needs in the workplace (Greenbaum, Graham, \& Scales, 1996; Madaus, Foley, McGuire, \& Ruban, 2002; Madaus, Ruban, Foley, \& McGuire, 2003; Price et al., 2003).

\section{Definition of Terms}

Demystification

Demystification is "the process through which adults talk to children about the nature of their learning disorders and strengths" (Levine, 1994, p. 7)

Mark A mark is a sign of deviance that may label a person as flawed, limited, spoiled, or undesirable (Jones et al., 1984). 
Self-determination

Self-presentational strategies

Specific learning disability
Self-determination is the ability to identify and achieve goals based on a foundation of knowing and valuing oneself" (Field \& Hoffman, 1994, p. 164).

Self-presentational strategies are methods a person employs to address a concealable or apparent mark (Jones et al., 1984).

"A specific learning disability is a disorder in one or more of the basic psychological processes involved in understanding or in using language, spoken or written, that may manifest itself in an imperfect ability to listen, think, speak, read, write, spell, or to do mathematical calculations, including conditions such as perceptual disabilities, brain injury, minimal brain dysfunction, dyslexia, and developmental aphasia. The term does not include learning problems that are primarily the result of visual, hearing, or motor disabilities, of mental retardation, of 
emotional disturbance, or of environmental, cultural, or economic disadvantage "34 CFR 300.7(c) (10).

Stigma "A stigma refers to an attribute that is deeply discrediting" (Goffman, 1964, p.3).

\section{Purpose of the Study}

Much of the research conducted about adults with learning disabilities has been quantitative research. While this research has provided data on the effects of disabilities throughout the lifespan and the disclosure of a learning disability in the workplace, the underlying stories of the lived, rich experiences of persons with learning disabilities and their disclosure decision-making have been limited in the research. The purpose of this explanatory study (Yin, 2003) is to examine the how and why persons with learning disabilities come to understand what their learning disabilities mean and may or may not choose to disclose a learning disability. Understanding how individuals with learning disabilities come to know what their learning disabilities mean to them, and why and how they choose to disclose or not to disclose their learning disabilities may enable educators, counselors, family members, and others to better prepare students for more successful experiences in their adult lives. 


\section{Research Questions}

RQ 1: How does an individual with a learning disability come to understand what his or her learning disability means?

RQ 2: How and why do participants engage in self-disclosure?

RQ 3: What self-presentational strategies do adults with learning disabilities use to manage their disability status? 


\section{CHAPTER TWO}

Review of the Literature

The purpose of this chapter is to review the literature on adults with learning disabilities and the self-disclosure of their learning disabilities as it relates to their professional and personal lives. Areas incorporated in this review include learning disabilities, adults with learning disabilities, stigma and self-presentational strategies, self-disclosure of learning disabilities, and self-determination.

\section{Learning Disabilities}

Before Samuel Kirk used the term, learning disabilities, in 1993, physicians were studying their patients with brain injuries to determine the underlying causes of difficulties in language, memory, attention, perception, and daily living skills. Although initial research was conducted with adults, beginning in the 1950s, the focus shifted to children (Gerber, 2003; Lerner, 2003). The focus on the study of learning disabilities in children has continued over the years. Recently, however, some researchers have begun to study learning disabilities in adults (Patton \& Polloway, 1992). According to Gerber (2003), this lack of previous interest in adults with learning disabilities resulted from the misconception that all children with learning disabilities would either be cured of their learning disabilities or outgrow their learning problems by the time they exited secondary school. As the school-aged children identified under PL 94-142 became adults, the realization of this misconception became more obvious. Researchers began to investigate adults with learning disabilities in order to understand the needs adults with learning disabilities (Patton \& Polloway, 1992). 
Adults with Learning Disabilities

Researchers suggest that the impact of learning disabilities in adulthood be examined within the frameworks of adult learning theory models (Gerber, 1994; Price \& Patton, 2003). The demands documented by adult developmental theories indicate that the lives of adults are more multi-faceted than those of children (Patton \& Polloway, 1992). Erik Erikson, Robert Havighurst, Daniel Levinson, Roger Gould, Jane Loevinger, and Carol Gilligan provide theories of adult development that can be used when researching the lives of adults with learning disabilities (Bassett, D.S., Polloway, E.A., \& Patton, J.R., 1994). Gould's model might be especially appropriate. As Bassett et al. (1994) noted

Gould addresses the on-going struggle adults experience between their child and adult personae. Indeed, this struggle might be exacerbated for many adults experiencing learning problems because they may not be able to shed the childhood scripts of failure and isolation they have experienced (p. 15).

As life demands change, learning disabilities in adulthood may manifest themselves differently than they do in childhood and adolescence. Gerber (1994) proposed that the task demands of the differing developmental stages of adult lives might influence the ways learning disabilities impact adults. Several studies have been conducted that attempted to identify the differences throughout the lifespan.

Higgins et al., (2002) conducted a 20-year longitudinal study of 41 individuals with learning disabilities who had attended the Frostig Center. They concluded that individuals who accepted their learning disabilities as adults passed through the stages of: "(a) awareness of their 'differentness'; (b) the labeling event; (c) 
understanding/ negotiating the label; (d) compartmentalization; and (e) transformation" (p. 3).

McNulty (2003) conducted in-depth interviews with 12 adult participants diagnosed with dyslexia. The results indicated that difficulties with self-esteem may begin early in life and are confirmed by the failures experienced in school. In many cases, these self-esteem issues continued throughout adulthood. Some adults used their strengths to compensate for the functional limitations imposed by their disabilities by creating niches. The participants noted the importance of support persons in the development of coping strategies.

Although research has increased, it was primarily focused on adults with learning disabilities who have participated in post-secondary education. These samples are not representative of the entire population (Buchanan \& Wolf, 1986). A few studies have also investigated the impact of learning disabilities using participants in Adult Basic Education, clients of Vocational Rehabilitation Services, and the general adult population as research subjects.

Early research found that adults with learning disabilities struggle academically, vocationally, and socially. In a review of the literature of adults with learning disabilities, White (1985) noted that results indicated adults with learning disabilities have difficulties with social skills, relationships, careers, self-esteem, dependence, reading, spelling, finances, and organization.

White \& Polson (1999a, 1999b) studied adults who participated in Adult Basic Education to develop basic competency in reading, mathematics, or written language or to pursue the General Equivalency Diploma. They concluded that as many as one- 
third of the participants in Adult Basic Education might have disabilities, that learning disabilities might account for one-fourth of the disabilities (White \& Polson, 1999b), and that Adult Basic Education accommodations are the least expensive and not necessarily the most effective (White \& Polson,1 999a).

Ross-Gordon, Plotts, Joesel, \& Wells (2003) conducted quantitative and qualitative research that focused on the assessment of adults with learning disabilities. Adult Basic Education service providers and adults participating in Adult Basic Education indicated dissatisfaction with obtaining formal assessments and understanding the interpretations of results. When evaluations were done, service providers and participating adults reported the lack of communication between themselves and evaluators. Many times reports of results were not provided, or the information provided was too complicated for the adult participants to understand, thus the adults with learning disabilities did not have a clear understanding of their personal strengths and needs.

Academic impact. Many adults who have experienced academic learning difficulties in childhood continue to experience them in adulthood (Buchanan \& Wolf, 1986; Gerber et al., 1990; Hoffman et al., 1987; Malcolm, Polatajko, \& Simons, 1990; Price et al., 2003; White, 1992). Individuals who did not attend college (Minskoff, Hawks, Steidle \& Hoffman, 1989) exhibit greater academic deficits than other adults with learning disabilities.

Frauenheim and Henkerl (1983) in their early longitudinal study of adults with dyslexia found that the areas of weakness identified when these adults were diagnosed as children remained. These included: slow oral reading, poor sight 
vocabulary, and poor decoding skills. Research suggested that spelling was the most significant area of difficulty.

Buchanan and Wolf (1986) used the formal evaluations of 33 adults who had been referred for assessment to study the effects of academic difficulty in adulthood. The researchers collected comprehensive information from the tests (Weshler Adult Intelligence Scales Revised, Woodcock Johnson Psycho-Educational Battery, a writing sample, and occasionally the Developmental Test of Visual Motor Integration) administered to the participants as well as their documented educational histories and an extensive intake questionnaire. The results indicated difficulties in written expression, reading, mathematics, and memory as well as problems with disorganization, mood, discouragement, self-image, and motivation. The researchers questioned the issues with motivation since many of the participants indicated that they worked much harder than those around them to accomplish their goals. Finally, between two-thirds and three-fourths of the individuals reported negative school experiences throughout their lives.

Gerber and Reiff (1991) interviewed nine adult participants with learning disabilities. Based upon educational and vocational achievement, the participants were classified as highly adjusted, moderately adjusted, or marginally adjusted to adulthood. "The interviews of the study's nine subjects demonstrate clearly that each day is one of trials and tribulations stemming from and related to learning disabilities" (Gerber \& Reiff, 1991, p. xiv). The impact of the disability was influenced by its severity. 
Hoffman et al. (1987) surveyed three groups about their perceptions of areas of difficulty that adults with learning disabilities face. The information collected from these groups--381 adults with learning disabilities, 948 service providers such as vocational rehabilitation counselors, teachers, and psychologists, and 212 consumers or advocates—suggested that academic difficulties continued throughout the lifespan. The adults with learning disabilities reported problems in reading and spelling (63\%), arithmetic (47\%) and written composition (41\%). Of the underlying processing skills, memory problems were cited most frequently (30\%). The service providers perceived reading (64\%) and memory (33\%) as the major difficulties, and consumers agreed with both groups that reading and memory were the most significant problems.

In a study of 80 adults suspected of having learning disabilities, Malcolm et al. (1990) found that academics difficulties experienced in childhood continued through adulthood. Seventy-five percent of the study participants reported long-standing problems with reading, writing, and understanding that began in the elementary years. A majority of participants (83.8\%) reported problems with daily living skills such as organization.

Gerber et al. (1990) administered a questionnaire to 133 subject to study the persistence of problems over time. The sample consisted of individuals nominated by national organizations as highly successful adults with learning disabilities. Using established criteria, the researchers classified the participants as either highly successful or moderately successful. The results of the study indicated that difficulties persisted through adulthood, and in many cases grew worse. For example, 
$51 \%$ of the highly successful group and $54 \%$ of the moderately successful group identified reading as becoming worse in adulthood.

In a review of follow-up and follow-along studies of adults with learning disabilities, White (1992) concluded that the academic problems of individuals with learning disabilities persisted throughout adulthood, and the significance of the academic problems was greater if the adults with learning disabilities were participating in post-secondary education. Blalock (as cited in White, 1992) found that $50 \%$ of the participants still experienced reading problems.

Minskoff et al. (1989) concluded that adults with learning disabilities who did not attend college and who were participating in vocational rehabilitation had severe deficits. They found deficits in intelligence, academic achievement, attention, reasoning, auditory memory, language, and self-esteem for the group of 145 adults studied.

In summary, most adults with learning disabilities continue to be plagued by their learning disabilities. The difficulties encountered include reading, written language, math, organization, memory, attention, self-esteem, and motivation. For many adults with learning disabilities, the impact of the disability becomes greater over time. This is especially true of those who did not complete high school.

Vocational impact. Adults with learning disabilities were impacted vocationally because of their learning disabilities. The stigma of the disability, discussed in a later section of this review, coupled with the academic, behavioral, and social manifestations of the disability negatively affected employment (White, 1983; 1985; 1992). 
Adults with learning disabilities experience difficulties with employment. In a study comparing 50 adults with learning disabilities and 50 adults without learning disabilities, White $(1983 ; 1985)$ concluded that adults with learning disabilities were employed in lower status jobs, had lower aspirations, and were less satisfied with their jobs. White's (1992) review of follow-up and follow-along studies of adults with learning disabilities found the greatest amount of research with adults to be in the area of employment possibly because the research in this area is easier to quantify than in the areas of academics and social adjustment. From the research reviewed, White (1992) concluded that a learning disability impacts the areas of socialization, employment, and self-sufficiency. Studies in White's review differed on employment rate of adults with learning disabilities with rates ranging from $36 \%$ to $87 \%$.

Madaus et al. (2003) noted an increase in employment for college graduates with learning disabilities. In their study, perception of self-efficacy was a significant predictor of job satisfaction. While White $(1983 ; 1985)$ found that individuals with learning disabilities were less satisfied with their jobs, Madaus et al. found job satisfaction to equal that of peers without disabilities.

Social impact. In addition to experiencing problems in academic skill competency over the lifespan and issues with employment, adults with learning disabilities exhibit social functioning deficits (Buchanan and Wolf, 1986; Lewandowski \& Arcangelo, 1994; Vogel \& Forness, 1992; White, Alley, Deshler, Shumaker, Warner, and Clark ,1982). White et al., (1982) explored the impact of learning disabilities on individuals after they exit high school. In a comparison of 47 young adults with learning disabilities and 69 young adults without learning disabilities, the 
researchers discovered that the individuals with learning disabilities participated in fewer social and recreational activities than their research counterparts. Buchanan and Wolf (1986) reported that the adults with learning disabilities they studied described themselves as withdrawn, shy, overly passive, moody, insecure, easily discouraged, and self-conscious.

In their extensive review of the literature on social functioning, Vogel and Forness (1992) identified clinical and research studies that documented the difficulties adults with learning disabilities experience. These studies reported a myriad of problems in social functioning: feelings of isolation and loneliness, low selfesteem, problems with interpersonal relationships, helplessness, and social withdrawal. Vogel and Forness (1992) also cited the causes for disorders in social functioning found in the literature. These included: neurological dysfunction as evidenced by word-finding verbal fluency, verbal processing, and memory difficulties; co-morbidity with nonverbal learning disabilities; educational isolation related to the stigma associated with learning disabilities; family systems that are overprotective and encourage learned helplessness; and low self-esteem related to repeated school failure. Price and Patton (2003) noted the effects of educational isolation and low self-esteem. "A lack of self esteem and childhood rejection may be only two ways that learning disabilities will strongly shape the daily lives of students with this invisible disorder" (p. 333).

Lewandowski and Arcangelo (1994) compared the social adjustment and selfconcept of 40 adults with learning disabilities to 41 adults without learning disabilities. The adults with learning disabilities had participated in a resource room or self- 
contained classroom for students with learning disabilities. Study participants completed a set of questionnaires including the Social Adjustment Scale-Self Report and the Tennessee Self-Concept Scale. Researchers found no significant differences between the two groups on either scale. Lewandowski and Arcangelo concluded "any negative effects of a disability classification abate once individuals leave the public school environment, and that previous forecasts of the socioemotional status of adults with learning disabilities may be unnecessarily pessimistic" (1994, p.598). In direct contrast to the conclusions of Lewandowski and Arcangelo (1994), McNulty (2003) found that individuals whose dyslexia was diagnosed in childhood experienced self-esteem issues and insecurity throughout the lifespan. He concluded that they had life-long struggles trying to cope with functional difficulties and the self-esteem issues caused by these difficulties.

Reiff and Gerber (1994) concluded that emotional difficulties might be caused by repeated failures that contribute to feelings of incompetence. In their studies of highly and moderately successful adults, they found that "even successful adults with learning disabilities who have obviously demonstrated keen intelligence, disclose an overwhelming psychological backlash that undermines social relationships" (p. 73).

Not all research on social functioning suggests that individuals with learning disabilities were less well-adjusted than those without disabilities. Goodman (1987) conducted a follow-up study of 29 pairs of female students with learning disabilities and their sisters without learning disabilities. The students with learning disabilities had received support services for academic difficulties at a private center between 1951-1962. The results found little significant difference between members of the 
group in educational attainment or self-concept. The females with learning disabilities were employed in helping professions while their counterparts without disabilities were employed more frequently in scientific or writing professions. Significantly more adults with learning disabilities found educational experiences more difficult and less enjoyable.

In conclusion, many adults with learning disabilities differ from adults without learning disabilities in a variety of ways. They experience more lifelong academic deficits; they have difficulties with unemployment, underemployment, and learning disabilities as they relate to work, and they have less than satisfactory social functioning.

\section{Stigma and Self-Presentational Strategies}

Society views persons with learning disabilities as stigmatized. "Persons with disabilities have often been seen as a marginalized group who experience lower incomes, less job satisfaction, and social stigma" (Field, Price, \& Patton, 2003). The term, learning disabilities, is misunderstood because of a "lack of general knowledge and significant confusion" (Price et al., 2003). This misunderstanding is usually a result of confusion with terminology. Many times persons with learning disabilities are believed to have mental retardation and to be intellectually challenged (Brown, 1994; Gerber \& Price, 2003).

Stigma. In his preface to Stigma: Notes on the Management of Spoiled Identity, Goffman suggests that stigma is "the situation of the individual who is disqualified from full social acceptance" (1964, preface). Society sets standards based upon preconceived attributes. When the individual is different from the set 
attributes for a specific social setting, he or she may be seen as unacceptable or negative (Goffman, 1964).

Goffman (1964) distinguished between those with immediately recognized differences--the discredited, and those whose differences are not immediately known--the discreditable. Jones et al. (1984) used different terminology, but the concept was the same. The term "mark" signifies the conditions or perceived conditions that might lead to stigma. A markable person possesses a mark that might or might not be readily apparent. For the marked person, the difference is recognized; for the markable person, the difference might be concealed. When the difference is revealed, the person becomes marked (p. 8). For example, a person with a physical disability is discredited or marked because the disability is easily recognizable. On the other hand, a person with a mental illness might be considered discreditable or markable since the mental illness is not easily seen (Goffman, 1964).

Link and Phelan (2001) recognized the connection between attribute and stereotype presented by Goffman (1964, p. 4). They broadened the concept of stigma to include five interactive components: "labeling, stereotyping, separation, status loss, and discrimination" (p. 367). The labeling of differences and the separation into "us" and "them" is especially relevant to special education where the segregated classroom or resource room maintains the "us" and "them" philosophy.

Finally, McLaughlin, Bell, and Stringer (2004) defined the stigma of disability as it relates to workplace acceptance as the "perceived negative attributes or consequences of the disability (e.g., with respect to appearance, health, or capabilities). These perceived negative attributes or consequences are implicitly 
deviant from the norm, or expectations for coworkers without disabilities" (p. 304). McLauglin et al. (2004) noted the importance of positive coworker attitudes to the social adjustment of individuals with disabilities in the workplace. They surveyed 643 undergraduate students enrolled in organizational behavior courses; 93\% were currently employed or previously employed. The major findings included: 1) coworker acceptance of a person with disability was not related to physical attractiveness or unpredictable behavior but to whether the disability would impact work performance and 2) stigma mediated coworkers' acceptance of a disability.

For individuals with learning disabilities, the stigma resulting from being labeled as special or not normal, may contribute to the reluctance to disclose their learning disabilities in their professional and personal lives. Placement in a segregated or resource room may reinforce this stigma. The hesitancy to disclose a learning disability may result from a concern that the disability will be interpreted as retardation or a lack of capability.

Self-Presentational strategies. Marked or markable persons can address stigma in several ways. Goffman (1964) discussed two of these: passing and covering. He defined passing as the "management of undisclosed, discredited information about self" (p. 42). For example, a person with a hidden disability might choose to stay away from activities that would expose the disability. For the markable person, one whose stigma is not readily apparent, hiding the mark might be a form of information control (Jones et al., 1984). 
Covering might be used when the mark is known. It involves strategies to minimize the mark's importance in certain situations (Goffman, 1964). Goffman gave the example of a person with severe visual limitations. This person might refuse to read aloud in public to prevent the attention from magnifying the visual disability.

Jones et al. (1984) discussed other self-presentational strategies: withdrawal-staying away from those who do not possess the stigmatizing mark; concealment-similar to passing and covering; role acceptance--living up to the stereotype; and confrontation and breaking through--acknowledging the mark as only one part of the marked person's makeup. They suggested that passing might cause great distress to people trying to conceal their marks. Markable people might have to listen passively to prejudicial remarks about a stigmatizing mark while hiding the mark (Goffman, 1964). They might feel deceitful because of their lack of self-disclosure, and later, others might feel resentment towards them if the mark is revealed. Cohen (cited in Vogel \& Forness, 1992) reiterated these observations. He stated that his clients' fear of being "found out" made them extremely vulnerable. However, others (Olney, Brokelman, Kennedy, \& Newsom, 2004) perceived the denial of a disability as an effective coping strategy because of the stigma associated with the label.

Adults with learning disabilities substantiate the distress of living with a concealed disability (Valle, Solis, Volpitta, \& Conner, (2004). According to Pelkey (cited in Valle et al., 2004), the lives of individuals with learning disabilities parallel the lives of gays and lesbians. Pelkey says

Being LD must be similar to how some gay people feel. You spend so much time and energy trying to hide who you really are. You are ashamed of what you are, and at times you long to be like others, but you are who you are, and so you lead this double life (p.4). 
Valle et al. (2004) used the metaphor of "coming out of the disabilities closet" to illustrate the lives of four practicing or prospective special education teachers with learning disabilities. The researchers conducted three in-depth, one-to-one interviews with each of the four participants. A group meeting was also used as a debriefing strategy and final data collection opportunity. The interviews and meeting were tape recorded, transcribed, coded, and analyzed. The research results indicated that selfdisclosure by the adults with learning disabilities was influenced by their experiences with those to whom they were disclosing. One interviewee described his situation:

I made a very conscious decision...not to tell anybody because of that prejudice...I saw it constantly of how they [the students labeled as learning disabled] would be called dumb and stupid by the people [teachers] who supposedly knew and understood (p. 11).

In conclusion, the stigma surrounding persons with learning disabilities may result from a misunderstanding of terminology (Brown, 1994; Gerber \& Price, 2003) or the labeling and separation process (Link \& Phelan (2001). In the workplace, this stigma may result from the negative attributes individuals attach to the label (McLaughlin et al., 2004). For individuals with learning disabilities, self-disclosure may be difficult because of the discrimination due to stigma. Employers choose not to hire persons with learning disabilities because of prejudice (Minskoff, Sautter, Hoffman, \& Hawks, 1987). Some prefer to hide the disability rather than disclose it even though this can be distressful (Valle et al., 2004).

Self-Disclosure

Considering the perceived stigma surrounding persons with disabilities, selfdisclosure might be difficult. Research indicates that learning disabilities negatively 
impact employment. Many adults with learning disabilities elect to remain silent about the disabilities although they are entitled to accommodations (Greenbaum et al., 1996; Madaus et al., 2002; Madaus et al., 2003; Price et al., 2003). Greenbaum et al. interviewed 49 adults with learning disabilities who had graduated from a large university. Forty percent of the participants did not disclose their disability for fear of discrimination in hiring or stigma and prejudice.

Madaus et al., (2002) surveyed 132 graduates with learning disabilities who attended a large university to assess rates of and rationales for self-disclosure to employers. From the responses of 89 individuals, the results indicated that $66.3 \%$ did not disclose their disability; $53 \%$ felt no need to disclose; over $46 \%$ believed that disclosure would have a negative impact on relationship with supervisor (20.2\%), with coworkers $(13.5 \%)$, or on job security (12.4\%).

Even though learning disabilities were reported by adults to impact their job performances, frequently they did not self-disclose to employers or coworkers because of the fear of negative repercussions (Madaus et al., 2003). Research suggests that employers have negative attitudes towards hiring persons with learning disabilities. Minskoff et al. (1987) surveyed 36 employers from six states. The results indicated that only one-half would hire persons with learning disabilities. Although knowledgeable about learning disabilities, the employers were reluctant because of prejudice or lack of experience. Scheid (2005) concluded that stigma concerning mental disabilities such as learning disabilities affected employers' responsiveness to the Americans with Disabilities Act (ADA). The study's employers reported they were 
more comfortable hiring high school dropouts than employees with learning disabilities.

Kakela and Witte (2000) studied the reasons that college graduates disclosed or did not disclose their learning disabilities to their employers. Of the 22 survey respondents, $71 \%$ had not disclosed their disabilities to their employers because they did not see a need to disclose. Fear of reprisal and misperception were also given as reasons. Of the $29 \%$ that disclosed, respondents accepted that their disabilities were just a part of who they were.

In addition to the reasons given for non-disclosure of a learning disability to employers such as fear of discrimination, misunderstanding of the learning of the learning disability, and the lack of need to disclose, individuals might not be aware of the protections provided by the Americans with Disabilities Act. Laws have been enacted to prevent discrimination in the workplace. Anderson, \& Kasmierski (1995) noted that the Titles I and II of the Americans with Disabilities Act have the most impact on individuals with learning disabilities. Title I prohibits employment discrimination because of a disability, and Title II prohibits discrimination in all aspects of state and local governments. Greenbaum, et al. (1996) concluded that adults with learning disabilities were "either unaware of, or unwilling to exercise, their legal rights as defined by the Rehabilitation Act of 1973 and the Americans with Disabilities At of 1990" (p. 172). Madaus, Gerber, and Price (2008) substantiated this conclusion. They reported, "Adults with LD are largely unaware of the ADA" (p. 149). Harlan and Robert (1998) found that instead of disclosing learning disabilities and requesting accommodations in the workplace, adults with learning disabilities 
may conceal or minimize their disabilities through personal compensation. They found that adults with disabilities may conceal their disabilities by "limiting their own opportunities" (p. 416) by not seeking a job or quitting a job that may reveal their disability. Adults with learning disabilities may minimize the impact of their disabilities by working "harder and for longer hours as others in the same job title" (p. 415).

Adults may not disclose their learning disabilities for a variety of reasons. Price, Gerber, and Mulligan, (2007, p. 343) list six concerns that hinder selfdisclosure:

1. knowing how to talk about LD;

2. knowing one's specific LD profile;

3. knowing the risks and benefits of self-disclosure;

4. knowing how to self-advocate on an on-going basis;

5) knowing the elements of the ADA and how to put them into action; and

6) knowing accommodations and supports that can be helpful in a work environment.

Research suggests that they may fear negative repercussions or a misinterpretation of the learning disability. Madaus, Gerber, and Price (2008) emphasize the importance of self-awareness and self-determination in disclosing a disability.

\section{Self-Determination}

As the focus of learning disabilities shifts from children to include the wider age span of adults with learning disabilities, the transition from secondary education to adulthood needs to address the planning and preparation for settings demands of the adult world. The secondary curriculum must be adjusted to be proactive and preventative instead of reactive and remedial. Transition plans should focus on adult adjustment and include strategies that promote self-determination. Self-determination 
is "the ability to identify and achieve goals based on a foundation of knowing and valuing oneself" (Field \& Hoffman, 1994, p. 164).

Although transition plans are mandated in high school, several researchers indicate that self-awareness should begin in elementary school (Hitchings, Retish, \& Horvath, 2005; Kohler \& Field, 2003; Levine, 1994). Kohler and Field (2003) suggest "students develop and strengthen self-determination skills through practice" (p. 176). They stress that self-awareness-a component of self-determination--is especially important in developing short- and long-term goals.

Levine (1994) discusses the importance of demystification, "the process through which adults talk to children about the nature of their learning disorders and strengths" (Levine, 1994, p. 7). Demystification develops self-awareness. The five steps for demystification included: introduction, discussion of strengths, discussion of weaknesses, induction of optimism, and alliance formation. During the discussion of strengths and weaknesses, adults provided concrete examples followed by feedback from the students. This process is a continuous one; it permits the individual to develop a self-awareness of individual strengths and weaknesses especially as they apply to specific situations.

Gerber, Ginsberg, and Reiff (1992) determined the themes that pervaded the lives of highly successful adults with learning disabilities. Foremost was control; these successful individuals took control of both the internal and external decisions that shaped their lives. Internal decisions involved desiring to excel, setting goals, and reframing experiences with learning disabilities. Reframing requires a person to reinterpret the learning disability in a way that is more positive. To do so, one must 
identify strengths while still being aware of the weaknesses (Gerber, Reiff, \& Ginsberg, 1996); reframing requires self-awareness. The external condition of adaptability is also necessary. Highly successful individuals with learning disabilities are persistent, look for goodness of fit, use creativity, and find supportive social ecologies (Gerber et al., 1992). Goodness of fit enables individuals to fit themselves into situations that use their strengths (Ginsberg, Gerber, \& Reiff, 1994). In order to so do, one must be aware of personal strengths—self-awareness.

Gerber and Price (2003) reported the importance of self-awareness and selfadvocacy in employment. They concluded that employers wanted individuals with learning disabilities to be self-advocates by providing guidance and feedback about their disabilities. Many employers were willing to make accommodations once the employee provided information concerning his or her strengths and weaknesses (Gerber \& Price, 2003).

Although self-determination seems to be a natural goal for the secondary, or even elementary curriculum, several researchers reported that transition plans do not address it. Grigal, Neubert, Moon, and Graham (2003) surveyed parents and teachers about self-determination for students with disabilities. They found that although $98 \%$ of the parents believed self-determination to be important for adult success, only $78 \%$ believed that the skills necessary for self-determination were being taught. Smith, Finn, and Dowdy (cited in Kavale \& Forness, 1996) found that many high school Individual Education Plans do not focus on the difficulties students will face during adulthood. Because of this students might not have the necessary understanding of their strengths and weaknesses to become self-advocates. 
The research on self-determination suggests that even though success in adulthood requires an awareness, understanding, and acceptance of strengths and weaknesses, some individuals with disabilities still lack these. Madaus et al. (2008) concluded that adults with hidden disabilities need "a knowledge of both strengths and weaknesses, as well as a high level of SD [self-determination] skills" (p. 151). Without these, adults with learning disabilities may have difficulty reframing their disabilities in the most positive way.

\section{Summary}

Learning disabilities impact individuals throughout the lifespan. Difficulties in basic skills and behavior continue throughout adulthood. As with many other disabilities, the stigma of being different can affect self-disclosure, social adjustment, and employment. Although laws are in place to protect individuals with disabilities from discrimination, many adults either do not know about the laws or choose not to use them. Successful transition to the adult world requires an awareness, understanding, and acknowledgement of the individual strengths and weaknesses. By using this knowledge, adults with learning disabilities can successfully adjust to the demands of their ever-changing adult roles both in their personal and professional lives. The skills necessary for self-determination must be a part of the secondary, and perhaps, the elementary curriculum for anyone identified as disabled. 


\section{CHAPTER THREE}

Method

This study will explore how adults with learning disabilities come to understand their learning disabilities and how and why they make choice about self-disclosure and self-presentational strategies. The main focus of this study is to describe the phenomenon of learning disabilities and how this phenomenon affects self-disclosure of the learning disability.

A case study "investigates a contemporary phenomenon within its real-life context" (Yin, 2003, p. 13). A collective case study was used to investigate the how adults with learning disabilities come to understand their disabilities and make decisions about self-disclosure and self-presentational strategies. Stake (2000) explains a collective case study is an instrumental case study-one that examines a specific issue_-and that "a researcher may jointly study a number of cases to investigate a phenomenon" (p. 437). This collective case study has a phenomenological focus, and this focus represents "the people's experience of the world" (Patton, 2002, p.107).

Because the researcher is the instrument in a qualitative study, the researcher must establish credibility. She must discuss the personal lens through which the information is being filtered, and "report any personal and professional information that may have affected data collection, analysis, and interpretation" (Patton, 2002, p.107).

This chapter begins with an introduction of the researcher and the background brought to the study by the researcher. It then moves to a discussion of the purposlve 
sampling of the participants and data collection. Finally, it concludes with the data analysis procedures.

\section{Introduction of the Researcher}

For over 30 years, I have been aware of the negative perceptions of others about learning disabilities. From my first teaching experience in 1974 to my current position as the director of a college learning center, I have been repeatedly reminded of the negative impressions others have about individuals with learning disabilities. Since my students do not learn in traditional ways, teachers and other students perceived them as unmotivated and less intelligent. Every time I changed jobs, I had to teach other faculty and administration that the students I taught were competent individuals. I became aware of a variety of strategies that individuals used to protect themselves from failure and from others finding out about their disabilities. Their learning disabilities were not self-disclosed; they had no choice about disclosure since the identification of the disability was directly tied to program services.

About midpoint during my career, I heard Paul Gerber and Henry Reiff speak at a Council for Exceptional Children convention about their research on successful adults with learning disabilities. I became a proponent of self-awareness and selfadvocacy for individuals with learning disabilities. I saw self-disclosure as a positive way of coping with a learning disability. At this time, my college students would speak about their learning disabilities to elementary-high school students. They traveled throughout West Virginia serving mentors and role models to students throughout the state. Upon exiting college, the attitudes of some of the students towards selfdisclosure changed. Some students became silent about their disabilities. It was 
almost as if they felt the disability would disappear if they did not talk about it. For example, a former student, who is now a teacher, hides her learning disability from her students even though she teaches middle school students with learning disabilities. A very personal experience helped me to feel the potential of stigma and discomfort that I suspect many of my students coped with on a daily basis. Our son is diagnosed with Attention Deficit Disorder (ADD), but we rarely discuss this outside of our family. While in high school, his dad and I were driving him and a very popular teammate to a hockey tournament. Our son had just recently transferred to this school, and he was just beginning to make friends. His teammate was describing another player who had ADD. He stated that the ADD made the other player "crazy," and that it was difficult to play with someone who acted "nuts" all of the time. I sat silent, saddened that our son had to listen to someone whom he respected berate another student about a disorder similar to his own. I was angry, hurt...silent. The car that had just been filled with excited chatter about the upcoming game was silent too. After a few moments, our son said confidently, "I have ADD too, and I'm not crazy." Instead of being proud that my son was comfortable disclosing this, I was fearful of the negative consequences to come. There were none. Instead, the teammate replied, "Oh, okay," and the conversation switched to fast food. I realized that daily individuals with learning disabilities might repeatedly experience the discomfort that I felt in the situation.

Within the last few years, I have provided academic skills instruction to a student-athlete with a learning disability. When I attended his games, I was bombarded with the ignorance of other students and adults who ridiculed him by 
chanting "Hooked on Phonics." I listened to adults comment that he would never get into a college because he was in special education and that he was not "smart enough" to play at a higher level. I was, and still am, very angry about how others perceived him.

I worked very hard to not only acknowledge the feelings that I have about learning disabilities, stigma, and self-disclosure, but also to assure that these preconceptions did not bias how I collected and analyzed the data, and I documented this in a researcher's notebook. In qualitative research, transparency enables the reader of the study to "assess the intellectual strengths and weaknesses, the biases, and the conscientiousness of the interviewer" (Rubin \& Rubin, 1995, p. 86). Rubin and Rubin (1995) recommend two researcher's notebooks—one for interview notes and another to assist with the development and demonstration of transparency.

\section{Participants}

Purposive sampling relying upon specific criteria was used to select participants for this study. Purposive, or purposeful, sampling "focuses on selecting information-rich cases whose study will illuminate the questions under study" (Patton, 2002, p. 230). The specific criteria for this study were: 1) Each participant must have been identified as having a learning disability by a qualified professional and have received services in elementary and/or middle school, and 2) Each participants must have or had a job—full or part-time—within the last year.

Participants for the study were solicited from a high school and college within the state. Morse (as cited in Ryan \& Bernard, 2003) "suggests using at least six participants in studies where one is trying to understand the essence of an 
experience" (p. 274). Fourteen persons responded that they would like to participate in the project. Four persons did not meet the criteria to participate in the study, were unable to participate in face-to-face interviews, or were unable to be contacted, thus ten participants were interviewed. Three of the participants were female, and seven were male. Seven were college graduates, and three attended college but did not graduate. All had or were holding a full-time job during their the last year. All had been diagnosed with a learning disability during their elementary years and had received special education services.

\section{Procedure}

Before collecting data for the study, the researcher presented the prospectus to her doctoral committee. Once the prospectus was approved, the researcher constructed the semi-structured interview protocol based upon subject areas discovered during the literature review. The original interview protocol was submitted to a panel (Reiff, Gerber, \& Ginsberg, 1997) of three experts-Dr. Paul J. Gerber, Dr. Joseph Madaus, and Dr. Michael McNulty--for feedback. Each of these individuals has expertise in both qualitative research and adults with learning disabilities. Drs. Gerber and Madaus also have expertise in self-disclosure in the workplace. The feedback focused on word choices and the ordering of questions. The revised interview protocol (Appendix A) was submitted to the Institutional Review Board (IRB) along with the letters of support from the Superintendent of the public school system and the Vice President of Academic Affairs of the college. 


\section{Data Collection}

Once IRB approval was received, the Special Education Department Chair of the high school and the Director of Disability Services were contacted and provided with packets containing a cover letter explaining the purpose of the study and a numbered, colored response card and a self-addressed, stamped envelope to be returned to the researcher if the recipient was or was not interested in participating. Ninety-eight packets were mailed to students with learning disabilities who had attended the college within a five-year span and who had disclosed their disabilities. Eighteen response cards were returned-eleven willing to participate and seven not willing. Sixty-four packets were mailed to students with learning disabilities who had attended the high school. Seven response cards were returned-three willing to participate and four not willing.

Once the response cards were received, the researcher attempted to call each responder who was interested in participating. Three of the respondents were disqualified; one had never had a job; one was not diagnosed until her senior year of college, and one could not do a face-to-face interview because she lived in England. The researcher was unable to contact through mail, email, or by phone the fourth responder who did not participate in the study.

The face-to-face, semi-structured interviews took place in seven states and at the convenience of the participants. In semi-structured interviews, "the interviewer introduces the topic, then guides the discussion by asking specific questions" (Rubin \& Rubin, 1995, p.5). The participants chose the locations for the interviews. They included homes, recreation facilities, restaurants, libraries, and places of work. The 
semi-structured interviews lasted between $1 \frac{1 / 2}{2}$ and $3 \frac{1}{1} 2$ hours and were taperecorded. The researcher recorded impressions of and notes about the interview in a second researcher's notebook. Each of the tape-recorded interviews was transcribed verbatim for use during data analysis.

\section{Data Analysis}

The data were analyzed using the approach described by Rubin and Rubin (1995). "We each read and reread the interviews to note core ideas and concepts, recognize emotive stories, and find themes. We code the material to group similar ideas together and figure out how the themes relate to each other" (p. 229).

Several readings of the transcript interviews provided the initial codes or categories. The categories were listed in the researcher's notebook with a specific definition for each category. As the transcripts were re-read, words, groups of word, sentences, or paragraphs were underlined and categorized. As new categories emerged, they were added to the notebook. The 3, 421 data segments were transferred to data cards, and the cards sorted into the different code categories. To enhance the authenticity of the analysis as well as refine the code definitions, checkcoding (Miles and Huberman, 1994, p. 64) was done. An independent coder with experience in qualitative research and learning disabilities sorted 100 cards into their respective code categories. Each time a code differed from that of the researcher, the difference was discussed to determine alternative views. Using the formula

$$
\text { Reliability }=\frac{\text { Number of agreements }}{\text { total number of agreements + disagreements }}
$$

intercoder reliability was $73 \%$ for the first 100 cards. Miles and Huberman (1994, p. 64 ) indicated that the initial coding is usually no better than $70 \%$. After six of the 
twenty codes were clarified by adding examples and non-examples, $88 \%$ agreement was obtained on the remaining 200 data cards. This was very near the $90 \%$ suggested by Miles and Huberman (1994, p. 64).

Rubin and Rubin (1995) suggest that clustering or axial coding be used to determine themes. Axial coding is "organizing the ideas into grouping of ideas that are thematically related" (p. 247). Each of the coded categories was then grouped into six themes and sixteen subcategories. Four of the initial code categories were combined into two categories-Negative actions of others and Positive actions of others became Actions of Others, and Positive words of others and Negative words of others became Words of others. Two of the initial categories were subsumed within another. To whom not disclosed was subsumed into To whom disclosed, and Stigma was combined with Perceptions of the disability. This resulted in sixteen subcategories. Table 1 visually represents the connections of the themes and subcategories to the three research questions: 1) How does an individual with a learning disability come to understand what his or her learning disability means? 2) How and why do participants engage in self-disclosure? 3) What selfpresentational strategies do adults with learning disabilities use to manage their disability status? 
Table 1

Relationship of Themes and Subcategories to Research Questions

\begin{tabular}{|c|c|c|c|}
\hline & $\begin{array}{l}\text { Research } \\
\text { Question } 1 \\
\end{array}$ & $\begin{array}{l}\text { Research } \\
\text { Question } 2 \\
\end{array}$ & $\begin{array}{c}\text { Research } \\
\text { Question } 3 \\
\end{array}$ \\
\hline \multicolumn{4}{|l|}{ Theme 1} \\
\hline Reaction of Others & $\mathrm{x}$ & & \\
\hline Words of Others & $\mathrm{x}$ & & \\
\hline Actions of Others & $x$ & & \\
\hline \multicolumn{4}{|l|}{ Theme 2} \\
\hline Reaction to Self & $\mathrm{x}$ & & \\
\hline Self Comparison to Others & $x$ & & \\
\hline Self-Evaluation & $x$ & & \\
\hline \multicolumn{4}{|l|}{ Theme 3} \\
\hline Impact of Support Systems & $\mathrm{x}$ & & \\
\hline Impact of Individuals & $\hat{x}$ & & \\
\hline Impact of Placements & $\mathrm{x}$ & & \\
\hline \multicolumn{4}{|l|}{ Theme 4} \\
\hline Changes Throughout the Lifespan & $\mathrm{x}$ & & \\
\hline Impact of Disability & $x$ & & \\
\hline Perceptions of LD as a Stigma & $x$ & & \\
\hline \multicolumn{4}{|l|}{ Theme 5} \\
\hline Disclosure Decisions & & $\mathrm{x}$ & \\
\hline Type of Disclosure & & $\hat{x}$ & \\
\hline To Whom Disclosed & & $x$ & \\
\hline Purpose of Disclosure & & $x$ & \\
\hline \multicolumn{4}{|l|}{ Theme 6} \\
\hline Management Techniques & & & $\mathrm{x}$ \\
\hline Withdrawal & & & $\hat{x}$ \\
\hline Passing & & & $\mathrm{x}$ \\
\hline Covering & & & $x$ \\
\hline Role Acceptance & & & $x$ \\
\hline Confrontation and Breakthrough & & & $x$ \\
\hline
\end{tabular}

After grouping the data into themes and subcategories, interview summaries were written that presented an overview of each interview along with the words the participants used that illustrated the themes and subcategories. 
To establish the authenticity of the study, member checks were used. Lincoln and Guba (1985) state that member checking is "the most critical technique for establishing credibility" (p. 314). Participants reviewed their interview summaries for completeness and correctness. They responded with their thoughts by email or phone. Phone conversations were tape-recorded-with the permission of the participant-and the tapes transcribed. Only one participant did not respond to the interview summary. Examples of participants' comments about the interview summaries are found in Appendix B. 


\section{CHAPTER FOUR}

Results

\section{Introduction}

The purpose of this chapter is to report the data from the interviews of ten adults who were identified as having learning disabilities and who received special education services during their K-12 experiences. The data were recorded and analyzed according to the method described in Chapter Three. This information is presented in three sections. First, a summary of each interview is included to provide an overview of each participant's experience with her or his learning disability. The summaries tell the stories of the participant's life experiences with their disabilities.

Second, the interviews and interview summaries are collapsed into a composite summary. The composite summary focuses on the six themes uncovered in the analysis of the interview data. These themes are: Reactions of Others, Reactions to Self, Impact of Support, Changes Throughout the Lifespan, Disclosure Decisions, and Management Techniques. Each of these themes is broken down into sub-themes or categories.

The first four themes, Reactions of Others, Reactions to Self, Impact of Support, and Changes Throughout the Lifespan, are associated with the first research question: How does an individual with a learning disability come to understand what his or her learning disability means? The first theme, Reactions of Others, is used to describe how others contribute to the participants' understandings of their learning disabilities. This theme includes the sub-categories of Words of Others and Actions of Others. 
The second theme, Reactions to Self, is defined as the participants' comparisons of themselves to others and their examinations of personal strengths and weaknesses. This theme includes Self-Comparison to Others and SelfEvaluation.

The third theme, Impact of Support, describes the effects of placement decisions and support persons on the participants' understandings of their disabilities. The sub-categories associated with this theme are Impact of Individuals and Impact of Placement.

Theme Four, Changes Throughout the Lifespan, depicts the participants' views on their disabilities and the impact of the disabilities throughout their life spans. The sub-categories are Impact of Disability and Perception of the Learning Disability Label as a Stigma.

The fifth theme, Disclosure Decisions, addresses the second research question: How and why do participants engage in self-disclosure? This theme describes the level of disclosure, to whom the disability is disclosed, and why/when the disclosure occurs. The subcategories for this theme include Type of Disclosure, To Whom the Disability is Disclosed, and Purpose of Disclosure. The final theme, Management Techniques, addresses the third research question: What selfpresentational strategies do adults with learning disabilities use to manage their disability status? Management techniques include those strategies used by the participants to hide or minimize the impact of the learning disability. The five subcategories covered in this theme are Withdrawal, Passing, Covering, Role Acceptance, and Confrontation and Breakthrough. Covering is defined as strategies 
for minimizing the effects of a known disability or weakness, and Passing is defined as strategies for hiding the disability or weakness. Role acceptance is accepting the stereotype of the mark or disability and acting in accordance with the stereotype, and Confrontation and Breakthrough is the acceptance of the learning disability as a part of the whole identify and not the whole identity.

\section{Interview Summaries}

\section{Cassie}

Cassie was a 25-year-old female who lived and completed her K-12 schooling in the same Mid-Atlantic state in the United States. After graduation from high school, Cassie began attending a community college; she withdrew after a semester because she believed she was "not good at college." She held several part-time jobs before being employed full-time for the last five years as a child-care provider at daycare facility. She lived at home with her parents and sister.

Cassie remembered being retained in the first grade. Even before entering public school, she had speech and language services from an independent agency. Cassie was diagnosed as having a learning disability in the third grade, and she remembered the term, learning disabled, being used to describe her when she was in the fourth grade and "things just got harder." She did not receive much in-school support. "I did get help on some tests. I always felt the lack of something because I didn't receive the help I needed." Cassie was mainstreamed for all of her classes with resource support as necessary. To supplement the school support, she met with an outside tutor several days per week. 
Cassie viewed her strength as "hand-on learning," and elaborated that "if it is more hands-on, I can probably do it." Cassie noted her weaknesses as comprehension, writing, and math. "Uhm, comprehending things, understanding things. Sometimes it takes me a while. Sometimes reading and then trying to get it down on paper. Sometimes I don't get it right away."

Cassie's understanding of her learning disability developed primarily through the actions of other and self-evaluation. Cassie stated that she was protected during her life because she got severe migraines. "I was kind of sheltered. I feel that I was sheltered more and maybe I wasn't allowed to do the normal things that other kids were allowed to do because I had to be careful." Many of the actions of teachers were the things the teachers did not do. Cassie reported that she did not receive much help from teachers while in school. "If I did need help, I did get help on some tests, but other than that-nothing. No one taught me how to prepare." Cassie did not believe that the help she was getting was what she needed. "If I needed help with a test, I would go down and take my time. If I needed extra time, I would just go down. I don't know. Sometimes I wondered if it was helping me." Cassie stated that both in school and on the job she wasn't provided with the help she needed. While attending community college, she found support was lacking. "I tried to talk to the learning lady down there, but she just acted like she didn't have time." She also spoke to her professor. "She was new, but I talked to her in class. She was like, 'You need to go to tutoring,' and I did, but tutoring did not work." Of her previous jobs, Cassie said, "I think in the past, I had trouble working with things, sometimes understanding things. They didn't show me how to understand it. You just had to figure it out on your own 
or you were up the creek." Cassie's family's and current employer's actions supported her. "My parents and sister are just they for me. They help immensely. They would find me help with anything." Of her current employer, she stated, "They set me up, and I did graduate from child care classes. I am going to start another class; it's continuing education and more hands-on. They make sure that I understand." Cassie understood the Americans with Disabilities Act was enacted to provide persons with "disabilities the right to the same things as everybody else." She did not see how it applied to her in her adult life.

Cassie's self-evaluation also helped her to understand her learning disability. Cassie's comments about her education and lack of support, her need for hands-on learning to be successful, and the impact of her disability were examples. Cassie found learning frustrating.

Not knowing how to do it; not knowing how to get from here to there pains me. I try to understand it the best I can, and if I don't, I ask questions. I would get frustrated. It just felt like I was always behind.

Cassie openly talked about her learning disability, but her disclosure usually focused on where she needed help. Her friends, boyfriend, and employer knew that she had trouble "comprehending." Cassie's boyfriend accepted her disability. "He knows that I don't understand. I am very open with him, and he loves me anyway." Cassie also stated, "I just don't go out and tell everybody. I just don't go up to someone and say, 'I have a learning disability. I would tell them that I have trouble understanding and I may need some extra work. I am not one to cover up. Cassie's attitude about acceptance is 
I more or less let people come to me. If they want to be my friend, they need to take me as I am. If you want to gravitate to me, fine. If not, I will wave to you and that's it.

Cassie's self-presentational strategies included passing and covering. Cassie admitted to staying away from activities that exposed her learning disability. She did not want to do the nursing assistance program recommended by Vocational Rehabilitation because it would tap into the areas in which she displayed weaknesses such as math and science. On the other hand, Cassie was forthright about her weaknesses and her need for support. She asked for help when necessary explaining that she was a little slower about understanding things. When asked about the Americans with Disabilities Act, Cassie indicated she knew very little. She believed "that every American with disabilities has the right to the same things as everybody else."

Overall, Cassie understood that her learning disability complicated her life by affecting her educationally. She was open to those with whom she felt comfortable and would ask for help from family, friends, employers, and education personnel. Although she disclosed her needs, she did not fully discuss a learning disability, thus her disclosure was partial. Cassie was satisfied with her current job but continued to consider other avenues for employment, as long as they did not magnify her disability. Cassie was secure in knowing that she had a family and a significant other that understood her disability and helped her to manage its impact on her life. George

George was a 31-year-old male who lived most of his life in a metropolitan area of a Mid-Atlantic state. The only exception was the four years that he spent 
attending a small, Southern liberal arts college. After graduating from college, George had a variety of full-time jobs in recreation management, education, and high-end retail. He was currently employed as a program coordinator for a social service agency. Throughout his schooling and employment, George had uneven successes. George recounted that he "managed to excel in some things and struggle with other things, uhm which has kind of been the story of my life."

George remembered that his learning disability was diagnosed near the end of fourth grade. He had been attending a public elementary school with large classes, and he began falling behind. "I got lost in the shuffle," he stated. His mother, who was an educator, noticed something was wrong, had him tested, and transferred him to a small, private school that he attended until the end of eighth grade. The private school classes averaged 6-8 students, and it "had a great support system, brilliant teachers, probably one of the best grade schools in the country." George transferred to the large public high school in the ninth grade, but found services lacking. "They didn't have a proper support system for learning disabilities and things of that nature." George's learning disability affected many aspects of his life. He noted that when he was younger, his major problem was in reading, but he also had difficulties in organization, attention, memory, writing, and oral language. He stated I have a lot of problems, some problems in writing. I would say, um, putting my mind on paper, putting my thoughts on paper. I struggle with that a lot. Also interpreting things-speaking to people, explaining things, I specifically struggle with.

These problems affected George's life daily. His performance evaluations and his personal life were influenced negatively by his disability. "I usually do not get a good organization performance record. Uh, to be honest with you, it is something I still 
have problems with." As for his personal life, his disability caused complications in his marriage. George described an incident where he tried to explain something to his wife, but he couldn't do it properly, and it escalated into an argument. His confusion was apparent.

I really hit a point where I was just so upset about it, so upset and frustrated and really it was just explaining something that somebody else said-just the way it came out was all wrong, It was horrible. And I remember thinking, "Why the hell... how in the hell does this happen to me?'

George's learning disability continued to affect his life in a variety of ways, and he commented, "As I get older, the more I realize that it is with me every day [emphasis added], and it's not going away."

George's understanding of his learning disability was based upon the actions of others, self-comparison to others, and self-evaluation. The actions of others contributed to George's initial understanding of his learning disability.

I remember hearing the buzz about it through my mom. I remember her talking to people about it, and I have to admit, it hurt. They way they went about treating me was like they took me out of the classroom.

George had a supportive family. "My family has been very understanding of it for the most part. They have definitely been a help to me." Although they were supportive, the reactions of his family to the complications caused by his disability were troublesome. "I think the worst effect was the stress on my family, putting my parents through stress. I could tell sometimes. I could definitely see it. I had my mother who was sympathetic but frustrated at the same time." George found that most of his high school teachers lacked understanding of his disability. "When I was like, you know, 
I'm having problems with this, that, and the other thing, it would be, 'Too bad; it's what you got."'

George also compared himself to his peers. He remembered, "There were three or four of us in our own little reading class which was a little slower and worked at a different pace." Studying for and failing tests was frustrating and George concluded, "Everybody wants to be an A student, and I couldn't be."

Although the actions of others and his self-comparison to his peers influenced the way George understood his learning disability, his self-evaluation was significant.

I was very bitter about it because I had some bitter experiences. Things happened to me that I thought were unfair. I think you think when you are younger that if you do it right, everything is supposed to happen right. I can't tell you how many times when I was younger I would study for tests and still fail, and I would just be so upset thinking it wasn't fair. Like what's the point? Why even study?

George's repeated failures led to a feeling of helplessness. "Sometimes I would give up on things. Sometimes I would not try hard. It has this ripple effect. Why bother trying hard if it doesn't matter anyway?"

The results of George's Scholastic Aptitude Test (SAT) caused him to question his intelligence again. He reported, "I prided myself on being intelligent and smart, and if you looked at my SAT scores, you would think otherwise." He took the test twice—first without accommodations, and second with extended time. He was very disappointed that there was only a 20-point difference between his first and second scores. "I thought there was something really wrong with me, but I didn't know that it was permanent. I didn't know that I couldn't get rid of it."

In addition to his family and a few friends from school, George's wife knew about his learning disability, but she had a difficult time understanding it. "She 
definitely can see my learning disabilities. It's hard for her because she doesn't have them, and I don't think she has ever been around anybody with them."

George partially disclosed his disability to his boss, but he did not do so until he felt comfortable with him. "I am not the type that will yell out my weaknesses, you know. 'I have a learning disability.' I will establish my strengths beforehand." To others, George said he might generally discuss his weaknesses. "It's not a situation where 'You know what? I have a learning disability.' I don't think I can do that. It's more just like common talk." On the other hand, George would not disclose his disability to those with whom he was not comfortable. "I guess if I feel like a situation where I didn't want anyone to know, I wouldn't be honest about it, or I would avoid it or suffer."

George had a minimal understanding of the ADA and its application to him. "I have to admit most of the time I am thinking of somebody in a wheelchair when I think of that (the ADA). To hide his learning disability or minimize it effects, George used passing and covering as his self-presentational strategies. To minimize the effects of his disability, George relied on the computer for checking his spelling. "The one way technology has helped me which has been a blessing, and I don't think anybody quite realizes, but spell-check. That's definitely helped people, I think. Everybody." George also used others to help with proofreading. He stated, "If I type up a nice letter that I want to send out to an organization, I will show it to my supervisor first." George's major method of passing was to avoid situations that tapped into his disability. George reported that he was a people-person, and he had "a very good understanding of what people want and what people need." His 
program coordinator position required little paperwork and permitted him to work to his strengths. "It's like teaching, and they show you how much they love it, and they want more, so it is different from what I was used to, and I love it." George relied on jobs where his learning disability was not a hindrance.

I would sometimes talk myself out of jobs knowing I don't have good organizational skills, you know. I think one of the hard parts of learning disabilities is sometimes you short-change yourself. I kind of have a history of doing that.

Overall, George was able to function at a job that he enjoyed. George had a variety of career interests, but he did not pursue them as strenuously as he could. He partially disclosed his disability to several people although he was careful in doing so. George did not ask for accommodations by declaring his learning disability. After the interview, this interviewer had the opportunity to observe George's interactions with the clients of his workplace-many with dementia or Alzheimer's. George made sure that they had the necessary supplies for their activities, spoke to each of them in a gentle, directive way, and responded to their questions and statements carefully and fully. George and the clients demonstrated a reciprocal caring for each other. During the interview, George had described his work.

It is a very rewarding job, emotionally. It's very rewarding and I really like it cause sometimes I am able to teach and what I get back is a lot of good, you know, they very much appreciate it. Sometimes working with the elderly is the fantasy for a teacher in a sense. It's like you're teaching and they show you how much they love it, and they want more.

Although George's job was emotionally rewarding, it was not financially rewarding, and this caused ambivalent feelings. He liked his job but could not keep it because it did not pay enough. George has little, if any, personal support for his learning disability. His two main life-long supports, his mother and grandmother, were 
deceased, and his wife did not understand the impact his disability had on him.

George recognized that his disability continued to affect his life. He concluded

I had this mindset that once you left school, they would go away because in school, you are there for learning. It should be life disabilities or going through life disabilities. They're forever with you. In fact, it gets harder because there's no help; there's no support system. You have to figure out your own support system, and that's hard. That's really hard.

Heather

Heather was a 31-year-old female who lived in North Eastern and Pacific Coast states while attending primary and secondary school. After graduating from college, she returned to the Pacific Coast to teach for a year, and then settled in New England where she earned a Master's degree in Education and continued teaching.

Heather was diagnosed with a learning disability in the fifth grade. Prior to the fifth grade, Heather reported, "I always sat in the back of the room. I was the dumb kid; I was the lazy one. I was the mess-up." Her father wanted to know what was wrong with her. "My dad said, 'She can't read; she needs to be tested. Something is going on with her brain." She recalled the first time she heard the words learning disability applied to her.

I remember sitting, when I was diagnosed in the fifth grade, sitting at a big, huge table in the conference room at my school-all these people sitting there; I was sitting at the end of the table. That's when they said, "Your brain doesn't work right; you have something called a learning disability."

The evaluator explained to her father and stepmother that a learning disability could be inherited. Her father responded, “Well, I didn't do it to her; I didn't make her this way." After being diagnosed, Heather was placed in a self-contained, special education classroom with two other girls. "We were all in the same boat. We were all 
reading The Cat in the Hat in the sixth grade because we couldn't read anything else." Heather remained in this placement until the eighth grade, which was the turning point in Heather's secondary education. She was placed in some mainstream classes with support in the resource room. The "dummy class" was on the top floor of the school. Heather wanted to fit in so she began rebelling—smoking, cutting classes and getting detentions for not doing homework. "I was kind of lost eighth through tenth grade." Finally, in the tenth grade she was expelled from her public school and transferred to a private, all girls, boarding school that had no services for learning disabilities. For the first few months, Heather did well. Then classmates started harassing her about her disability. "Heather can't write, she can't do this, and she can't even read out loud in class." The smoking, cutting classes, and fighting began again, and Heather was expelled. After a few months of being tutored at home, Heather was admitted into another private boarding school. Although this school had a support program, and Heather did better academically, she was expelled two months before graduation; she appealed the expulsion and graduated. Heather believed that the reason she got into so much trouble was "the non-acceptance that my dad had for me, just being me—-not understanding the world, not understanding reading, writing, not processing."

Heather summarized her learning disability as one of comprehension and written expression. “I'm a terrible writer-I can't write, I can't spell. I don't write; I don't read books because I can't. I can't sit long enough to read books because it takes me so long." Heather also cited her strengths. "Oral communication is one of my biggest strengths, and organization as far as my professional life goes." 
Heather developed the initial understanding of her learning disability through the negative words and actions of others. Heather stated, "My dad had pretty much convinced me that there was some kind of hole in my head that all the information that I was getting about anything would come in and just fall out, fall out of that hole." He impressed upon Heather how she was a failure. "I remember him sitting in the counselor's office and just saying, 'She's dumb; she's not going to go anywhere. I wanted her to be an attorney."' When Heather's stepmother informed the dad that she wanted to be a teacher, he responded, "Oh, that's crap! She is never going to amount to anything." This treatment continued until she graduated from college, and she severed her relationship with her father. Heather's classmates' actions and words were also harmful. Heather reported that many of her classmates did not want to be friends with her because she was in the "dumb class." They also would comment on the things she could not do such as read aloud in class. Even one of Heather's teachers commented, "You're just lazy. You're going to fail like the rest of them."

On the other hand, later in life, the positive words and actions of others helped Heather to form a different understanding of her learning disability. Of her mother, she stated, "She never called me dumb, not once. I can bet a million dollars on that. The million dollars would be a dollar for every time my dad called me dumb." Heather recalled how one of the teachers from her last boarding school had a huge influence on her academically and emotionally. 
I sat with her, I remember sitting with her hours on end after school. She lived right on campus-doing my homework, reading, understanding, using tape recorders and listening to my voice, listening to how I read. She was the one that pretty much brought me out of my shell, and then I started to excel.

The positive actions and words of a learning specialist in her college support program continued to change Heather's perceptions of her learning disability. She described, Brenda, her support specialist as her "saving grace." Heather was not using her support services, and her learning specialist confronted her.

I remember Brenda coming to my room to introduce herself. She pulled me out of my room, brought me back to her office, and said, "Here's the deal. You come to me, and I will help you in any way, shape, or form. I will never put you down." Brenda made me not feel that I was dumb. I was just a typical person, just a typical student that needed extra help.

In addition to the words and actions of others, Heather relied on selfcomparison to others to help her understand her learning disability. "I have a younger sister who excelled in schoolwork. I was just dumb; dumb was the big word." Heather also commented, "I have a slowness of processing information that I need to process. I am just a little slower than other people." Heather did not see herself as one of the "cool people" and commented that they did not want to hang out with her. Instead, she stated, "All of my friends throughout my life have been in the same sped programs as myself."

Although she had many difficult experiences because of her learning disability, Heather freely disclosed her disability to friends, students, parents, her employers, her graduate school professors, and other teachers.

I am very open with mine, very open. Before, back in high school, I wasn't because I always got shot down. Since I graduated college, anybody and everybody has been very cool with it, and I tell everybody now. It's funny; I walk around with a big LD on my head. 
Heather's friends all knew and accommodated for her. They allowed her extra time because they knew she took longer. She told her graduate professors. When asked during her interview why she wanted to get a Masters degree in Special Education, Heather replied, “Because I need to give back what I didn't get when I was younger. I was diagnosed with a learning disability in the fifth grade, and I had a very hard time growing up." Heather spoke to undergraduate classes about her learning disability. When interviewing for her first teaching job, she responded to her principal's question, "What is your weakness?" by replying, "I am not going to be able to understand all of this paperwork. I'm not sure whether I should tell you this, but I do have a learning disability. It was diagnosed in the fifth grade." The principal provided accommodations, and because of her positive response, Heather became more open. "But with that opening from her, I was able to express to anybody and everybody that I do have a learning disability." Heather was most adamant about disclosing her learning disability to her students and the children that she tutored. "That is my mission in life right now, just to teach people about their learning disabilities to help them to understand what I have just understood recently, and I have been diagnosed since the fifth grade." Heather explained the different tests and the results to her students. She shared her Individual Education Plans, and she explained how her learning disability manifested itself and impacted her life. "If I could have my students come here, they could tell you what their disability is and what their strengths are and what their weaknesses are."

When Heather was an adolescent, her self-presentational strategy was role acceptance. She lived up to the stereotype of a student with a learning disability by 
using her disability as a crutch. "I don't want to take this test because I have a learning disability. Can you write this for me because I have a learning disability?" In adulthood, Heather's self-presentational strategy was confrontation and breaking through. Although Heather knew that the ADA was legislation for people with disabilities, she equated it only with accommodations in education, thus she did not use its protections. She recognized her learning disability was just one part of who she was. She accepted and accommodated for her learning disability by using technology and asking others for help. Heather listened to books on tape. "It is actually funny. I have books on tape in my car now...all the time." She relied heavily on the computer to word process her reports and letters, and had others proofread anything that went home to parents.

In conclusion, Heather's early life with a learning disability was a journey through emotional abuse, deep confusion, and self-destruction. She struggled through her early life with a learning disability that was not explained to her. Her father berated her for not achieving up to his standards, and her teachers ignored or punished her. Because of this, she felt that she was inferior to her classmates and her family members. As Heather explained

When I was younger, I was, pretty much, just looking for a way to fit in. The support for me was there, but it never came to me. I was always supposed to go to it, and I didn't know how until Brenda.

Heather struggled with her learning disability because she did not understand what it was. Instead, her father and peers caused her to believe that she was stupid. Slowly, this belief changed, beginning with the help of the learning specialists who accepted her unconditionally and carried on by her employers, coworkers, friends, and 
significant other. Heather now saw her life as one filled with promise and purpose. She viewed her disability as an important part of her makeup. As Heather stated, "I can say, within this year, I can say successfully that I am very pleased at who I am today cause of the avenues that I took growing up."

Henry

Henry was a 28-year-old male who spent his entire life in a suburban area of a Mid-Atlantic state except for the four years that he attended a small, southern liberal arts college. After graduating from this college, he taught for several years before joining a private company and obtaining a Master of Business Administration from a state university. He continued to be employed as the product and IT manager and sales representative for the private company.

Henry stated that he had attended one of the top school systems in the United States for students with special needs. He was identified as being gifted and talented in early elementary school. "I have always had a high vocabulary, and I have a very great memory. I was slotted as talented and gifted and went to special programs when I was early identified." Henry was identified as having a learning disability around the third or fourth grade. Henry explained his learning disability.

My problem area was written expression. I just could not grasp those concepts. I would miss the ed's, the periods. I would capitalize things that weren't supposed to be capitalized, spelling. I would get things backwards. My thoughts, my sentence structures. I would speak it as clearly as I would read it to you, but if you looked at what I wrote, it's not what I was talking' to you about.

Although he was identified as having a learning disability in elementary school, Henry reported the realization did not affect him until middle school. "When I got to middle school, you could start to see that maybe I wasn't around average in certain areas. 
Honestly, I felt stupid." In high school, Henry struggled with his learning disability because of its social limitations. "The high school mind is based upon everyone is looking at you and you want to fit in. And having a learning disability makes you not fit in." Henry's learning disability continued to impact his adult life. Henry reported that although his performance evaluations were usually above average, "there were things that I needed to improve on and exactly where my learning disability was were the things that were my problems."

He had no understanding of the Americans with Disabilities Act and how it applied to him.

Henry's understanding of his learning disability was shaped by the actions and words of others as well as self-comparison with others. The action of being pulled out for help affected Henry.

Being taken away to a resource room for speech therapy or learning that took you away from the classroom. That was something that made you know there was a problem with you. I knew something was wrong, but I didn't know what it was. I just knew that I was different.

Henry was pulled out of his elementary classes several times per week for speech, so when he was pulled out for resource assistance in elementary school, the transition seemed like an extension of speech services. "It seemed like I was continuously going into a resource room. I knew there were not a lot of other people in the class that were having the same difficulty that I was." Henry viewed being placed in the resource room as a stigma. "I was put in this resource room so when you're in the resource room, you are excluded from the classroom. You feel different. The stigma that is stuck to it is, uh, stupid." Because of the stigma Henry felt when 
leaving the classroom for special education services, he would hide where he was going from his peers.

It was very emotional for me to be separated. When you go back to class and the other kids are like, 'Where'd you go?' I would say I was in another room doing math or whatever and slide it off like it was nothing.

The actions of others continued to reinforce Henry's perception of being different in a negative way because of the lower level work he was given. Henry was denied the opportunity to read books that his classmates were reading. His disability was not in reading, but since reading and writing were grouped together, he was placed in the remedial English classes. "I didn't get to read the books I wanted to read. We were stuck reading books which were below-level reading books compared to, like people were reading Macbeth and The Diary of Anne Frank." Henry noted that some students wanted to remain in remedial classes where the work was easier. He, on the other hand, wanted to be "in the average English class, that's all I ever wanted to do [italics added]. So then finally, my senior year, I got to a level...that was like winning the lottery." The actions of Henry's family also affected him. "I was very difficult, and my parents tried to make me sit down and do all the work. My mother, my mother you know, cried [italics added] some days, and l'd say, 'Don't cry,' and it'd make me cry."

Just as influential on Henry's understanding of what his learning disability meant were the words of others. In his elementary years, his mother and teachers stressed strengths and weaknesses. "'Oh, you're not stupid honey...it might just take you a bit longer to do the work," and "There are certain areas where you are just not as strong. And that's the thing that was ground into me." During high school, 
counselors' and teachers' words had major impacts. My counselor told me, 'You should not look into college.' That's what my counselor, my high school counselor, told me." Other teachers echoed this.

There were other teachers who told me, 'Well, your grades aren't really that good; you don't seem like you can handle it. Maybe college isn't for you. And boy did that piss me off more than anything else in the world, so from that point on, my whole goal was-l'm provin' them wrong.

Henry's self-comparison to others contributed to his understanding of his learning disability. He compared himself to both his father and his sister. Of his father, he said, "My father said he always had a difficult time in school; he was never a great student, and he wasn't until he took his SATs and scored so high he was admitted to MIT on a scholarship." He compared himself to his "absolutely brilliant" sister. "I had to work double as hard as my sister would do."

Henry also compared himself to his peers. He described his perceptions of those in remedial classes with him.

I was with people who, still my friends, they just weren't very bright; they weren't-I don't want to say very smart, but they were either lazy, or it was that they did have a learning disability that was legitimate. It was a very, it was hard.

Some of Henry's other friends completed their work more quickly than Henry. "My other friends could breeze through books or breeze through vocab. or things like that, and I would be just, 'Wow! Why not me?'” These self-comparisons to others along with the actions and words of others helped to shape Henry's understanding of his learning disability. 
In many instances of disclosure, Henry partially disclosed his learning disability, relying mostly on descriptions of how the disability affected him. He described his disclosure as

I don't necessarily go out and shout to the world that I have a learning disability, but I don't conceal it either. If it comes out that I have a spelling problem, I am straightforward. If I am on the soccer field, and someone says, "I have this big report due, and I can't spell anything," I would say, "Yes, I have a problem like that too."

Henry reported specific times that he used the term, learning disability, when discussing his disability. The first situation was his disclosure to his wife, a guidance counselor, when they were dating. "I know it was not a big deal. It was just something that I said." The second was to a committee when being interview for a teaching position. "I told them flat out when I was being hired. I have a learning disability. The number one thing of my learning disability is my written expression." The final instance was to his middle school students. "Yes! Absolutely I told them. I had no problem saying that to them. I was like, 'I have a learning disability. This is where my strengths and weaknesses are.' So, it is not embarrassing." Outside of these situations, Henry relied on partial disclosure.

Henry's self-presentational strategy was covering. Although he did not conceal his learning disability, he used every resource available to him to minimize its impact on his life. Assistive technology was very important to Henry. He used Dragon Dictate to compose all of his professional and graduate work. "The miracle that happened was Dragon Dictate. That is the miracle of modern technology!" Henry described Dragon Dictate's usefulness as enabling him to use sophisticated language when writing. “I don't have a problem articulating what I want to convey. I 
only have that problem when I want to write it down. I use kindergarten words because I can't spell the high-class words."

Henry used others to help him pass. He remembered that when he started dating, he was very upfront asking his dates about their English and proofreading skills. "I know this sounds kind of funny like I was going through their resumes, but I knew that that's what I needed—someone to balance me out." In his own classroom, he would minimize the impact of his poor handwriting. "I had a student go up there who had nicer handwriting and write it down." At work, he had the assistance of proofreaders. "If I am writing a letter, I told Cindy, who is our research technician, that I have a problem spelling and proofreading. I need you to come over here and edit my paper." Even after he used Dragon Dictate, Henry had his wife proofread his graduate school papers.

Henry was a very successful business administrator. He used every available tool to organize himself and fulfill the requirements of his current position. While he partially disclosed his learning disability most of the time, he had fully disclosed his disability in a few instances. Henry's learning disability continued to impact his life.

Every day...every day. It affects the way I think, the way that I try to get things done and accomplished. I feel like I have overcome it. I can use the positive experiences that are around me that I don't ever have to feel that I can't get things done. That is the most confident thing that I can possibly say, but now, it has taken me 28 years to get to, but I know what my limitations are, but even though I know what they are, I can still meet them and try to learn more, and try to better myself, and realize that I have these other things that I can get around the problem. 
Nanci

Nanci was a 26-year-old female living in a New England metropolitan area. She had moved frequently during her school years living in Midwestern, Middle Atlantic, and New England states. She stated that she "had never been in one school for more than two years." At the time of the interview, Nanci had attended a community college, a small, four-year liberal arts college, and a university for a total of five years. She did not have a degree. Nanci bounced around jobs. She was employed as a photo lab technician, an office manager, a human resources assistant, and a telecommunicator. She currently worked as a barista at a local coffee shop and as a theatre stage manager.

Nanci remembered being identified with a disability early in her life. Her mother, who "worked with retarded children before I was born," suspected that Nanci was not progressing and had her tested in the first grade. She was diagnosed with a processing disability and attention deficit disorder. Nanci described her mother as "the one that made sure that I was on the right path to my education from the get go by making sure that she knew what was going on. She did something about it." Nanci received support services in the form of a special school, special classes, or a resource room throughout her elementary and secondary education.

Nanci acknowledged both her strengths and weaknesses. She viewed her strengths as organizing for others, getting along with people, and being creative. As a stage manager, Nanci organized auditions, call-backs, props, director's notes, actors' information, rehearsal schedules, and all aspects of the back-stage show during production. Nanci commented 
A lot of people growing up probably thought I could never do the job I do with stage managing, but I do it well. People recommend me, and a few of the shows that I have done have been nominated for awards. I was nominated for the best stage manager of a musical. I am great [italics added] at what I do, and I really love [italics added] it.

Nancy also recognized the difficulties that her learning disability and attention deficit disorder caused her. She had a hard time with written and some oral communication. "At writing, I suck. I still find a roadblock in my verbally communicating about certain things. Sometimes when I am trying to ask a specific question, and it does not come out the right way, I get so confused." Nanci's processing speed affected the way that she functioned, especially in school.

It was frustrating when teachers came in and said this is what we are learning; this is what is going on, and as they write, you have to write as fast as they do. And everybody has all these pages, and you haven't even written the first sentence. And you are like, I can't... hold on, and then it's gone, and you are like, okay, hopefully I will remember it.

Nanci's attention deficit disorder complicated her learning because her mind was so "scattered" and her brain "just keeps on going and going and never shuts off."

Nanci's personal support system during her life consisted of primarily of her mother, supplemented by a few teachers. Of her mother, Nanci commented

She has pushed me; she breaks things down for me; she never looks at me like I am dumb when I ask questions. She is there to make sure that I have every support in the world that I need.

Nanci understood what her learning disability meant to her because of the actions of others, self-comparison with others, and self-evaluation. The actions of others played a major role in how Nanci viewed her learning disability. Nanci found the actions of many teachers or other individuals disturbing. She explained that some 
folks found it easier to do for her than to teach her how to do. "I've always had people frustrated with me and wanting just to-they just do it for me because they would rather do it than explain it." She commented on the impact of their frustration.

Nobody would let me do what I had to do. They wouldn't let me process in my own time. They wouldn't take the patience to say, "Okay, this is how we need to break things down to learn." I always felt like I was dumb.

Nanci stated that no one ever called her stupid directly, but that certain actions such as "the way their body moved, the way they said things to you...talked down to you, " led her to believe this. She questioned, "Why do I care?" Why am I alive?" Why do I even want to be here in this world?" Nanci believed people "talked at me, but never to me."

The actions of the school system also contributed to Nanci's understanding of her disability. The school system denied Nanci the freedom of choice. "I wanted to take an advanced class, but I wasn't allowed to do it because I had a learning disability, and it might affect my grade point average." She also was denied the opportunity to take a foreign language with her peers because it "might be too much for [her]." Not having a choice was frustrating to her.

Nanci recounted the positive actions of others as well. Nanci found attending the private school for learning disabilities in the third grade helpful. The class had a specific daily routine, and much of the instruction was hands-on. "They taught us to like load and unload a dishwasher, how to set a table, and how to make sure that your plates are clean before you do this." The tasks and structure were important in Nanci's learning but so was the demeanor of the teachers. "They took the patience and time to make sure that you understood things and that it was a process, and you 
had to be patient." Later in her school career, Nanci had a resource teacher that she stated was helpful. "I had a class with her which was pretty much a study hall so she would help me out. She never gave me the answers or anything. She made me do it, and that was fine." Nanci also reported that the support program at the liberal arts college was helpful, and that the staff did not "talk down to you."

Self-comparison with others contributed to Nanci's perceptions of her learning disability as well. Nanci commented that she felt less intelligent than her peers when she was younger. "Thinking that you're stupid when you can't do the simplest little task in the world, and everybody else can do it. I always felt slower than the other kids. I always felt that I was just stupid and couldn't do anything." As Nanci moved into middle and high school the self-comparison continued. Nanci stated that not being able to take certain classes, such as French, when her peers did was frustrating. She said that she did not read many of the books her peers did and missed out on much of her education because she moved from school to school. "Even today, I feel dumb when I talk to certain people because I have no clue what you are talking about." Her self-comparison with peers continued into adulthood.

You know, you listen to other twenty-six-year olds talk, and they have jobs. Most of them have really good jobs. A lot of my friends, and some of them have started families and some of them are starting to move on with life, and I'm still working in a freaking coffee shop, wandering from one dead-end job to another.

In addition to the actions and words of others and self-comparison to her peers, Nanci's understanding of her disability was based on her self-evaluation. Nanci repeatedly used the word stupid throughout the interview when describing how she felt throughout her life. She would not ask for help with notes from classmates 
because "you don't want them to think you are stupid or anything." She would not ask her classmates for clarification.

I would never ask them for help, of course, because then they would really find out how stupid I was, you know what I mean? Like, in my mind, I was like, no, never ask for help because then they would be like, "Wow! She doesn't know the simplest thing."

In junior high school, "when learning disability was associated with me, it meant that I was stupid and couldn't comprehend what I needed to." Nanci described herself today. "Even today, I feel dumb when I talk to certain people," and "I still feel I'm stupid sometimes. I know that I am not a stupid person, but I feel stupid."

On the other hand, several times Nanci spoke positively about herself especially when describing her theatre work and how well she performed her many responsibilities as stage manager.

Nanci stated that she would disclose her disability if she were directly asked about it. "If it came up in conversation, if they asked me directly, I would tell them. Other than that, why would they need to know?" Although Nanci said that she would disclose, she had not done so, thus she was a non-discloser. The only person with whom she interacted and who knew about her disability in her adult life was her mother. Of her father she said, "He has no feelings about it at all. He never addressed it."

Nanci's self-presentation strategy was passing. She hid her disability by seeking help from her mother or avoiding situations where her disability would become evident. Nanci relied on her mother to assist her in concealing her disability when it was problematic. When she did not understand the wording of a brochure for 
the insurance she was representing, she used her mother to help her. "I'm like, 'Oh, my God, I don't get this.' So I called my mother, 'I don't have time to look this up so please tell me."' When she did not want to complete essays for jobs, her mom motivated her and helped her to write the essays by talking through the content with her. Nanci avoided the results of the SATs by never taking them. Instead, she attended a community college so that she could transfer without having to have the standardized scores. "I figured community college because you can do two years and then transfer everything that way so you don't really ever have to take your SATs." Nanci avoided jobs that would highlight her disability.

Why would I want to do anything that is hard, not necessarily hard but that you don't like? Why would I pick a job that has what I want in it, but at the same time, I know that it is going to be too much of a challenge?

Nanci concluded, “I pretty much like everything I do. I try not to do things that I don't like to do."

Nanci admitted that she had no knowledge of the ADA and how it could assist her. She concealed her disability during her adult life by avoiding jobs that might expose the disability. She also relied on her mother to lessen the impact of the disability in certain situations. Nanci had conflicting feelings about her learning disability. She took jobs that made her happy, but then criticized herself because her jobs were "dead-end." She claimed that she would be open about her disability then told no one but her mother. Nanci summed up her learning disability by stating, "I am twenty-six-years old and have had a learning disability my whole life. It is normal to me. It is a part of me, and I know it is, but it's hard." 
Pete

Pete was a 30-year- old male who was born and completed his K-12 schooling in the northeastern part of the United States. He graduated from a four-year liberal arts college, and after a few temporary jobs, was working as an administrative assistant for a government official in a large metropolitan area. This position required him to organize the daily affairs, coordinate meetings, and do "behind the scene type things" for his employer.

Pete could not remember the exact age when he was identified formally as having a learning disability. He believed it to be around the fourth or fifth grade when homework increased, and his struggle became more apparent to his parents. His mother, who was an educator, suspected a disability earlier. Pete stated, "She pretty much knew right off the bat that I was different" (used fingers as quotation marks while saying different). According to Pete, he did not recognize that he was struggling early on. "I never...I just never saw it."

Pete viewed his strengths as his persistence and methodical approach to tasks. "If I rush, the disorganization manifests itself in such huge ways so I say my main strength is being persistent, not slow, but doing things in a very step one, step two, step three type of way."

Pete's learning disability displayed itself primarily through his lack of organization in his written language as well as his poor spelling and illegible handwriting.

My learning disability is organizational. The ideas are there but as far as putting those ideas out in some sort of organized fashion which I think, what I think is organized is totally backward, not 
totally backward, but it comes out to somebody reading it to be disorganized.

Pete came to understand what a learning disability meant primarily through his comparison to others although the words and actions of others also contributed to his understanding. Pete compared himself both to his sister and to his peers. When comparing himself to his sister, Pete recognized that he had to work harder to achieve than his academically successful sister.

She got... what came...growing up, what came to her easy through school. I struggled, and I worked my butt off for a B. I've always compared myself to wanting to be a lot like my sister grade-wise. I know she worked her butt off too, but to my perception, she worked a hell of a lot easier than I did.

This perception of the need to work harder and longer than others was reinforced by Pete's self-comparison to his peers. "It's tough for a twelve-year-old to accept when everybody else is like breezin' through all their classes, and you're stuck at the back of the line cause you're still inside, you know, finishing up while everybody is outside playing."

While in college, Pete also used peer comparison to differentiate his learning from that of his peers. He frequently used the notes of his fraternity brothers. "I was like, 'Dude, just let me borrow your notes because mine are horrible.' Where somebody might write down one or two things, I write down everything because to me everything is important."

Self-comparison with others, while it differentiated him from his peers also highlighted similarities. While in college, Pete participated in a support program for students with learning disabilities. Several of his fraternity brothers were also a part of the program. "My friends at [the fraternity] were great because there were a bunch of 
us in the group, the same boat, and if you needed that extra help, you knew where to go, like to the seniors who had been in the program the longest."

The actions of others added to Pete's understanding of his disability. Pete's mother monitored and assisted with him with his homework daily, and this led to conflict.

Getting homework done was a bear. My mom took the brunt of it. My mom would sit me down. "It's time to do your homework," like I couldn't do it in my room. I had to do it at the countertop. It was a part of the clash with my mom always drilling me and wanting me to do this while I just wanted to go out and play.

Pete also believed a part of the population identified as having a learning disability used it. "I know that there are a lot of people who, who use it, can use it as an excuse for the reason why they don't do well."

In addition to self-comparison with others and the actions of others, the words of others influenced Pete's understanding of his learning disability. His mother explained that learning did not come easily to him. Any reference to his difficulty learning did not alleviate the difficulty so Pete believed the reference useless. "She probably tried to tell me as she was tryin' to teach me this math, and I was like, 'This isn't helping [italics added].' You're telling me that I am special because I can't? I need a way to pass Geometry so I can get out of school."'

Although Pete could see that he learned differently than others, he did not see himself as a person with a learning disability. "I get confused because I really don't see myself as learning disabled." He does not voluntarily disclose his learning disability to anyone, and he was adamant that his disability was a private matter. "It is one of those things I just don't discuss. It makes me uneasy to discuss it, but it is 
nobody's business. Personally, it is nobody's business, and l'll just leave it at that." Although Pete chose not to reveal his disability, if someone did discover it, he would be able to handle it. "If people find out, they find out."

Because Pete chose not to disclose his learning disability, he used passing as the self-presentational strategy to hide the possibility that his learning disability would be discovered. For Pete, working harder and longer than others was something to which he was accustomed. While in school, Pete worked longer on his work, stayed after school for extra help, and spent hours on his homework. Pete became a perfectionist. "I have developed myself to try to become a perfectionist type person." To accomplish this perfectionism, Pete worked harder and longer than others. "I kind of jump into it with both feet. My attitude has always been either I sink or swim. So I just work as hard as I can to get it right." Pete continued by saying, "I am also one of those people who would make the time myself whether it be staying late for work or coming in early in the morning." The use of the computer also permits Pete to conceal his disability.

I love Bill Gates and the computer; that's the savior right there cause I can't write; I can't write on paper, uhm. One, my handwriting's so bad, and two, it's a whole organizational thing. I do all of my written work on the computer.

Pete understood that the ADA provided protections for people in the workplace, but he did not use these protections. Instead, because of the accommodations that he has made for himself, Pete is able to conceal his disability from others. His efforts have helped him to deal with his learning disability in a way that is acceptable to him. His disability still afected him, and Pete referred to it as "the one gift I would love to give back," stating that, "It's time for someone else to enjoy it." Pete's determination 
to succeed and willingness to sacrifice personal time and activities to produce perfect work have enabled him to survive in a challenging environment. Pete concluded the interview by stating, "Honestly, it's, I never thought that I would be able to talk this much about something that I just put in the back, just put in the closet hoping for it to go away."

Richard

Richard was a 27-year-old male who was born and raised in the mid-Atlantic region of the United States. His K-12 education consisted of parochial school for grades K-3 and public school for grades 4-12. After graduating from a four-year liberal arts college, Richard immediately obtained and maintained consulting work in the science field. His position required that he did both field work and the supporting paperwork, and Richard commented, "A lot of the people who are in my field are not the strongest writers."

Richard clearly remembered being tested for a disability in the third grade. The teachers could not understand why he was falling behind and suggested intelligence (IQ) testing for Richard. "I mean, the advice my mom was getting was that I was like--it was a Catholic school--and they didn't know how to treat it, like it was maybe borderline retardation." According to Richard, the professional who administered the IQ test explained that IQ was not the problem; Richard needed more testing to evaluate for a learning disability. The following year, Richard transferred to a public school where he received support services that continued throughout his education. 
Richard's learning disability manifested itself in several areas—reading, writing, spelling, memory, and auditory comprehension. Richard's difficulties with written expression embarrassed him. "Spelling is the worst. I wrote this note on the board and I wrote 'girl,' but I put the ' $r$ ' before the 'I,' and I didn't notice it until after all of my friends did. I never write something where people can see it unless I know." About auditory comprehension, Richard reported, "It could go in one ear and out the other. It's more comprehension and taking stuff in that people tell me and trying to filter it in my head."

Richard's understanding of his disability was based initially on the words of others. Both the evaluator and his mother explained to him what his disability was and was not. The evaluator assured him that he did not have low ability and that his disability was based on strengths and weaknesses. Richard stated that he had a "good mother that made sure I understood exactly what it was that I had and how it made me...that it didn't make me different...that it made me have to use more tools." In elementary school, Richard worried about being perceived as less intelligent. "I am trying to remember if I got called stupid or something like that-I think it was maybe just in arguments." His three life-long friends continued to tease him about his writing. "They get it sometimes in my emails...they make fun of the way I write when I try to write something fast and don't spell-check it."

Richard's understanding also developed because of the actions of others. Placement in a pullout or inclusion class concerned Richard. "It was always being in the lower groups or being in assisted classes or something and having to leave the class awhile...it was...it was some pretty hard times with that." Because he did not 
attend special education classes in high school, some teachers doubted the existence of a disability. "In high school, it was kinda like they didn't really believe you because you weren't in those classes. They always thought you were trying to get out of something."

Richard also compared himself to his peers. He recognized that he was not the best student in his class, and this had consequences. "Being marked as, you know, that you're not as smart as some of the other kids. You just don't get the same respect as far as the kids that are getting the A's in the class." Richard also compared himself to other students who had difficulties in school. He recalled, "They don't maybe learn as fast or they don't...they aren't driven as much to wanna do the homework or do good in school." The words and actions of others, and Richard's self-comparison to his peers contributed to his understanding of what a learning disability meant to him.

Richard did not voluntarily disclose his learning disability. Several friends from college knew about Richard's learning disability, but he only voluntarily disclosed his learning disability to one person during his college days—his current wife. Although he made the choice to do so, it was not an easy one for him.

It wasn't until her sophomore year when she started getting into taking special ed. classes and she was talking about learning disabilities, and I told her. I said, "You know, I have a learning disability," and then she was curious and wanted to know what and how. I mean I held it from her a lot.

With the exception of his wife, family, and a few friends from the past, none of Richard's current acquaintances knew about his learning disability. He did not disclose this and sees no reason to do so except litigation. 
If something went to trial, if we were getting sued, and I was the consultant on the site, and the plaintiff would want to judge my ability, then that [the learning disability] would probably, I mean, I guess that would have to probably come up.

Although his disability continued to impact his life, Richard preferred to hide it. He believed people would misunderstand what a learning disability was by thinking those with learning disabilities "fell below on the IQ scale." He stated, "As I'm older, I don't want an employer or somebody to really know that I have a learning disability because I don't think that they'll truly understand."

Richard used passing to hide his mark. He knew that his learning disability fell under the ADA and that employers could not discriminate because of this, but he did not disclose his disability. He relied heavily on technology and his wife to hide his learning disability. In discussing technology, he said

Spell-checker is my ace in the hole. I thank God for spell-check on email, because I would be sunk without it. When I just want to drop somebody a line or pick up a card and write a note, it takes me a lot longer. I turn on the computer, and write it first on the computer, and then I handwrite the copy into the card or note.

Richard's wife was also an important resource for hiding his disability. She helped him to edit his work, especially for spelling and grammar mistakes.

My wife, she has been a great tool as far as, you know; I am never embarrassed to go to her and ask, even if it is something little, you know, fourth grade level, just to have a second set of eyes look at it to make sure I didn't put something where it shouldn't be.

Richard's self-presentational strategies permitted him to conceal his learning disability. He believed that others would question his ability if he disclosed his learning disability. As Richard concluded 
I just, I always have had a hard time disclosing it-that's one of my biggest problems. I don't want to be labeled as being dumb. I don't tell them you know. I just, uh, I know that I am smart. I just don't want people to think that I am not.

Richard continued to struggle with other's misconceptions of the meaning of the learning disabled label. He chose a career that relied on his strengths instead of tapping into his weaknesses. With the help of technology and the personal support of his spouse, Richard was able to succeed in his chosen career without the need to disclose his disability.

Stan

Stan was a 26-year-old male who was born in the Midwest but moved to New England when he was seven. He completed his elementary and secondary schooling there. After attending and being dismissed from a small liberal arts college in the south, he graduated from a state university in New England. He was employed as an audio engineer, and his responsibilities included recording and mixing for bands and the audio of video recordings.

Stan did not remember when he was diagnosed as having a learning disability but recalled being pulled out of class for extra help as early as the second grade.

I know that beginning in the second grade they pulled me out for an hour a day, but I don't know per se that I knew that I was being pulled out because I was learning disabled. Honestly, the first time it clicked was in middle school.

Stan's learning disability was written language primarily handwriting and spelling. He expressed, "My learning disability, I cannot spell with a darn, that's for sure. That's the biggest one. Uh, my handwriting is very messy to say the least." Although he was never diagnosed as having an Attention Deficit Disorder, he could 
"definitely lose train of thought or focus on something real quick." Stan remembered learning as very difficult for him. "Learning didn't come easy to me, uhm, it was a struggle or battle; it was real work. I had to work!" The impact of his disability continued into his adult life. "You want to write someone a note, and I feel, I won't say ashamed, but I feel like I don't want to do it." Stan received services for his learning disability throughout his educational career including while attending both higher education institutions.

Stan learned what his disability meant through a combination of others' actions and words and self-comparison with others. The actions of others contributed to his understanding. He mentioned that he was always being tested. "They always had me doing these tests...I wouldn't say stupid tests...intelligence tests and everything else." Being taken out of the classroom was problematic for Stan.

When I was younger, I felt singled out. At that grade level pretty much the classes stay together, but you're going out for an hour; it kinda singles you out. People notice that you leave the classroom to go to the special room.

The words of others have impacted Stan's understanding of his disability also. These words have had both negative and positive influences on his understanding. One guidance counselor commented

You need to make a decision with your life now, and maybe every day public high school isn't for you; maybe you should think of going to a trade school. Maybe you don't want to go to college because you're learning disabled.

Stan stressed that this comment disappointed and angered him. On the other hand, Stan's father, who has dyslexia, told Stan about his disability. His father's spelling is "horrible," and his handwriting is "not the neatest." Stan's family has always instilled 
in him that everyone is different. "My family has always been supportive of me. They're always, if you have a decision, we will support you." Stan stressed being told about his ability level. "They said I was fairly smart" and "All of my life I have been told I am intelligent."

Stan compared himself to others. He compared himself to his father who worked at a job that required him to write extensively. Stan's father was very successful in his job, and Stan cited how they both had similar learning disabilities and used similar strategies. They relied on Stan's mother for assistance. "Between me and my father, always, 'How do you spell this?" Stan traveled extensively and saw himself as fortunate when compared with others who experience difficulties. "I have also seen other people on earth that have, that have it so much worse than me so I am just thankful that I don't have it much worse than I have." Stan also stated that it took him longer than his peers to get some concepts. "I would say my learning curve is a little slower especially with to-two-too and there, they're, and their. I would never get it properly."

Stan partially disclosed his learning disability to a selected others. He did not use the term "learning disability," and instead chose to discuss his messy handwriting or poor spelling. "I don't just tell. I would say I'm definitely more apt to say, 'I, jeez, I can't spell worth a darn' up front, you know much sooner than the reason why [italics added] I can't spell." Stan's friends and boss knew that he had difficulty with spelling and handwriting. "All of my friends know that I can't spell a darn."

Stan's job did not require much writing, but he told his boss that his handwriting and spelling were poor. "My boss knows to just once over everything. He 
just doesn't know" (that Stan has a learning disability). He would tell other employers as well. "To a potential employer, I won't say it the first thing, but I would definitely let them know that I don't have the best spelling ability." Stan also stated, "If someone just outright asks me, l'll tell them."

During the time that his disability was known to others because the disclosure was mandatory, Stan used role acceptance--living up to stereotypes-- as his main self-presentational strategy. From diagnosis through adolescence, Stan reported not working up to his capacity. "I never really applied myself to my fullest ability; I've always done just enough. I'm lazy." In college, he attempted to use his disability as an excuse for failing out of college.

I said, "I'm learning disabled," and gave him this whole big spiel. There was no real reason for me to pull that card; I mean it was my own fault. I think that was the only time in my life, or the biggest - the most major--that I played the learning disabled card.

Stan also relied on covering as a self-presentational strategy in college. "One of my friends was going to school to become an editor. I made sure that I was his best practice patient ever. I gave him my papers to edit for proper English, spelling, and everything else."

In adulthood, unless he had disclosed, Stan used covering and passing as his self-presentational strategies. This entailed the use of assistive technology to minimize his disability and avoidance of situations to conceal his disability. Stan employed the computer as a way of minimizing his disability. "I love computers, and I love spell-checkers. Technology has definitely helped with my spelling although sometimes I am so far off that it has no idea." Stan concealed his disability by avoiding situations where his disability would become apparent to others. "I shy away 
from things that involve my learning disability—reading in front of the class or writing things down, spelling things, and because of that I try and shy away from things."

Stan did not see his current job as permanent, and believed a more traditional job would challenge his perceptions of his disability.

I don' think I'll be here forever, and I think one day, I 'm going to get the 9-5 push the pencil job, and I think then it could be a slap in the face. It could be a reality check then of how I really have to deal with my learning disability.

Stan had limited understanding of the Americans with Disabilities Act. He believed, "You should really not be discriminated against because...just because you are in a wheelchair or something like that." He did not see the need for using the ADA himself.

Stan chose to be employed in a job he enjoyed that did not focus on his disability area. He explained that in the future, he would have to get a "real" job, and that his learning disability may then become more of an obstacle. Stan's choices concerning his learning disability have enabled him to conceal the impact of his disability from those to whom he does not want to disclose, but he concluded, "If I didn't try and shy away from those things because of my learning disability, I would have applied myself more in those areas; I would have not necessarily done better, but I would have done more with what I have."

Steve

Steve was a 26-year-old male who was born in the northeastern part of the United States. He completed much of his elementary education there before moving south, where he attended school until he graduated. His earned his undergraduate degree from a four-year, liberal arts college. Upon graduation, he began a series of 
internships and volunteer projects that permitted him to travel to several countries. He was currently a high school teacher in a rural school system.

Steve remembered taking remedial classes in elementary school but was not identified as having a learning disability until the fifth grade. "They cited poor handwriting, low reading level, poor reading comprehension, and I am sure there are others that I have left out." Steve remembered little about his elementary remedial classes, and found his middle school accommodations lacking. "I was supposed [italics added] to get notes and have tests read to me. This didn't necessarily happen all the time. It would depend on the teacher." Steve's accommodations in high school and college were provided consistently. Steve commented that there were times he did not use accommodations that may have been useful for him because he did not like the amount of time they took.

Steve's learning disability affected several areas because of its languagebase, and Steve was cognizant of his weaknesses. "I am a miserable speller with poor grammar. Content was never a problem, but it was the grammar, spelling, and handwriting." Because of his disability, Steve was frustrated with learning. "I remember getting frustrated many, many times... reading assignments, when I really didn't understand something, l'd get frustrated, and it would just... it would just bring down my whole day." His disability concerned and frustrated him in adulthood, although to a lesser degree. Completing job applications, writing on the board, and keeping up with educational reading were all negatively impacted.

Steve's understanding of his learning disability was based primarily upon his comparison to others. He compared himself with his classmates. "The reading in the 
fifth grade was out loud, and my reading... wasn't anywhere close to grade level at the time. I was so miserable at it." Steve also compared himself to his classmates in the special education program and was concerned about being grouped with them because he saw them as less intelligent and unmotivated. "In some classes, I was grouped with those [italics added] kids, I was. They were not the brightest. They were the kids that were not motivated in school. They were the kids who got in trouble all the time." Many of Steve's current students had Individual Education Plans, and Steve saw these students as being very similar to those with whom he was grouped for special education services when he was a student.

If someone were to criticize the mental capacity or the work ethic of some of the students that are in my inclusion class, I would say, "You are right." I remember being in a similar situation when I was in school, and they just frustrated the hell out of me.

Steve noted that he was not very motivated in middle and high school since he was a "typical teenager who was into just getting by." His resource room time replaced content classes, and he welcomed this. "I don't have to be in woodshop, or this is great, I get out of science. I can do my homework." This time assisted Steve in getting by although he "hated it at the time."

The actions of his father motivated him to get his work done. "I was afraid that, uh, if I didn't get work done, I would be in trouble. My father knew all the tricks, and he knew the lies before they came out of my mouth."

Along with the actions of his father, the words and actions of others also contributed to Steve's understanding of a learning disability. Steve got defensive with others if the term learning disability was used "in a negative light like that person is not intelligent." He believed that this perception was encouraged because of how 
students with learning disabilities were placed in classes. "Throughout our public educational system, people with learning disabilities are grouped in slower classes. I was." Steve experienced this in the high school inclusion class he taught. "I have about 15 IEP students, 2 ESL students, and about 5 low-level students that don't have IEPs that probably should, so they group them into one class."

Steve did not accept a person saying that someone with a learning disability was less intelligent but found negative comments on that student's work ethic and behavior acceptable.

If someone says, "This kid is a dummy because he has an IEP," I would get a little bit offended, but if they say, "This person doesn't work, doesn't apply himself, doesn't follow instructions, and acts like a fool all day long in school," I would probably say, "You're right."

These negative comments were acceptable because Steve found some of his students to be similar to those with whom he was placed when in middle and high school.

Steve knew a little about the Americans with Disabilities Act. He stated, "People cannot be discriminated against because of their disability, and there needs to be certain, uh, certain services provided for those that have them." In the past, Steve partially disclosed his learning disability. He did not use the term, learning disability, but discussed his weaknesses. For example, he disclosed his poor handwriting to his previous principal during his interview, and cleared that he could use the overhead projector to display his daily objectives. When the assistant principal did Steve's evaluation, she criticized his handwriting and told him that he 
had to work on his writing so that he could handwrite the objectives on the board instead. Steve became angry and informed the assistant principal that he had been working on it for years, and it was not going to get better. He explained that was why he used the overhead projector, but she refused the accommodation. "At one point, they took the overhead projector away from me because they thought I was using it too much." He was comfortable joking about his poor handwriting with his students but disclosed nothing specific about a learning disability.

To hide his learning disability, Steve used passing as his primary selfpresentational strategy. Steve either avoided situations where his disability could become obvious to others, or he found a way around the disability's impact. For example, Steve concealed his reading disability. To avoid it, Steve reported, "I don't read; I just don't read." Instead of reading, Steve preferred to use the television to get the current news and content for his classes. He also used the computer extensively to compensate for his poor handwriting and spelling.

I would not be able to get along without a computer. Everything that I do, I use the, even if I write a referral, I go to that computer and type it out first, get the spelling mistakes, and then write it out, so I really use the computer an awful lot.

Steve's choice not to disclose his learning disability to his students, particularly his inclusion students, may be loosely construed as withdrawal, another selfpresentational strategy. Those who use this strategy avoid contact with individuals with similar marks. Since Steve's job required him to interact with students with disabilities, he limited the personal and emotional interaction with them concerning their common mark, the learning disability. Steve realized that a disclosure perhaps would enable his students to relate to him more easily, but he chose not to 
acknowledge the similarity. Steve's rationale for not disclosing his disability, even to those students identified as having a learning disability, was that this disclosure could open him up to being victimized. "Some students would take this as a weakness and then try to exploit it," Steve stated.

Steve was able to hide his learning disability and resulting weaknesses from others unless he saw a necessity to disclose them as he did with the principal. His self-presentation strategy of passing was effective in hiding his disability. To Steve, his learning disability "is not something that I tattoo to my forehead. You know, I try to make it a non-issue as much as possible."

Vincent

Vincent was a 21-year-old male who had lived in two Mid-Atlantic states during his K-12 school years. He moved from one state to another when he entered ninth grade. After graduating from high school, he began community college; he withdrew after the first semester because he did not like the school and didn't know how to get any help there. He had been employed as a telemarketer and a part-time laborer, but he was currently unemployed. He moved out of his mother's house six weeks prior to our interview.

Vincent was diagnosed with Attention Deficit Hyperactivity Disorder when he was in the first grade. The doctor "put me on Ritalin and that didn't work. I did not like it, and my mom saw what it was doing to me so she took me off of it." In the third grade, Vincent was identified as having a learning disability. His learning disability was in the area of reading. Hearing the words learning disability applied to him, Victor questioned his ability. "'Am I stupid?' That was what came to my mind." After being 
diagnosed with this learning disability, Vincent was placed in a self-contained classroom for three years. "I was basically in one room. I just had one class. I didn't go to no other rooms, and I had the same teacher all day from fourth to sixth." In middle school, Vincent switched among three special educators. "That was the only thing that made you feel like you were a regular student in middle school because you could go to different classes." When Vincent moved to another state, he went back to a self-contained class for the first few weeks of ninth grade. He was then mainstreamed into some general education classes, but still remained in special education for his core academic classes. In high school, Vincent was placed in all mainstream classes with one resource period. "I liked it because I felt like a regular student there."

Vincent's learning disability manifested itself in poor decoding and problems with reading speed and fluency. He found it frustrating when others would tell him the word he was trying to decode.

If I am reading, and I can't get the word out, don't tell me the word before I have a chance to sound it out. I hate when people do that. I hate [italics added] that! I got in so much trouble in school from telling people to shut up.

Victor's attention deficit disorder also impacted him negatively. It caused him to miss out on things that were important. For example, Victor told about being in church, and something happened in the congregation. When his mother and sister were discussing it with him after church, he did not remember any of it. This led to an argument. Victor said this happened repeatedly to him.

And with my ADD, you might be talkin' to me, and I start lookin' at something else. I'm gonna tell you about my ADD. I can't look a lot 
of people straight in the eye when I talk because I start thinkin' of something else, and I can't catch up.

Vincent discussed his strengths too. "My writing is strong. I wrote poems and everything. They got published in the school literary magazine." In addition to his writing, Vincent sees math as his other strength.

Vincent's disability affected him in his adult life, especially in the area of employment. When working for a telemarketing company, Vincent found the reading difficult. "As soon as we got to Discover, there was too much to read. It was so much. It was like 500 words, and I was like, I can't do this." His attention deficit disorder impacted his telemarketing job performance as well. Victor commented, "I had no attention span going on, daydreamin' a lot, and I only got one sale so they laid me off." His attention deficit disorder caused confusion at his home and was a precipitating factor in his being asked to move.

My mom, she be, she says I got a one-track mind, and I do. She'll tell me to do something, and I forget. This happens all the time. She tells me the only thing I do is watch TV. Me and my mom got into it, and I moved out.

Vincent's understanding of his learning disability and ADHD came from the words and actions of others as well as self-comparison to his peers. Vincent had many positive experiences because of the words and actions of others.

People around my mother told me about their ADHD, and they said they had that. I know people who have dyslexia. I know people in high places that say I had this. When I was younger, I had that, so it is okay for someone to have learning disabilities and be successful at the same time.

People were very willing to help Vincent when he asked them to do so. In school, he had a science teacher who would give him copies of the notes and drawings. "I 
appreciated her for that because it was hard for me to listen and do many things." People also helped him while telemarketing. The supervisor permitted him extra practices before the tests, and he "had a lady that sat next to me that helped me all the time if I didn't know the words." Vincent readily asked for help, and he mentioned the need to do so several times during the interview.

Vincent found his mom and sister supportive in both actions and words. He recalled, "I had people always in my life who were positive about it. No negatives. My mom and my sister and all the people that had a learning disability that told me about it."

In addition to the words and actions of others, Vincent also used peer comparison to understand his disability. He positively related to those who told him about their disabilities. Several times he mentioned that he "felt like a regular student" when mainstreamed. He reported, "I just take things slow; I just take things slower than other people do." With his writing, he worked slower.

I felt slower than everybody else. If you had some other people in here and gave them something, they would get done before me. I write slower. I get it done slower because I gotta know that I got it done right.

He compared himself to his mainstream classmates. One history teacher gave two tests per week. Vincent said he made Ds while most of his classmates made As and Bs. On the final exam, most of his classmates scored Ds while Vincent earned a C. “And they were like, 'What you got?' And I said, 'I gotta C.' And they were like, 'What?"'

Vincent fully disclosed his learning disability and attention deficit disorder. He explained it to his employers, to the other employees, and to his friends. "I tell people 
I have a learning disability and an attention deficit disorder." He discussed the Americans with Disabilities Act with a telemarketing customer. "I told her I had a learning disability and ADD too. So she talked to me about it and how people need to follow the law." He did not disclose the disability to those who might "cap on you all the time."

Vincent's self-presentational strategy was confrontation and break-through. Vincent acknowledges his learning disability and ADHD. He willingly accepts help when he asks for it. He believes that it is important to tell others about his disability just as others have shared the knowledge of their disabilities with him.

A lot of my friends keep this to themselves. Some people feel like they are in a closed closet, and they can't come out and tell people that they have a learning disability or attention deficit. That's how most of my friends are. But they need to come out and tell people, "Hey, I have a learning disability, and if you don't like it, so what." They need to say, "I just have a different learning process, and I need help."

In conclusion, Vincent spent time in self-contained special education classes and resource rooms. He had instances where his placements helped him be successful, but these same placements made him feel less intelligent. Vincent expressed the surprise of many of his mainstream classmates when he scored better on an examination than they did. He had a good understanding of what he did well and how his disability impacted his life. He willingly asked for help with his various jobs, but he did not know how to seek help in post-secondary settings using the ADA. Overall, Vincent was very outspoken about his disability and encouraged others with disabilities to get over their desire to hide them. 
This summary of each of the interviews presented an overview of the topics covered and answers received from the interview participants. The words of the participants were used to highlight specific concepts or ideas they expressed during the interviews. Next, these concepts and ideas will be formatted into a composite summary reflecting the common themes discovered during data analysis.

Composite Summary

The composite summary collapses the words of the participants to illustrate the themes and subcategories reflective of each of the research questions in this study.

Theme One: Reactions of Others

The first theme, Reactions of Others, consisted of two subcategories-Words of Others and Actions of Others. The verbal and non-verbal cues, reinforcement, or feedback that the participants received from others in their environment shaped the development of their understanding of the term, learning disability, and what the term meant to them personally.

Words of Others

For seven of the ten participants the words of others had powerful impacts on their understandings of their learning disabilities. These words from family, teachers, support staff, friends, peers, significant others, and mentors influenced how the participants viewed their learning disabilities.

Negative words. Five out of seven participants reported negative comments from others, and these negative comments from family members and professionals hindered, angered, and embarrassed the participants. For years, Heather's father 
berated her ability and work ethic. Heather believed that she was "stupid." Her father's negative words confirmed her belief. He frequently told Heather and others that "She's dumb; she's not going to go anywhere...She's never going to amount to anything." Additionally, one of her teachers reinforced her father's words. "You're lazy. You're going to fail like the rest of them." The frequent berating Heather experienced from her father and others strengthened her belief that she was damaged. Steve, Henry, and Stan found the words of others who implied persons with learning disabilities were less intelligent offensive. Henry's guidance counselor and teachers questioned his capability for college. "You should not look into college," said his counselor. His teachers agreed, "You don't seem like you can handle it. Maybe college isn't for you." Stan's guidance counselor discouraged him also. "Maybe you should think of going to a trade school. Maybe you don't want to go to college because you are learning disabled." For George, the negative affect of the words came earlier in life. Of one of his first memories of the term, learning disability, George stated, "I remember hearing the buzz about it from my mom. I remember her talking to people about it, and I have to admit it hurt."

Positive words. In addition to the negative words, the positive words of others influenced five of the seven participants. Although Heather suffered years of verbal abuse from her father, several people--her mother, a boarding school teacher, her college support person, and her graduate school professors--positively influenced her with their words. Richard reported that he "had a good mother that made sure I understood exactly what it was that I had and how it made me...that it didn't make me different...that it made me have to use more tools." Stan's father, who had 
dyslexia, shared information about his disability with his son. Stan reported that "All of my life I have been told I am intelligent." Stan equated his ability and possibility of success with those of his father. Henry's mother also chose to focus on his strengths. In explaining his disability, she emphasized the strengths while saying that "It might take you longer to do the work," and "There are certain areas where you are not just as strong." For most of the participants, the positive remarks were reassuring; for Pete they were frustrating. Pete's mom explained that he was "special," but this did little to increase his self-esteem. Instead, it increased his frustration because being special did not alleviate his learning problems. His reaction was "This isn't helpin' [italics added]! You're telling me that I am special because I can't?"

For most of the participants, the words of others had an impact on them. Whether negative or positive, the words contributed to how they understood their learning disabilities.

Actions of Others

Just as important as the Words of Others, the Actions of Others were instrumental in forming the participants' understanding of their learning disabilities. The actions of others shaped the understanding that nine of ten participants had of their learning disabilities. As with the words of others, the actions of othersintentional or accidental--were both negative and positive and had similar impacts.

Negative actions. Eight of the nine participants who reported that the actions of others shaped their understandings were influenced by negative actions. For Cassie, the negative actions of others revolved around her schooling. Cassie stressed the lack of support that she received in high school, "I did get help on some 
tests, but other than that—nothing. No one taught me how to prepare." She had a negative experience when seeking appropriate help in college as well. "I tried to talk to the learning lady down there, but she just didn't have time." George noted that his high school teachers' noninterest when he expressed difficulty affected him. "When I was like, you know, I'm having problems with this, that, and the other thing, it would be, 'Too bad; it's what you got."' George also replied that his disability affected his family's actions. "I think the worst effect was the stress on my family, putting my parents through stress. I could tell sometimes. I could definitely see it. I had my mother who was sympathetic but frustrated at the same time." George's wife, who does not understand his disability, became irritated. She acted out of frustration and this upset George. "I really hit a point where I was just so upset about it...and I remember thinking, 'Why the hell, how in the hell does this happen to me?"' Heather's early life was filled with the negative actions of her schools, her father, and her peers. Before she graduated from high school, Heather had been expelled from three different schools. Her father frequently reminded her that she would not meet the standards of success in her family. He assigned people to check up on her. Heather's peers heckled her about not being able to read or write well. Heather noted that these peers did not want to be friends with her because they thought she was dumb. Both Henry and Nanci were denied the opportunity to select classes they would like to take. Henry was scheduled into remedial English; although he was reading at grade level, he was forced to read remedial books. Nanci was not permitted to take a foreign language because her teachers believed it would be too difficult for her. The negative actions of others that affected Nanci also involved 
teachers who would not take the time to explain or break down concepts for her. She was frequently frustrated with teachers who would rather "do it for me because they would rather do it than explain it." She was disturbed by teachers who "wouldn't let me process in my own time," and frustrated by their actions such as "they way their body moved, the way they said things to you, talked down to you." Vincent also became angry when people would help without being asked to do so. "If I am reading, and I can't get the word out, don't tell me the word before I have a chance to sound it out. I hate when people do that." Pete found the actions of his some people towards their learning disabilities offensive. "I know that there are a lot of people who, who use it, can use it as an excuse for the reason why they don't do well." Richie commented on others' perceptions of those with learning disabilities as slackers too. In high school, he did not attend self-contained or resource classes. Because of this, Richie believed that many of his teachers thought he was just trying to manipulate them. "In high school, it was kinda like they didn't really believe you because you weren't in those classes. They always thought you were trying to get out of something." For Stan, the frequent testing and evaluations bothered him. "They always had me doing these tests, I wouldn't say stupid tests, intelligence tests and everything else."

Positive actions. The positive actions of others influenced five of the nine participants, who indicated that the actions of others affected their understanding of their learning disabilities. In addition to her parents and sister whom she finds very supportive, Cassie also praised her employer's training program. "I am going to start another class. They make sure I that I understand." George explained the positive 
impact of the actions of his family. "My family has been very understanding of it for the most part. They have definitely been a help to me." Although Heather's father was very negative, her mother was just the opposite. She never berated Heather for her learning disability. In addition to her mother, Heather lauded the actions of her college learning specialist and a teacher she had in high school. Her high school teacher opened her home to Heather and would assist her with homework. Of her, Heather said, "She was the one that pretty much brought me out of my shell." Nanci found the actions of several of her teachers very helpful. About one resource teacher she said, "She never gave me the answers or anything. She made me do it and that was fine. Nanci found the teachers at the private school for learning disabilities she attended a positive experience. "They took the patience and time to make sure you understood things, and that it was a process, and you had to be patient." Vincent found the actions of his teacher and others helpful and reassuring. He stated people were helpful to him when he asked. He had a high school teacher who gave him copies of the notes and drawings from class. "I appreciated her for that because it was hard for me to listen and to do other things." Vincent was thankful for the people who opened up to him about their disabilities; he found that their actions made him comfortable with his own disability.

\section{Theme Two: Reactions to Self}

The second theme discovered in the stories of the participants was the participants' awareness of themselves during Self-Comparison to Others as well as Self-Evaluations. Self-comparisons led participants to become cognizant of similarities and differences between others and themselves, and self-examinations 
resulted in the recognition of their feelings and perceptions about their learning disabilities.

\section{Self-Comparison to Others}

Self-comparison to others influenced the participants' understandings of their learning disabilities. These comparisons included comparison to peers, comparison to family members, and comparison to others. All of the participants reported selfcomparisons when discussing their learning disabilities.

Comparison to peers. All ten participants compared themselves to their peers. For the most part, these self-comparisons led participants to the understanding that they were slower, or in some cases, less intelligent. Cassie reported that she was not permitted to do things that other children were. "I was kind of sheltered. I feel that I was sheltered more and maybe wasn't allowed to do things that other kids were allowed to do." George's self-comparison to peers led him to believe that he was slower than his non-disabled classmates. George remembered that "There were three or four of us in our own little reading class which was a little slower." Heather commented, "I am just a little slower than other people," a comment echoed by Nanci. "I always felt slower than the other kids." Vincent also saw himself as slower. "It made my education real slow. I felt slower than everybody else." Henry also reported that his friends "could breeze through books or breeze through vocab. or things like that, and I would be just, 'Wow! Why not me?" Stan, too, stated his "learning curve is a little slower" in some areas. Pete stated that his classmates also completed their work more quickly than he. "It's tough for a twelve-year-old to accept when everyone else is like breezing through all their classes, and you're stuck, you're 
still inside, you know, finishing up while everybody is outside playing." When comparing himself to his peers receiving special services, Richie stated, "They don't maybe learn as fast or they don't, they aren't as driven as much to wanna do the homework or do good in school." Henry's comparison to his peers highlighted his understanding of the ability levels of the students in his remedial classes. He stated that "they just weren't very bright" and that they were "either lazy or it was that they did have a learning disability that was legitimate." Steve, too, remarked, "In some classes, I was grouped with [italics added] kids; they were not the brightest." When she was younger, Nanci also questioned her ability. She remembered "thinking that you're stupid when you can't do the simplest little task in the world, and everybody else can do it." Richie felt he did not "get the same respect as far as the kids that are getting A's in the class."

The self-comparison to peers caused the interview participants to classify their disabilities as negative. The participants viewed themselves as less capable or slower than their peers, thus reinforcing the intellectual and academic differences between those with disabilities and those without.

Comparison to family members. In addition to comparison to their peers, four of the nine participants compared themselves to family members. Heather, Henry, and Pete had siblings who were very successful students. Heather's sister was an outstanding student. Heather's comparison was, "I have a younger sister who excelled in schoolwork. I was just dumb." Of his sister, Henry commented, that she was brilliant, and "I had to work double hard as my sister would do." Pete's sister excelled in school. "I've always compared myself to wanting to be a lot like my sister 
grade-wise. I know she worked her butt off too, but to my perception, she worked a hell of a lot easier than I did." Both Stan and Henry compared themselves to their fathers. Stan's father, who had dyslexia, struggled with spelling just as Stan did. Both frequently asked Stan's mom to spell words for them. "Between me and my father always, 'How do you spell this?'” Henry compared himself to his father, who had difficulty in school but scored well on standardized tests. "He took his SATs and scored so high he was admitted to MIT on a scholarship."

For the most part, the self-comparisons with family members resulted in the participants' realizing that they struggled more than their successful siblings. On the other hand, both students who compared themselves to their successful fathers saw similarities between themselves and their fathers, thus providing hope for positive outcomes even though they had learning disabilities.

Comparison to others. The final self-comparisons involved others in the participants' worlds. Stan and Vincent gained positive self-understanding from these comparisons. Stan compared the impact of his disability to others with disabilities. He remarked, "I have seen other people on earth that have it so much worse than me so I am just thankful that I don't have it much worse than I have." Adults disclosed their disabilities to Vincent, and Vincent compared himself to these adults. Because of the disclosures of adults in his life, Vincent was able to understand that "it is okay for someone to have learning disabilities and be successful at the same time."

\section{Self-Evaluation}

Self-evaluation is the information that the participants provided about their perceptions of their abilities, their expression of feelings, or their actions. All ten 
participants expressed some statements that were identified as self-evaluation. Most of the self-evaluations resulted in the participants' questioning their intelligence, expressing their frustration, or blaming their lack of effort.

\section{Abilities}

Five of the ten participants questioned their academic ability. They used "dumb" and "stupid" most frequently to describe their perceptions about themselves. Vincent asked, "Am I stupid?" and Nanci commented, "I feel dumb when I talk to certain people." She worried that others would discover she was less capable. "They would really find out how stupid I was." Heather, too, saw herself as less intelligent. "I was the dumb kid," she responded, and Henry described himself by saying, "Honestly, I felt stupid." Although George did not use the words, "dumb" or "stupid," he questioned whether he was okay. "I thought there was something really wrong with me."

\section{Social Acceptance}

The impact of the self-evaluation extended to the participants' perceptions of their social abilities and acceptance. Both Heather and Henry believed that they were not accepted socially because of their learning disabilities. Heather reported rejection by many of her classmates because she was in the "dummy class." Even though she wanted to fit in with the "cool kids," she explained that they never really wanted to hang out with her. Henry, too, felt that his learning disability impeded his socialization, especially in high school. "The high school mind is based upon everyone looking at you and you wanting to fit in, and having a learning disability makes you not fit in." 


\section{Feelings}

Although all ten of the participants expressed concern over their lack of achievement and academic and/or social difficulties, five of the ten participantsGeorge, Pete, Steve, Cassie, and Nanci-specifically used the words "frustrated, frustration," or "frustrating" when describing their feelings about their learning disabilities. George who struggled with attention, organization, and written expression felt that his frustration was "a fact of life." Regarding his learning disability, he stated, "I personally feel frustration. I kind of feel, sometimes I feel it [learning disability] shouldn't be an excuse for my problems, and I think that is when I am most frustrated." Pete described how his learning disability shaped his life. "I just reek of frustration. Uhm, I just get so frustrated so easily. I can go from zero to sixty in like, two seconds." The impact of this frustration debilitated him. "You just get that whole level of frustration without being able to organize your thoughts, it just manifests itself like frustration, wait, blind. I can't do anything. You freak out, just freak out. I freak out." Finally, Steve commented, "I remember getting frustrated many, many times, reading assignments, when I really didn't understand something, l'd get frustrated, and it would just, it would just bring down my whole day." In addition to frustration with himself, Steve would also get frustrated with his classmates, many of whom he saw as lazy. Steve describes them as "the kids that were not motivated in school. They were the kids who got in trouble all the time. They just frustrated the hell out of me." Cassie was frustrated with the lack of services as well as with herself. "Not knowing how to do it, not knowing how to get from here to there pains me. I would get frustrated. It just felt like I was behind." Nanci became especially irritated when she 
could not express her ideas or ask a question before someone else started talking. "I get so confused, and then I have to walk away because it is too frustrating to deal with it. Like, it is too overwhelming. The same thing when too many people talk to me at once." A sixth participant, Henry, gave an excellent example of frustration. Although he did not use the word, his description of solving math problems demonstrated his frustration.

I would do the whole equation completely right; I would get that whole algebraic equation all the way done, and I would flip something backwards, and it would drive me insane. And the teacher would go, "You did an excellent job through the step-by-step process of how you do it, but it is wrong."

In summary, the participants' self-comparisons and self-evaluations provided an overall picture of their perceptions about their capabilities and emotions surrounding their learning disabilities. For many of the participants, a learning disability meant they were less capable and less accepted, but for several, the selfcomparisons provided hope for a successful future. Frustration was the most frequently mentioned emotional reaction connected to the learning disability and its challenges.

Theme Three: Impact of Support Systems

Support systems were identified as both Individuals and Placements. For the participants, the importance of support persons was critical to their understanding of their learning disabilities. Each of the participants acknowledged the importance of support persons in their lives. Placements and the accompanying services were perceived as negative, positive, or mixed by the participants. 
Impact of Individuals

One of the most constructive contributors to the participants' understandings of their learning disabilities was the support of individuals. The ten participants cited at least one person who positively affected their perceptions of themselves. These persons included family members, significant others, teachers and support personnel, and mentors.

Family members. Participants recalled family members as vital to their understanding of their disabilities. For each of the ten participants, his or her mother was mentioned as a positive influence. The participants' mothers acted as advocates, tutors, homework monitors, and cheerleaders. Nanci's description of her mother's support reflected many of the commonalities of the other participants' mothers' impacts.

My mom has been a very big support. Oh, my God. She is the one that made sure that I was on the right path to my education from the get-go by making sure that she knew what was going on. She did something about it. If I give up, she is there. She's like, "Okay, you need to come in so we can do this.' She has always been there. Even if I am willing to give up, she is not willing to give up.

Richard's mother also advocated for him. "I mean, she just...she found out what the problem was and addressed it. I wouldn't have stayed and worked so hard in school if it wasn't for that." She helped to demystify the label of learning disability for him by explaining the term and how it applied to him. "I had a good mother who made sure that I understood exactly what it was that I had and how it made me...that it didn't make me different...that it made me have to use more tools." Pete and Henry noted that their mothers assisted them with homework, and that this was not a pleasant 
task. "Getting my homework done was a bear," Pete stated. "My mom took like a brunt of my...took the brunt of it that to do what she did with her students, her high school students, and then come home to helping me with mine." Henry reported, "I was quite a handful. I was very difficult, and my parents really tried to make me sit down and do all the work. My mother cried some days."

Several of the participants included other family members as positive support. Cassie, George, Stan, Steve, and Vincent specifically mentioned fathers, siblings, or grandmother. "I'd say first, my family—my mother and father—just because they've always been supportive of me, and they've instilled in me that everybody's always a little different," Stan stated.

Significant others. Three of the participants mentioned the positive support of significant others. Henry and Richard praised their wives, and Heather acknowledged her boyfriend. Richard's wife was very supportive. "She is a teacher, so she totally understands." Her accepting attitude enabled Richard to feel comfortable asking her for help. "I am never embarrassed to go to her and ask her, even if it's something little, you know, fourth grade level." Henry's wife was a guidance counselor. She helped him by proofreading his written work especially for his graduate classes. After experiencing a previous boyfriend who ridiculed her because of her disability, Heather was involved in a long-term relationship with a partner who assisted her vocationally and personally.

He reads all my papers; he reminds me of things, uh, he helps me just to organize certain things in the house; uh, I like to throw little sit-down dinners, but he'll go over the menu with me and say, "Look, you got this, you got that." He's fantastic with me! He's absolutely wonderful! 
Teachers and support personnel. Although participants cited immediate family members, especially mothers, most frequently as individuals who had a positive impact, they described teachers and support personnel as influential in their lives too. Almost everyone credited an educator as significant, but three participants—Henry, Richard, and Heather--expressed intense admiration and appreciation for certain educators in their lives. Henry discussed the accessibility of his college support specialists.

I have had two great, two great teachers that have really helped me. You could go to them without any embarrassment at all; I mean you just didn't feel embarrassed. You could ask them anything about, I mean, anything that you might be embarrassed about, you know, you wouldn't have to, you know, if you had a question or something very elementary or anything like that. $A$ lot of it was understanding, and a lot of it was you knew that they were there for you as far as if you needed them. It was almost, uh, like a family type, you know, feeling. It helped out a lot.

Henry, too, mentioned his college support personnel as being essential to his success in college.

That class [Study Skills] was pivotal in helping me getting through college. I mean, everything that was there, I owe, that's like why I was still shocked that they left because my whole idea was "I'm going to make lots of money and eventually when I make lots of money, I'm going back and I'm going to give it to them because those are the people who deserve it." And that's what I want to do. I mean when I take off, I will not forget them. Those are the people that, no, they helped me get to where I am. It was such a pivotal thing, I cannot imagine not having them.

Finally, Heather credited a high school teacher with motivating her and her college

learning specialist with changing her life. Of her high school teacher, she said

I had this wonderful woman, Mrs. Cornwell; she was absolutely phenomenal. She was the one that pretty much, I sat with her, I remember sitting with her hours on end after school-she lived right on campus-doing my homework, reading, understanding, 
using tape recorders and listening to my voice, listening to how I read. She was the one that pretty much brought me out of my shell that second eleventh grade year, and then I started excelling.

After living through years of verbal abuse and rejection from her father, Heather said the turning point in her life occurred when Brenda, her college support specialist, came to her room. "You come to me, and I will help you in any way, shape, or form. I will never put you down," the learning specialist stated. "If it was not for her coming to my room and telling me that she would never put me down, I probably wouldn't be where I am right now. I have no idea where I'd probably be, in jail, quite honestly."

Mentors. Both his family and a teacher impacted Victor, but he also recognized the importance of those who shared their difficult learning experiences with him. He was thankful to "all the other people that had a learning disability that told me about it. I had people always in my life who were positive about it." Impact of Placement

The elementary and secondary placements of the participants had both negative and positive impacts. Some found placement for services uncomfortable and unhelpful, while others found their placements useful. Six of the ten participants had negative reactions to their special education placements or services overall, while two had mixed reactions, and two had positive reactions.

Negative reactions to placement. Richard, Stan, Heather, George, Henry, and Cassie had negative opinions of their placements or services or the lack of these. For Henry, leaving the classroom to be in a "lower group or assisted class for special help" was a significant experience. He felt that this "marked" him as being less intelligent than his peers and that he did not "get the same respect as far as the kids 
that are getting the A's in class." Stan also responded that he believed that he was "singled out. They'd take you out of the classroom for an hour a day or whatever; it kinda singles you out. People notice that you leave the classroom" to go to the "special room." For Heather, being in the segregated, special education class with two other girls identified her with those students who were less intelligent. "I was in the dumb class, uhm, my family pretty much always said, 'You're in the dumb class."' George attended a private elementary school with small classes. The small class size helped him greatly, but he transferred to a public high school. This high school "didn't have the proper support system for learning disabilities," but had "some teachers that were very understanding who liked what they did and tried very hard and worked with me, but as far as a special ed. support system, I don't remember there being one." Henry labeled the placement and the services he received as negative. "I was put in the resource room so when you're in the resource room you are kinda excluded from the classroom so you feel, you know, like you're different." He recalled, "It was very emotional to be separated and, uh, when you go back to the class, and the kids are like, 'Where did you go?'” Being in remedial and special classes, Henry felt cheated out of the opportunities that others were given. He also noted that he was not taught the necessary skills to survive in an academic environment. "Nobody sat down and really taught you how to study and to do real good study habits." Cassie also believed that her high school special education program was unhelpful. "I didn't receive much [high school support]. I always felt the lack of everything I needed. Like on tests, learning how to prepare." Her main accommodation was extended time on 
tests. About this accommodation, she commented, "Sometimes I wondered if it was helping me out."

Mixed reactions. Vincent and Steve had mixed reactions to their support services. Vincent believed that being in special education classes separated him from the "normal" students, but he also appreciated the help he received. He had a "test strategies" class and stated, "If I had homework to finish up my first year, I did it in there." He recognized one teacher as being very helpful. Steve appreciated going to the resource room because he could avoid other classes. "I thought, 'This is great. I don't have to be in woodshop.' or 'This is great. I get out of science. I can get my homework done."' On the other hand, he resisted doing some of the work assigned in the resource room, especially the workbooks. "I remember those workbooks that some of the LD teachers would break out when I was finished with my homework. I don't want to work on my handwriting you know."

Positive reactions. Two of the participants-Nanci and Pete--believed that their support services were positive and helpful. When Nanci was in the third grade, she attended a private school for students with learning disabilities. The program was very regimented with highly organized routines and taught daily living skills. "They taught us to like load and unload a dishwasher, how to set a table, how to make sure the plates are clean before you do this. You know, just the daily things that you would normally have to do." Nanci appreciated that they were patient and understanding. "It was really good. I enjoyed it. Uhm, yeah." Nanci also found her high school support class helpful. It was "pretty much a study hall" so she [the teacher] would help me out. She was a good person to go to." Pete was grateful for the help he received 
when attending private school. He had a "learning skills partner" and together they "would get help with your homework." The ratio was two students to one teacher for the homework help, so it was easy to ask questions and get individual help.

\section{Theme Four: Changes Throughout the Lifespan}

Theme four was divided into two sub-categories_-Impact of the Disability and Perceptions of the Learning Disability as a Stigma. The learning disabilities remained a part of their lives, and for many participants, they continued to affect their professional and personal lives.

Impact of the Disability

Learning disabilities remained, and for many of the participants, adult life magnified their impact. Each of the ten participants continued to be affected by their learning disabilities. The disabilities impacted the participants' professional and personal lives. Nanci struggled with "wandering from one dead-end job to another, places I don't like, people I don't like." She was most successful at hands-on jobs with established routines. Since entering adulthood, Nanci experienced panic and anxiety attacks severe enough for her mother to suggest hospitalization. Juggling friendships, her job, and the daily stresses confounded her. The need for routine that she experienced in school was magnified in her adulthood.

There is a certain order to my life; there is a certain order that I have to have every day. Don't interfere because if you interfere you interrupt my whole entire day, and I cannot go back to what I was doing because you interrupted a process, and if it is a regular, daily routine, I get flustered. The hardest part of my life at this point is having the structure that I want.

As an adult, Pete did not see himself as having a learning disability even though poor handwriting, spelling, and written expression continued to plague him. "I 
get confused because I really don't see myself as learning disabled." Pete's job required him to organize the activities of others and to write frequently. Both of these responsibilities tapped into his disability areas.

I can't write; I can't write on paper. My handwriting, my handwriting is so bad. It's tough to organize your thoughts on paper, and my spelling is horrible. I don't know if that has anything to do with my organizational skills but my spelling is just, just horrible.

To get around these disabilities Pete became a perfectionist who did projects repeatedly until they were error-free. Cassie's learning disability hindered her training for another job. Rehabilitation Services wanted her to take courses to become a nursing assistant, but she believed that she would not be successful because of her difficulty "comprehending things, understanding things. Sometimes it takes me a while; I don't get it right away."

Steve and Henry's poor handwriting and spelling earned them subpar evaluations in certain areas of their job performances as teachers. Both had to write the daily objectives on the board, and both were reprimanded for their poor handwriting. Each chose to use the overhead projector so that he could type and spell the objectives correctly, but these accommodations were criticized. According to Steve

They wanted me to write the objective on the board, and I had already cleared it beforehand that it would be okay if I put the objective on the overhead. One of the administrators said, "Have you ever tried working on your handwriting?" I grew angry with her for the comment and responded back, "My handwriting has been this miserable since I was in kindergarten; it isn't gettin' any better!"

Instead of permitting Steve to use the overhead as an accommodation, "they took the overhead away because they thought I was using it too much." Steve expressed 
difficulty with completing forms error-free. "Job applications with my handwriting. That is extremely frustrating. That was often times two or three or four before I finally got one without any mistakes."

Henry's job performance evaluation as a teacher was affected by his learning disability too. "I got above-average evaluations. There were things I needed to improve on and exactly where my learning disability was were the things that were my problems." Henry considered his handwriting and spelling "kindergarten writing." To compensate for this as a teacher, he "had a student go up there who had nicer handwriting and write it down. The supervisor of the social studies department had a great problem with that." Just as Steve did, Henry tried the overhead with the same results. Henry described the process.

I was trying to think of a way to get around having this problem so I figured, okay, "'ll do an overhead." Montemma Public Schools did not want the overhead. They wanted you to handwrite it down...our objective for today's learning on the blackboard.

Henry recognized that his disability continued to impact him "every day... every day. It affects my, the way that I think, the way that I, uhm, try to get things done and accomplished."

Vincent's learning disability prohibited him from holding a job. Since graduating from high school several years ago, Vincent had several part-time jobs. Underdeveloped reading skills and poor memory and attention limited his success in telemarketing. "I couldn't remember nothing. This happens all the time. My mom says I got a one-track mind, and I do. She'll tell me to do something, and I forget."

Heather's life was intertwined with her learning disability. It affected her attention, memory, reading, written language, understanding of time, and 
organization. She made to-do lists for everything and frequently used Post-It Notes, which she usually misplaced. Even her students recognized her problem with memory. "Now, you walk into my classroom. If you say to my class, "What is the one thing Miss Heather does?' They would all say in sign language, 'She forgets."' Heather's friends knew about her learning disability because it influenced her sense of time. "They all know it takes me a lot longer to do things than it does for them, and I am always late." To remedy the lateness, her friends usually told her to be some place half an hour before she needed to be there. Heather still hated reading. "I don't read books. I don't read. I don't like to read. I like to listen." Writing became more time-consuming especially with all of the special education paperwork. Heather typed everything even personal correspondence that she copied in script. At home, she continued to be very disorganized even though her classroom and materials were organized.

Stan's learning disability limited his job choices. He never chose a job that would involve his written expression learning disability. As an audio engineer, he did very little writing. "I shy away from things that involve my learning disability—reading aloud, writing things down, spelling things."

Richard, too, avoided jobs that tapped into his learning disability. As an environmental scientist, most of his work was in the field. Richard did very little reading or writing, but when he had to write a report or note, he would type it and then have his wife proofread it. His spelling continued to be "the worst." Richard explained

It is hard for me to pick something up and write a note to somebody without having to have a spell checker there. I never 
want to have, you know, misspelled words or something like that. I formed a phobia so I kinda go into a shell when I want to write somebody a note or something.

Like Heather, Richard typed all personal correspondence, and then copied it into script. Richard described the process.

When I just want to drop somebody a line or pick up a card and write a note, it takes me a lot longer. I have to write it first on the computer, and I write it down so that's a hindrance to me.

He stated that "taking stuff in that people tell me and trying to filter it in my head" continued to be problems for him. To make connections and remember things still "takes a lot of repetition." Although Richard's difficulties remained in adulthood, Richard regarded his learning disability differently than he did previously. "As an adult, I accept it more."

Finally, of the participants, George described the most difficult adulthood, vocationally and personally, because of his learning disabilities. George held a series of jobs since graduating from college with a teaching degree, and admitted that work was "something that I have never really been that successful at." George was an inner-city substitute teacher for a short while but his lack of organization and discipline made the job very difficult. Of his substitute teaching job, George said it, "was horrible, and I regret every moment of it." Disorganization hindered George's work and caused him to receive poor evaluations in some areas. "I usually do not get a good organization performance record. To be honest with you, it is something I still have problems with." His disability impacted his work in other ways too.

Attention, getting focused, my mind wanders a lot, um, I have a lot of problems, some writing problems. I would say putting my mind on paper, putting my thoughts on paper, I struggle with that a lot, also interpreting things, speaking to people, explaining things, 
uh, I specifically struggle with these.

George noted other areas where his disability impacted his work. He became more aware of these as he became older.

I can't sit still, and I have a pretty short attention span so I really don't like sticking to one thing and doing it all day long in a cubicle. Like I said, my organizational skills are horrible and that has an effect on my supervisor and the people working with me like the janitor who has to clean up after me a lot.

Although George concluded that his disabilities limited his job possibilities, he believed that they also benefited his current position working with senior citizens. "It also enables me to do what I do now--which basically what I do is put out a lot of small fires--I am able to put out the fires non-stop, pretty rapidly."

George's learning disability shaped his personal life. The disability caused disagreements between his wife and him. George's difficulty with short-term memory made him forget activities and information on a daily basis. He explained, "it is frustrating for my wife sometimes. She can definitely see my learning disabilities. It's hard for her because she doesn't have them, and I don't think she has ever been around anybody with them." George's difficulty interpreting things and speaking to people escalated into family arguments. "I remember thinking, "Why the hell, How in the hell does this happen to me?"'

For George the term, "learning disability," was not adequate when describing the impact of his disabilities on his life.

I had this mindset that once you left school, they would go away. It should be life disabilities or going through life disabilities. What I realize is they don't go away. They're forever with you. In fact, it gets harder because there's no help; there's no special needs class for life. There is not a support system. You have to figure out your own support system, and that's hard; that's really hard. 
Perceptions of the Learning Disability Label as a Stigma

Nine of the ten participants identified the learning disability label as a stigma. Some used the word stigma or stigmatized while others just associated negative connotations or marks with the term. To the participants, being viewed as "different" or less intelligent by others was the stigma of having a learning disability. Henry felt stigmatized because of his placement and the label. "When I was growing up, and this is the stigma where I was, I was put into the resource room." Henry felt different from others. "I have a learning disability, and the idea is, the stigma of, and the thing that is stuck to it is--stupid." Richard, too, attached stigma to his placement and the learning disability label. "Maybe it was a stigma that I put on myself as leaving... as not being the same as the other kids." Receiving special services in a segregated setting and having to leave class, Richard had "some pretty hard times with that. Being marked as, you know, that you're not as smart as some of the other kids. It's just that you're leaving class for some special help." Stan stated that leaving the classroom was a negative. “The biggest thing in elementary school—I wouldn't say I was traumatized-was being singled out to go away for an hour to a special room or whatever." Heather, Nanci, and Vincent also spoke about the stigma of lower intelligence associated with a learning disability. Heather said, "I was always the dumb kid." "I kept questioning, ‘Do I have a hole in my head?'” Vincent commented, "The first thing that came to my mind was, 'Am I stupid?"' Nanci's feelings of intellectual inadequacy remained. She replied, "When learning disability was associated with me, it meant that I was stupid. I still feel stupid sometimes." Pete repeatedly referred to being normal. "Normal, like a normal person. I've always tried 
to be as normal as possible." George just said, "I thought there was something wrong with me." Finally, Steve reflected on the attitudes of others' comments about a learning disability. "If it is in a negative light like that person is not intelligent; he or she has a learning disability, then I naturally get defensive."

In summary, $90 \%$ of the participants associated a learning disability with the negative perceptions of lower intelligence or abnormality. Only Cassie did not mention feeling different or stigmatized because of the learning disability or leaving the classroom for special services. For the participants, the negative impact of the disability remained with them in adulthood. They continued to struggle with the ramifications of the disability on their daily lives.

\section{Theme Five: Disclosure Decisions}

Disclosure decisions involved a variety of subcategories. These were the Type of Disclosure, To Whom the Disability is Disclosed, and the Purpose of the Disclosure. In some instances, the type of disclosure varied at different points in participants' lives. In particular, the responses that the participants' received from those to whom they disclosed the disability influenced their later disclosures. Type of Disclosure

The type of disclosures fell along a disclosure continuum with the three main descriptors being full disclosure, partial disclosure, and non-disclosure. A few of the participants' disclosures fell in a different category earlier in their adult lives, but the type of disclosure was classified according to how they were presently disclosing. Seven of the ten participants either fully or partially disclosed their disabilities. The remaining three participants did not disclose their disabilities. 
Full disclosure. Full disclosure required that participants revealed they had a learning disability. The terms, "learning disability" or "learning disabled," were used during the disclosure. Heather and Vincent fully disclosed their learning disabilities. Each viewed the learning disability as just a part of who she or he was. For Heather, her disclosure enabled her to inform others and provide support to her students and their families. "Since I graduated college—anybody and everybody has been very cool, and I tell everybody now. I walk around with my big LD on my head." Heather used the label, learning disability, when disclosing. "I just wanted to mention that I have a learning disability. I was diagnosed in the fifth grade," she stated in her employment interview. After disclosing her disability, Heather elaborated on her strengths and needs. Heather became more open about her learning disability as she grew older. "I'm very open with mine. Before I wasn't, back in high school I wasn't, cause I always got shot down."

Vincent believed it was important to tell others about his learning disability. If someone asks me because they are interested, I would tell them because people told me. I tell people I have a learning disability and attention deficit disorder." Vincent was able to explain his disability and was not afraid to ask for help.

Partial disclosure. Partial disclosers discussed their weaknesses, but did not use the terms, "learning disabled" or "learning disabilities," when disclosing. Instead, they explained that they had problems with areas such as spelling, handwriting, or organization. Several of the participants fully disclosed somewhere in their adult lives but have chosen not to do so anymore; they now disclosed using areas of weakness and are identified as partial disclosers. For example, Henry fully disclosed to his wife 
while they were dating, to an employer during the initial interview, and to his students. During his interview, Henry stated, "I told them flat out when I was being hired. I have a learning disability. The number one thing of my learning disability is my written expression. That's exactly how upfront I was." Henry told his middle school students, "I have a learning disability. This is where my strengths and weaknesses are." More frequently, Henry described his weaknesses rather than using the label, learning disability. He spoke of his poor handwriting and spelling. "My handwriting is so awful that I should have been a surgeon."

Steve partially disclosed his disability through a description of his handwriting. In the past, he mentioned to several colleagues who were complaining about IEPS that he had an IEP in school, but he had not discussed a learning disability. "It's not something that I tattoo to my forehead. I try to make it a non-issue." Although he taught students with disabilities in his inclusion class and criticized his own handwriting to them, he had not disclosed or discussed his learning disability with them. Although he identified his learning disability as impacting reading, Steve did not discuss disclosing this.

Stan disclosed his disability by describing his spelling and handwriting weaknesses. "I just don't tell... without saying I'm learning disabled, some people like we're going back to before, when I tell people, uhm, I would say I'm definitely more apt to say, 'I, jeez, I can't spell worth a darn,' upfront, you know much sooner than the reason why I can't spell." Stan explained his rationale for this choice. "Maybe it saves a big conversation. Uhm, it just... because then, oh well, what's wrong with you, and you have to get in depth, and all this other stuff." Stan was a partial discloser. 
George and Cassie were partial disclosers also. George stated, “I don't think I ever said, 'I have a learning disability or whatever.' I think it was more like, 'You know, I'm just having problems with this, that, and the other thing."' Cassie also disclosed by telling people that she had "trouble comprehending."

Non-disclosure. The final type of disclosure was non-disclosure. Three participants did not disclose their learning disabilities or discuss their learning weaknesses or needs. Pete, Richard, and Nanci all believed that their learning disabilities were nobody's business but their own.

Because Pete did not see himself as a person with a learning disability, he did not disclose. "It is one of those things I just don't discuss. It makes me uneasy to discuss it, but it is nobody's business."

Only Richard's wife and a few of his friends from childhood knew about his learning disability. Richard did not disclose his disability to anyone else because of his fear that others would believe him to be less capable.

Growing up, I was ashamed or didn't want anybody to know about it, and to an extent as I'm older, I don't want an employer or somebody of that nature to know that I have a learning disability because I don't think they'll truly understand. I know that I am smart. I just don't want people to think that I am not.

Richard worried that if he disclosed his learning disability, others would underestimate him. "I always have a hard time disclosing it—that's one of my biggest problems. I don't want to be labeled as being dumb."

Nanci would only disclose a learning disability if someone asked her directly. She commented, "Other than that, why would they need to know?" Although Nanci 
indicated that she would disclose a disability if asked directly, she disclosed to no one in her adult life.

Very few of the participants identified themselves as having a learning disability when disclosing. If they disclosed, most of the participants chose to describe what they had difficulty with instead of using the label. They did not want anyone to misunderstand what the term, "learning disability," meant, especially if the interpretation was lower intelligence.

To Whom the Disability is Disclosed

Those participants who fully or partially disclosed their learning disabilities informed one or more of the following: employers, coworkers, significant others, friends, professors, students, or parents of students. Heather fully discussed her learning disability to all of those identified above, and her disclosures were received positively. She disclosed to potential employers during her initial interviews for teaching positions. She indicated that she was identified as having a learning disability in the fifth grade, and that organizing and completing paperwork would cause her difficulties. Heather also disclosed to her new principal. "Hi, I'm your special ed. preschool teacher, and I have a learning disability." The principal was impressed with the disclosure and asked Heather to talk with the middle school special education students and to advise their support group. Heather's coworkers knew about her learning disability, and they helped her cope with her disability. One coworker corrects and types Heather's portion of a weekly newsletter. "We've talked about it, and she takes care of it for me. She doesn't do it for anyone else." Heather told her significant other several months into their relationship. While reading a card 
she had given him, her boyfriend could not understand her spelling. She responded, "It must be my LD piece kicking in" and explained about her learning disability. She described his reaction. "He was really cool with it. He is just fantastic!" Heather's friends know about her learning disability and how affects her life. She has one friend who corrects and returns her emails. "At first, when she started doing that, I was like...'What are you doing?' But she said, 'No, it is actually going to help you.' And she was right because I print out the corrected emails and re-read them, and I am like...'Oh, yeah, I didn't do this, or the tense is wrong in this one, or that is a big fragment."' During her interview for graduate school, Heather disclosed. One of the professors asked why she wanted to be a special education teacher, and Heather disclosed her learning disability. Although the institution did not have a support program, the professor asked to be her advisor because Heather was "the first person in fourteen years who has point blank said, 'I have a learning disability, and I need help." Heather was adamant about disclosing her disability to her special needs students and their parents. She explained about her diagnosis, how little she knew about her disability growing up, and how she coped with her disability during adulthood. She shared her IEP with them [the older students she tutors] and explained their testing results and IEPS to them. Heather demystified their learning disabilities. She also explained this information to the parents of her students so that the parents would have a better understanding of how their children learned. 'I've had two parents ask me to talk to their older children who are not in high school and are failing because they don't want to go to the 'dumb' classes." Heather described 
herself, "I think that's what's really cool with me... is that I am pretty open with anybody and everybody."

Vincent fully disclosed his learning disability to his coworkers. He explained his needs and received help. "I had a lady that sat next to me that helped me all the time if I didn't know the words." He felt comfortable disclosing it to friends and others since adults had disclosed their disabilities to him while he was growing up.

Cassie partially disclosed her learning disability to her employers, coworkers, significant others, and professor with mixed reactions. Cassie told her employers that she needed to have things explained to her because she had trouble with understanding things. "They didn't show me how to understand it. You just had to figure it out on your own, or you were up the creek. In my other jobs, people would help me." As for her co-workers, Cassie said they talked about everything from drugs to sex. "The people I work with know. I told them that I have trouble comprehending. Explain that to me again. So yes, they know." Cassie's boyfriend also knew about her learning disability. "He loves me anyway. He knows that I don't understand. I am very open with him." Although Cassie disclosed to a professor and the support person at the community college, neither responded fully. Her college professor sent her to a tutor who was not helpful. As for the support person, Cassie stated, "I tried to talk to the learning lady down at [the college], but she just acted like she didn't have the time." Henry partially disclosed to his employer, coworkers, significant others, and students. In three instances in his past, Henry fully disclosed his learning disability although he has since discontinued doing so. While interviewing for a teaching position, Henry explained, "I told them flat out when I was being hired that I have a 
learning disability." Even though Henry explained that the disability involved written expression, he was chastised for not writing his objective on the chalkboard. Henry also told his future wife about his disability. "I know it was not a big deal," he stated. "It was just something that I said." Finally, Henry explained his learning disability to his middle school students. "I was like, 'I have a learning disability. This is where my strengths and weaknesses are." Henry partially disclosed his disability to his coworkers. At work, Henry told "Cindy, who is the research technician, that I have a problem spelling and proofreading." Steve partially disclosed his learning disability to an employer and co-workers previously. To the employer, he explained that he had problems with handwriting and spelling. This disclosure did not translate into any accommodations; Steve was penalized on his evaluations for asking a student to write the daily objectives on the board or using the overhead to project them.

Steve disclosed that he had an IEP in high school to several of his colleagues when they were discussing IEPs. Steve taught an inclusion social studies class but did not disclose his learning disability to any of his students for fear of persecution. He did disclose his poor handwriting.

George partially disclosed his learning disability to his significant other, but she did not understand nor accept it. According to George, this was difficult for her because she had never encountered anyone with a learning disability before. George's boss and co-workers knew about his problems with organization and written expression, not because George specifically disclosed them, but because they were observant. George stated, "I think generally people in the workplace figure out who you are, and they are either accepting of you or they're not. I'm fortunate to 
work in an environment where people pretty much are accepting." Stan partially disclosed his poor handwriting and spelling to his employer. He did not disclose the underlying reason for these weaknesses because he felt it "saved the big conversation."

Richard was a non-discloser. He fully disclosed his disability to his future wife when he was in college, but this was difficult for him to do. After a year of knowing her, he told her, "You know, I have a learning disability." He admitted, "I mean, I held it from her a lot." He no longer fully or partially disclosed his learning disability. Nanci disclosed her disability to no one. She considered it a privacy issue.

Most of the participants either fully or partially disclosed their disability to at least one individual in their adult lives. For some, the disclosure had positive effects; for others, the effects were neutral or negative. Although some disclosed to others previously, they chose not to continue the practice.

\section{Purpose of Disclosure}

The participants in this study had little, if any, understanding of the Americans with Disabilities Act (ADA), the Act's implications for disclosure of a learning disability, or the Act's protections. For the participants, the purpose of their disclosures fell into three main categories: information and clarification of the disability and/or weaknesses to prevent misunderstanding, request for help because of the disability, and the provision of emotional support for self and others. The purposes of the disclosures depended upon the situations and the persons involved. Information and clarification of the disability and/or weaknesses to prevent misunderstanding. Most of the disclosures occurred because the participants wanted 
to clarify the impact of their disability and/or inform others of weaknesses that might affect their job performance. This was especially true of disclosures to employers. Heather, Vincent, Cassie, George, Steve, and Richard all fully or partially disclosed to inform others. After Heather disclosed to her first principal, her principal responded, "I'm glad you told me because in two months, if you are all over the place, I could fire you or I can help you." Because of this positive response, Heather "was able to express to anybody and everybody that I do have a learning disability." On the other hand, Heather described a friend who refused to disclose her learning disability. “She's supposed to get things rushed. She can't rush it; she needs to take her time. I've said, 'Tell somebody!' But she says, 'I don't want to use it as a crutch.' If you teach somebody, they're going to understand."

Steve disclosed during his interview for a teaching position. He explained about his poor spelling and handwriting. He also disclosed to the assistant principal in his current teaching assignment. The disclosures provided information. Richard explained to his employers that writing was not his "strong point. I don't particularly come out and tell them that I have a learning disability."

Request for help because of the disability. Some disclosures laid the foundation for accommodations or assistance. Henry, Heather, Vincent, Cassie, George, and Stan disclosed because they needed help to perform their jobs properly. Henry fully disclosed during his interview for a teaching position. "I flat out told them when I was being hired. 'I have a learning disability.' He also explained how he would spell check everything, but that he would "like to go and give this to another teacher or just somebody else to look over before it was sent out." Most of the disclosures for 
help were to co-workers, friends, significant others, or professors. When George disclosed his poor written expression, he reported

I've had accommodations brought to me. If I type up a nice letter that I want to send out to an organization, I will show it to my supervisor first. I would rather have it look good. I would rather have it done right than not.

Cassie, Vincent, Heather, and Stan also received help from co-workers, friends, and significant others. Cassie and Heather disclosed their disabilities to professors so that they would receive help academically. Cassie received very little help, while Heather received strong support during her Master's program.

The provision of emotional support for self and others. Some disclosures occurred because the participants wanted emotional support for themselves or others. Heather and Henry disclosed their disabilities to their students because they wanted their students to understand that people with learning disabilities can learn, but they may have to learn in a different way. They wanted their students to know adults with learning disabilities who were successful. Vincent disclosed his disability because those who disclosed to him had been helpful. Heather, George, Henry, Cassie, and Richard disclosed to their significant others because they wanted emotional support from them. Some participants who chose not to disclose said they might if they felt very comfortable with a person; they had not reached that comfort level yet.

Overall, disclosure of a learning disability was a decision that was carefully made by the participants. Some felt the need to disclose using the label while others did not see the need to use a label that could be misinterpreted. The reasons for full 
or partial disclosure varied, and for a few, the type of disclosure changed. None disclosed to invoke the protections of the ADA.

Theme Six: Management Techniques

Management techniques are the self-presentational strategies that the participants used to deal with the mark of their learning disabilities. The participants used all five self-presentational strategies to manage knowledge about their learning disabilities. These strategies included withdrawal, passing, covering, role acceptance, and confrontation and breakthrough. Some participants used one strategy exclusively while others used a combination of strategies. Some strategies were used often while others were used less frequently.

\section{Withdrawal}

Withdrawal was defined as staying away from those without the "mark." Those using withdrawal did not want to be associated with those identified as having the mark. Steve's choice to conceal his disability from the students with learning disabilities in his inclusion class may be loosely interpreted as withdrawal, since he did not want to be identified with those students whom he regarded as lazy and disruptive.

\section{Covering}

The participants used covering as a way to minimize the impact of the disability when others knew about the disability or weaknesses associated with the disability. Heather, George, Henry, Nanci, and Stan all minimized the effects of their known weaknesses by using technology or people to assist them. Heather, although she was very open about her disability, relied on technology, her co-workers, friends, 
and significant other to proofread her written communications. She listened to books on tape to lessen the impact of her reading disability. Her significant other also helped her with organization in her personal life. George used a computer to compose and spell-check his writing, and his supervisor to proofread his work. Henry used Dragon Dictate to compose all of his professional and personal correspondence. In his college days, Henry's girlfriends edited his written work. He remembered, "When I started dating people I made sure, kind of, unfortunately, I asked people...I was very upfront about it, it's like, can you proofread? Do you have good English skills?" His wife, research assistant, and secretary edited his written work for his professional life and graduate school. Nanci's mother provided the support to minimize Nanci's learning disability. She assisted her with comprehension, writing, and motivation. Finally, Stan used computers for all of his written work. "God bless technology! I love computers and spell-checkers." He made sure that his employer proofread the few pieces of written correspondence that he composed. For each of these participants, technology and reliance on others was useful for helping to minimize the impact of their disabilities.

Passing

Seven of the ten participants used passing as their main self-presentational strategy. For Cassie, Stan, Richard, Pete, George, Nanci, and Henry passing hid their disabilities from others. Cassie, Richard, George, Stan, and Nanci concealed their disabilities from others by avoiding situations where their weaknesses would be noticed. Cassie refused to attend a training program because the program was not hands-on, and she was afraid she would not comprehend the information. Richard 
chose an occupation that had little, if any, writing; written expression was his learning disability. George concealed his disability by limiting his job opportunities. He was conflicted because of this. "I would talk myself out of it knowing that I don't have good organizational skills. I think one of the hardest parts of learning disabilities is sometimes you short-change yourself; I kind of have a history of doing that." Stan did not see his current job as his career. He believed that some day he would have a 9-5 job that tapped into his learning disability, "and then it could be a slap in the face." Finally Nanci stayed away from any job that would expose her learning disability. She commented, "Why would I want to do anything that is hard... not necessarily hard but that you don't like? "She also avoided taking the SATs.

Henry chose careers that highlighted his positive attributes. He advised, "When you have a learning disability, you have to identify what your strong points and your weak points re and what types of fields you can go into that can, you know, eliminate the negatives and accentuate the positives." Henry and Pete were able to conceal their disabilities by their work habits too. "I have to work double hard as everybody else, and that's how I have always done... worked double, triple hard that anybody else would do," Henry noted. Pete, too, concealed his disability by selectivity in his work and his work ethic. Pete remarked, "I've always done things that I am interested in. It is personally avoidance; the whole avoidance thing works wonders so I've always done things that I've wanted to do." Pete described his work ethic. "I'm one of those people who would make time myself to get something done whether it would be staying late for work or coming in early. It is always about putting the best foot forward and just doing it." 
The participants that used passing were able to hide their disabilities and the weaknesses that resulted from those to whom they did not want to disclose. They effectively did this by avoiding situations where their disabilities would be exposed.

\section{Role Acceptance}

Role acceptance was accepting the stereotype of the mark or disability and acting in accordance with the stereotype. This self-presentational strategy occurred in adolescence for four of the participants. Heather and Stan fell into the stereotype of the helpless individual with a learning disability. Heather remarked, "In high school, it [her learning disability] became a crutch. Oh, I don't want to take this test because I have a learning disability, can you write it for me cause I have a learning disability? I used it." Stan fell into the stereotype of using his disability as an excuse when he was dismissed from college.

I tried to play the learning disability card on that one with the Dean of Faculty. Uhm, I said, "I'm learning disabled" and I gave him this whole big spiel. It was a very negative thing. That's, uh, I learned my lesson on that one, that's for sure. First of all, not to screw around, but second of all, there was no real reason for me to pull that card; I mean, it was my own fault. Sure that didn't help, but I thought that would have been my best way back in, but. I, I think that was the only time in my life, or the biggest-the most major that I played the learning disabled card.

The Dean of Faculty rejected Stan's appeal, and Stan returned home to attend a state university. For Heather and Stan, the use of role acceptance as a selfpresentational strategy was short-lived.

Steve and Richard admitted doing as little as possible in high school. Both students fell into the learning pattern of the passive learner that reflected the majority of students in their special education classes. 


\section{Confrontation and Breakthrough}

For those who have accepted their disabilities as a part of who they are and not their whole identification, confrontation and breakthrough enables them to express this acceptance and move on. For Heather and Vincent confrontation and breakthrough was an effective self-presentational strategy. Heather recognized that by acknowledging her disability, she was able to receive the support she needed as well as share her story with others so that they could learn more about themselves. Heather's "mission in life right now is just to teach people about their learning disability or about some type of disability to make them understand what I understand just recently, and l've been diagnosed since the fifth grade." After struggling with his diagnosis, Vincent, too, accepted his learning disability. "I have a learning disability, and if you don't like it, so what. I just have a different learning process, and I need help."

Although only two of the participants fully acknowledged and accepted their learning disabilities as just a small part of their makeup, several of the other participants were beginning to consider confrontation and breakthrough as a selfpresentational strategy.

\section{Conclusion}

This chapter presented the interview summaries and composite summaries of the disclosure experience for ten selected adults with identified learning disabilities. The summaries indicated that the effects of learning disabilities remained, and in some cases, were exacerbated in adulthood. For those who chose to disclose the learning disability in adulthood, the disclosure was more frequently done by 
describing the weaknesses and not using the terms, "learning disabled" or "learning disability." Most of the participants concealed the impact of the disability by avoiding situations where the disability might be a factor, or minimized the impact of their weaknesses by relying on technology and others. The decision to disclose varied with the circumstances surrounding the disclosure and the feedback given after the disclosure. For those who fully disclosed and received positive feedback, the full disclosure continued. For those who fully disclosed and received negative feedback, the potential for full disclosure in the future lessened. Instead, partial disclosure or non-disclosure was used. 


\section{CHAPTER FIVE}

\section{Discussion}

This chapter focuses on four areas. First, previous research will be connected to the data reported in Chapter Four addressing the three research questions. These questions are: 1) How does an individual with a learning disability come to understand what his or her learning disability means? 2) How and why do participants engage in self-disclosure? 3) What self-presentational strategies do adults with learning disabilities use to manage their disability status? Next, recommendations from the research will be reported. Then, limitations of the study will be addressed. Finally, future research will be discussed.

\section{Understanding the Learning Disability}

The intent of the first research question was to discover how individuals with learning disabilities understood what having a learning disability meant to them. What specific factors contributed to the development of meaning? These factors were found in the first three themes--Reaction of Others, Reaction to Self, and Impact of Support--associated with the first research question: How did an individual with a learning disability come to understand what his or her learning disability meant? The fourth theme--Changes Throughout the Lifespan-addressed the changes in perceptions of the disability as the participants aged. Is there evidence that supports the theory of developmental stages suggested by Higgins et al. (2002), the life story described by McNulty (2003), or the process of reframing highlighted by Gerber et al. (1996) when accepting the label of learning disabled? 


\section{Reactions of Others}

The reactions of others shaped the participants' understanding of their learning disabilities. These included the negative and positive words and actions of others. The negative reactions of others played a part in participants' defining themselves as intellectually inadequate or socially unacceptable. On the other hand, the positive words and actions of others provided participants with the support and hope that they could be successful in life.

Negative words and actions. For each of the study participants, the reaction of others contributed to the understanding of their learning disabilities. The negative words and actions of others added to feelings of intellectual and social inadequacy. These negative words and actions fell on a continuum from overt comments about the participants' intellectual capacities to subtle gestures and facial expressions that displayed the impatience of teachers who had to wait for information to be processed. Shessel and Reiff (1999) found that negative words and actions contributed to social isolation as participants expressed feelings of being different. McNulty (2003) refers to these negative reactions of others including subsequent attacks on character and intelligence as "the adversarial subplot" (p. 372). The negative statements shared by the participants of the current study paralleled those of the participants in McNulty's qualitative study of adults with dyslexia. McNulty explained that the subplots "involved a benefit and cost" ( $p .372$ ). The benefits of the adversarial subplot included motivation to overcome the negative perceptions of others while the costs revolved around continued self-questioning about intellect. The participants in the current study reinforced both the benefits and costs of the adversarial subplot described by 
McNulty. Several participants described their motivation as proving wrong those who doubted their ability for success thus motivation became the benefit. Others reported feeling intellectually inferior in childhood and concerned about misinterpretations of a disclosure of a learning disability in adulthood to mean less capable or slow. Both of these examples illustrate the cost reported by McNulty.

Positive words and actions of others. The participants also reported the influence of positive words and actions. McNulty (2003) called this the "affirmative subplot" (p. 372). One of the benefits of this subplot was increased self-esteem, and an important cost included "sacrifice" (p. 372). For most of the participants in the current study, the positive words and actions of others provided the hope that they would overcome the challenges of their learning disabilities. Most parents explained to the student her or his strengths and weaknesses; teachers provided support for student learning through specialized instruction, and adults offered reassurance by sharing stories of similar learning difficulties. The accompanying sacrifices included loss of time, isolation from peers, and conflict with parents. Participants recounted stories filled with the loss of time for other activities because of the extra time spent on class work and homework. For example, they frequently remained in the classroom when others were outside playing. They sacrificed being an integral part of their mainstream classes because they were isolated from their peers as they received services in the resource setting. The parent-child relationship was jeopardized because of the stress and frustration surrounding the completion of homework. All of these situations corresponded to McNulty's classification of sacrifice. For one participant though, the positive words of others did not increase his 
self-esteem or help him to compensate for his disability. He became increasingly frustrated when his mother reassured him that he was special in a positive way. Instead of finding this comforting, he became angry because the description did nothing to resolve his learning challenges.

Reaction to Self

Reaction to Self, second theme, is divided into two subcategories--SelfComparison to Others and Self-Evaluation. The participants compared themselves to a variety of people with both positive and negative results. The self-evaluations identified feelings of frustration and incompetence as well as positive attributes such as persistence and creativity.

Self-comparison. The participants in this study compared themselves to classmates, family members, and other adults. The comparison of themselves to others often resulted in their identifying themselves as slower or less skilled. They perceived the speed at which they mastered concepts, completed work, understood directions, and demonstrated academic skills as lagging behind the speed of their counterparts without disabilities. Higgins et al. (2002) concluded that the participants in their study became aware of academic and non-academic differences. In some instances, their participants perceived themselves as being judged as not normal as reflected in statements such as "It's hard for me to not feel slower than the other children" (p. 9).

Several of the participants in the current study noted that their peers in classes for students with learning disabilities were not very bright, and others commented that they felt stupid in comparison to their peers. McNulty (2003) reported similar 
perceptions from his participants. In their elementary and middle school years, they also questioned their intelligence. "Participants most commonly felt that others thought they were 'lazy' or 'stupid,' leaving them with disturbing questions and selfdoubts" (p. 371).

Self-evaluation. Participants identified both positive and negative attributes because of self-evaluation. The negative attributes included concerns about intelligence, social acceptance, and emotional stress. When reflecting on their elementary and secondary school years, participants referred to themselves as dumb or stupid, which were corroborated by the findings of McNulty (2003) and Shessel and Reiff (1999). These concerns were validated by Reiff and Gerber (1994) who noted, "Perhaps the most pervasive reaction to school failures is a feeling of being stupid" (p. 73). In addition to questioning their intelligence, several of the participants believed themselves socially unacceptable because of their learning disabilities. One participant, in particular, stated that her classmates rejected her because she was in the "dummy class," so she became a truant. Frustration permeated the lives of many participants. The participants described feeling frustrated by confusing assignments, poor reading comprehension, ineffective support services, and organizational difficulties.

In contrast to the negative self-evaluations from childhood and adolescence described by the participants, many of the participants identified personal strengths in their adult lives as part of the self-evaluation process. These strengths included perseverance and creativity. Participants reported working longer and harder to complete tasks. They disclosed strategies such as adaptive technology and support 
persons for compensating for the effects of their learning disabilities. Gerber and Ginsberg (1990) found that successful adults with learning disabilities displayed persistence and learned creativity. They described persistence as doing "whatever was necessary" (p. 12) to accomplish a goal, and learned creativity as "ways to accomplish tasks and generally survive" (p. 13). Impact of Support

The third theme, Impact of Support, contained the subcategories of Impact of Individuals and Impact of Placement. Both of these subcategories had positive and negative results.

Impact of individuals. For the participants in the current study, the support of individuals was critical. Each participant mentioned at least one person who supported her or him unconditionally. All participants praised their mothers for their support. Other positive support persons were teachers, college support staff, spouses or significant others, or other family members. Corley and Taymans (2002), in their review of studies of highly successful adults listed personal support from family, mentors, and personal or work relationships as critical to adult adjustment. Werner (1993) as quoted by Corley and Taymans (2002) shared the importance of support persons. "The learning disabled youngsters who overcame the odds all had at least one person in their lives who accepted them unconditionally, regardless of temperamental idiosyncrasies, physical attractiveness, or level of intelligence" (p. 52).

Impact of placements. Special education placements had an impact on the participants. Most of the participants in the current study received assistance in pullout programs such as the resource room. Previous studies of students' perceptions 
of the resource room resulted in mixed findings. In their synthesis of research on inclusion and resource rooms, Vaughn and Klingner (1998) reported that overall, students with high-incidence disabilities in these studies preferred the resource room compared to the inclusive classroom for academic benefits. Students, especially intermediate students, believed the resource room was the best place for their learning to occur. Only two students in the eight studies reported that the resource room carried a stigma. Some students reported they preferred the general education classroom for social benefits because they made more friends there and did not miss out on any instruction. Instead of providing support for the participants in the current study, the majority of the participants in the current study regarded their pull-out programs as impacting them negatively socially, a finding consistent with that of Vaughn and Klingner (1998). The participants believed that pull-out programs singled them out as being different. Very few of the students commented on the academic assistance they received, but several said that they were not taught the skills that they needed. On the other hand, two of the participants, who attended private schools with intensive special education services, praised their special education placements as being helpful. Since services were provided to all students, being singled out was not an issue.

\section{Changes Throughout the Lifespan}

Changes Throughout the Lifespan was the fourth theme discovered in the stories of this study's participants. The subthemes were the Impact of the Disability and the Label as a Stigma. 
Impact of the disability. For most of the participants in this study, all of whom were labeled as having a learning disability during their elementary school years, the impact of the disability continued into their adult lives. The academic and organizational difficulties experienced in childhood because of their learning disabilities remained in adulthood. Previous studies supported the current findings that learning disabilities continued to impact individuals throughout their life spans (Buchanan \& Wolf, 1986; Gerber et al., 1990; Hoffman et al., 1987; Malcolm et al., 1990; Price et al., 2003; White 1985; White, 1992).

According to the results of Raskind, Goldberg, Higgins and Herman (1999), learning disabilities had their greatest stress on individuals during childhood, and the stress lessens throughout the life span. The reports of nine of the current participants were consistent with these findings. These participants stated that the learning disability and its manifestations impacted them more negatively during their elementary and secondary school years than during their adulthoods. On the other hand, Gerber et al. (1990) found that "a quarter or more of all respondents reported increasing difficulties in adulthood" (572). The tenth Individual in the current study believed that the learning disability was magnified in his adult life because of the growing demands of adulthood and lack of support services for guidance in coping with the demands.

Very little research has been done on what contributes to an individual's understanding of the learning disability, but two studies provided the main framework for understanding the stories of individuals with learning disabilities throughout their lives. Higgins et al. (2002) described how individuals with learning disabilities came to 
accept their learning disabilities. They identified the stages that individuals with learning disabilities went through to accept their disabilities. McNulty (2003) compared the stories of individuals with dyslexia to the development of a narrative. He identified the "prologue, exposition, plot, subplot, resolution, and epilogue" (p. 371) of his participants' life stories. Both of these frameworks provided sequential methods of discussing the impact of the disability through adulthood.

Higgins et al. (2002) explained the stages that individuals with learning disabilities experienced as they attempted to accept their learning disabilities. These stages included: "(a) awareness of their learning 'differentness'; (b) the labeling event; (c) understanding/negotiating the label; (d) compartmentalization; and (e) transformation" (p.3).

Self-awareness of the disabilities was divided into two categories: 1) the specific acceptance of the learning disability in which the individual used the term, learning disability, while describing herself or himself, and 2) the general selfawareness in which the individual did not use learning disability but described specific strengths and weaknesses. While telling their stories, only two of the participants described themselves as having a learning disability (specific awareness). The remainder chose to discuss their specific strengths and weaknesses (general self-awareness) instead. Statements from the participants in the current study illustrated each of the stages identified by Higgins et al.

Stage One was labeled as "Awareness of a Difference" (p. 8). In childhood, the participants of both the Higgins et al. (2002) study and this study recognized that they were different from their peers. Some stated that they had difficulty with 
academic skills while others expressed that they learned more slowly. The academic differences were described as specific weaknesses in subject areas such as handwriting or spelling. Comments about additional problems related to academics such as organization, attention, and memory mirrored the descriptions of the Higgins et al. participants. Although several participants in the Higgins et al. research identified their differences as totally non-academic, no participant in the current research did so.

The Higgins et al. (2002) study also examined the affective/behavioral domain. The participants in that study described deep emotional feelings connected with being different. This confirmed the finding of Shessel and Reiff (1998) who concluded that a "negative self-concept was an ever-present issue" (p. 310) because of feelings of incompetence. Repeatedly, the participants in the current study reported feeling dumb, stupid, and inadequate.

Stage Two, "The Labeling Event," described the process of identification of the disability as well as the negative and neutral descriptors (Higgins et al., 2002). For the participants in the current study, the process of identification was not particularly significant. Only one participant reported any memories of the testing process. He described how he was always being tested. "They always had me doing these tests, I wouldn't say stupid tests, intelligence tests and everything else." The other participants reported labels such as slow, different, special, and retarded being attached to them by parents, teachers, and others. These labels corresponded to those cited in the Higgins et al. study. 
Stage Three, "Understanding/Negotiating the Label," included discovering what the individual with the learning disability was and was not able to do as well as what placement and resources were necessary (Higgins et al., 2002). In both the Higgins et al. study and the current study, participants commented on the specific academic difficulties and strengths they had. The Higgins et al. study discussed the parents and students struggling with these issues, and the current findings suggested that most of the individuals with learning disabilities had no clear understanding of placement decisions or their strengths especially at earlier ages. Some were confused and angry about being pulled out for special classes and stigmatized by the process. On the other hand, one study participant recounted how his mother explained both his strengths and weaknesses to him. This explanation began the self-awareness process for him. Levine (1994) described this as demystification, "a process through which adults talk to children about the nature of their learning disorders and strengths. It is based on the belief that children cannot work on their problems if they do not really understand them" (p. 7). For the majority of the participants in the current study, demystification did not occur early in their lives. They were left with feelings of inadequacy. For some, these feelings of inadequacy possibly accounted for their passivity in adolescence. As Barton and Fuhrmann (1994) noted, "Persons who, from childhood on, internalize beliefs of incompetence have a monumental task in disputing and developing beliefs in their own competence" (p. 84).

Stage Four, "Compartmentalization," permitted the individual with learning disabilities to "minimize weaknesses and maximize strengths" (Higgins et al., 2002, p. 
12). For many of the current study participants, this occurred in adulthood as they discovered creative ways of minimizing their learning disabilities while using the management techniques of passing and concealment, which will be discussed more fully as a part of the third research question. Gerber, Reiff, and Ginsberg (1996) discussed the process for evaluating a learning disability to determine the strengths and weaknesses as reframing. Individuals who reframed their experiences by going through the stages of recognition, understanding, acceptance, and plan of action used their strengths to "accomplish 'goodness of fit' in work or in one's personal life" (p. 100). Most of this study's participants did not reframe until adulthood although Gerber et al. suggested that reframing is on-going and should begin in childhood Stage Five, "Transformation," enabled participants to view their learning disabilities as something positive. They were able to view their disabilities as adding a special dimension to their lives (Higgins et al., 2002). Of their successful participants, not many reached transformation. The current study had similar results. Only a few attributed positive outcomes to their learning disabilities. As one participant stated, "I'm almost grateful in a way that I do have a disability because I think it made me a better person...just because people aren't good in writing or maybe reading, or you know, numbers, they do have other abilities."

Whereas Higgins et al. (2002) employed stages to discuss the acceptance of a learning disability. McNulty (2003) used the development of a narrative to explain his participants' life stories. The components of the story-the prologue, exposition, plot and subplots, resolution, and epilogue—clarified the events in the participants' lives. Individuals with learning disabilities began to notice something was different about 
them during the prologue of early childhood. This difference became apparent because of the words and actions of others. As McNulty noted, not everyone in his study mentioned this experience, and only a few in the current study did as well. During exposition, the McNulty participants experienced difficulties because of their learning disabilities that caused them to question their intelligence. These findings were paralleled in the current study. The plots and subplots in McNulty's study were both positive and negative and involved benefits and costs to the participants. These were more fully explained previously when discussing the words and actions of others. McNulty's resolution involved tentative compensation where the participants had difficulty completing tasks in their personal and professional lives, alternative compensation where the participants chose to avoid areas that tapped into their learning disabilities, gifted overcompensation where participants strongly pursued areas of strengths, and compensation where participants slowly adapted over their lives to professional and personal challenges. Participants in the current study demonstrated each of these types of compensation. For example, George still had difficulty at work and home, and he believed that he short-changed himself. Nanci and Stan decided on jobs that did not tap into their learning disabilities. In college and in his career, Henry chose areas that focused on his strengths, and he fiercely pursued them. Richie and Steve had success in their chosen careers, and both were intensely private about their learning disabilities because of the fear of people questioning their intelligence. Finally, the epilogue gave participants a chance to resolve their feelings of incompetence and low self-esteem. In adulthood, participants in the current study wanted to reward those who assisted them and confront those 
who minimized them, share their experiences with others, and improve self-esteem by focusing on achievements. All of these activities were similar to those cited by McNulty as part of the epilogue.

The label as stigma. The label as stigma is the last subtheme in theme four. Nine of the ten participants in the current study identified some aspect of a learning disability as a stigma. In childhood the stigma was most frequently associated with leaving the classroom for the resource room. Participants noted that this singled them out from the other students. Participants also noted that being labeled as having a learning disability made them question their intelligence. They believed that lower intelligence was associated with a learning disability. In adulthood, many of the participants did not use the words learning disability or disabled to describe themselves because of their fear that the label would be misinterpreted as lower intelligence, a fear confirmed by Brown (1994) and Gerber and Price (2003).

\section{Disability Disclosure}

The aim of the second research question was to begin to understand how and why participants with learning disabilities chose to disclose their learning disabilities to others. This theme described the level of disclosure, to whom the disability is disclosed, and why/when the disclosure occurs. The subcategories for this theme include Type of Disclosure, To Whom the Disability is Disclosed, and Purpose of Disclosure.

Seven of the participants in the current study disclosed their disability either through describing themselves as having a learning disability or describing their weaknesses without using the learning disabled label. Three of the participants did 
not disclose their disability. Individuals who disclosed used full disclosure, using the terms learning disability or learning disabled during the disclosure, or partial disclosure, describing the areas of weakness such as poor spelling or handwriting. Two of the participants considered as partial disclosers did fully disclose at one point in their adult lives but chose not to do so anymore. The participants disclosed their learning disabilities to a wide range of individuals.

Full disclosure. The participants disclosed their learning disabilities to a wide range of individuals. Both Vincent and Heather, who fully disclosed their learning disabilities, shared the information with employers, coworkers, friends, and teachers. Heather also shared the information with her students, parents of students, and significant other. Vincent and Heather received positive responses from those to whom they disclosed their learning disabilities. Employers and co-workers made the necessary accommodations. Heather and Vincent responded that they would continue to fully disclose their learning disabilities.

Partial disclosure. Those who partially disclosed their learning disabilities had mixed reactions to the disclosures. Henry and Steve, who fully disclosed to their employers earlier in adulthood, later were reprimanded for their disabilities. Both were teachers with handwriting and spelling difficulties, and both received criticism from supervisors for using compensatory strategies such typing objectives on transparencies for the overhead projector instead of writing them on the board. Henry fully disclosed to his students with positive results, but he is no longer teaching, and Steve did not fully disclose to his students. Neither fully disclosed their learning disabilities again. Cassie, Henry, Steve, George, and Stan partially disclose their 
disabilities by discussing their weaknesses. Each had disclosed to one or more of the following: employers, co-workers, significant others, professors, and friends. While most received understanding from those to whom they partially disclosed their disabilities, Cassie found her employers and teachers less responsive.

Non-disclosers. Richard, Nanci, and Pete currently did not disclose their disabilities to anyone. When in college, Richard had previously disclosed his disability to his future wife, but he did not do so until after knowing her for a year. He no longer fully or partially disclosed his disability to anyone. Nanci and Pete believed that disclosure of their disabilities and accompanying weaknesses were not necessary.

No research was found specific to learning disabilities and the disclosure in adulthood to those outside of the workplace. Previous research found that full disclosure—specifically identifying as having a learning disability—in the workplace was uncommon (Gerber \& Price, 2003; Greenbaum et al., 1996; Madaus et al., 2002; Madaus et al., 2003; Price et al., 2003). The participants in the current study confirmed this finding.

Reasons for disclosure. The full or partial disclosure of a learning disability occurred for a variety of reasons. These included: information and clarification of the disability and/or weaknesses to prevent misunderstanding, request for help because of the disability, and the provision of emotional support for self and others. The two main reasons for non-disclosure of a learning disability were fear and lack of need. Although their learning disabilities were reported by adults in previous studies to impact their job performances, self-disclosure did not occur because of the fear of repercussions (Greenbaum et al., 1996; Kakela, M. \& Witte, 2000; Madaus et al., 
2003; Price et al., 2003). The fear of using the term, learning disability, revolved around its misinterpretation. Brown (1994) summarized the confusion surrounding the term to include it being confused with mental retardation, a confusion that is perpetuated by the media's using the terms interchangeably. The second reason for non-disclosure in the current study was lack of need. Madaus et al. (2003) reported the majority of the respondents who did not disclose gave no need as the reason for non-disclosure. Some adults in the current study no longer viewed themselves as having a learning disability or felt their learning disability did not impact their work performance. Price et al. found that over half of the subjects did not identify themselves as having a learning disability in adulthood even though they were diagnosed as such in school.

Most of the participants in this study disclosed their learning disability by the acknowledging specific weaknesses such as handwriting or spelling. When participants fully or partially disclosed their disabilities, they disclosed to persons a variety of settings. Disclosure occurred for several reasons including information and clarification of the disability and/or weaknesses to prevent misunderstanding, request for help because of the disability, and the provision of emotional support for self and others. The two main reasons for non-disclosure of a learning disability were fear and lack of need. Overall, the participants in this study had limited or no knowledge about the Americans with Disabilities Act (ADA) and how this legislation applied to them. Price et al. (2003) reported that over $75 \%$ of their respondents has never heard of the ADA. 


\section{Management Strategies}

The self-presentational strategies described by Goffman (1964) and Jones, et al., 1984) were used as the framework for identifying how adults with learning disabilities responded to their learning disabilities and subsequent weaknesses. Respondents used three of the five strategies_covering, passing, and confrontation and breakthrough—in adulthood and one-role acceptance—in late adolescence and early adulthood. One participant used a strategy that loosely could be construed as Withdrawal.

Five participants reported using covering as a management strategy. Covering is used as a way to minimize the impact of the disability when others know about the disability or weaknesses associated with the disability. Technology played an important role in covering. Participants listened to books on tape, used speech-to-text software, and relied on spell-checkers and word processing programs. Raskind (1994) noted the importance of compensation instead of remediation. He highlighted the use of assistive technology as "the most expeditious means of addressing specific difficulties within particular contexts" for adult (p. 159). Covering was also accomplished by relying on others to assist with proofreading. The respondents in other studies used proofreaders (Greenbaum et al., 1996; Madaus et al., 2002). Participants that used covering were creative problem-solvers. Gerber and Ginsberg (1990) discussed learned creativity as it applied to highly and moderately successful adults. Highly successful adults with learning disabilities used learned creativity to excel while moderately successful adults with learning disabilities used it to conceal the effects of the disability from others. 
Seven of the ten participants in the current study used passing as an effective self-presentational strategy. Passing involved avoiding certain jobs or activities to hide the disability from others. Participants chose occupations that did not access the disability area, refused participation in training programs, limited job opportunities, and worked harder and longer to be successful. Harlan and Robert (1998) found that employees with learning disabilities put in extra time and limit their job possibilities rather than ask for accommodations. Some types of passing depended on goodness of fit. Gerber and Ginsberg (1990) described goodness of fit as "fitting into the surroundings in which they could succeed" (p. 11). Those who avoided jobs or activities where their disabilities would negatively impact them and chose jobs or activities that utilized their strengths demonstrated goodness of fit.

Confrontation and Breakthrough was the final self-presentational strategy chosen by the participants in the current study. This strategy reflected the participants' understanding that their disability was just a part of who they were and not their whole identification. Two of the participants demonstrated this strategy. Confrontation and Breakthrough corresponded to the acceptance stage in the model of reframing proposed by Gerber et al. (1996). Both participants were able to accept both the positives and negatives of their learning disabilities.

Overall, the management strategies demonstrated by the participants worked well for minimizing or hiding their disabilities. The technology they used and the personal assistance they received enabled them to perform their jobs successfully. However, for some participants, the choice of occupations resulted in jobs that did not tap into their capabilities. 


\section{Recommendations}

The results of this study lead to several implications. These include: 1) the importance of demystification, 2) the need for early instruction in assistive technology, 3) the importance of education in the Americans with Disabilities Act, 4) the awareness of resources and supports for adults with disabilities, and 5) the development of sensitivity towards people with disabilities.

The Importance of Demystification

Demystification (Levine, 1994) assists individuals with developing an understanding of their individual strengths and weaknesses. As soon as an individual is identified as having a learning disability, demystification must begin. Parents, educators, ancillary personnel, and service providers must have a full understanding of the disability so that they can facilitate the process. Helping individuals with learning disabilities understand their strengths and weaknesses contributes to selfawareness, and in turn, to the development of self-determination. Self-awareness is a component of reframing which Gerber et al. (1996) describes as "a key for achieving high levels of vocational success in adults with learning disabilities" (p. 98). Demystification must include the role of the service delivery system and how the special education services will help with student weaknesses. Opportunities for questions and feedback from those with learning disabilities must be provided. Participants in the current study were able to identify areas impacted by their disabilities, but they did not explain why they had these difficulties. Demystification is an on-going process that can assist with transition planning. Hitchings, Luzzo, Ristow, Horvath, Retish, and Tanners (2001) indicated between $17 \%$ and $20 \%$ of 
high school students participate in transition planning. As the settings demands change and skills development, individuals with learning disabilities need to reevaluate how their strengths and weaknesses impact the areas of their lives and what can be done minimize the negative impact in their future.

The Need for Early Instruction in Assistive Technology

Students must be taught to use assistive technology from an early age. The participants of this study relied on spell checkers, speech to text programs, and books on tape to minimize the impact of their disabilities. Students must successfully acquire the necessary knowledge about assistive technology and how its use can facilitate learning. Raskind (1984) reviewed assistive technology that may compensate for learning disabilities. This technology included word processors, spellcheckers, proofreading programs, outlining/brainstorming software, speech recognition software, screen readers, optical character recognition systems [Kurzweil], speech-controlled tape recorders, and talking calculators. Raskind (1984) noted that remedial efforts have been unsuccessful for many students, but that the use of assistive technology will help students to compensate for their disabilities by tapping into their strengths.

\section{Americans with Disabilities Act}

Both individuals with learning disabilities and employers need information about the Americans with Disabilities Act. For individuals with learning disabilities, this education must begin in early high school so that they are aware of the components of the act and how to access its protections. The majority of participants in the current study were college graduates. They knew little, if anything, about the 
ADA. Madaus, Price, and Gerber (2008) reviewed the results of research about ADA knowledge and concluded that individuals with learning disabilities had limited knowledge of the ADA and its components; they also were unsure of the knowledge that they had. If accommodations are necessary, individuals with learning disabilities need to know what accommodations they need, what accommodations are covered by the ADA, how to get the appropriate accommodations, and the recourse when accommodations are denied. A discussion of how and when to disclose a disability and how to ask for accommodations must also be a part of this education. College students with learning disabilities suggested mentors with learning disabilities internships, and transition-to-work seminars as possible ways of exploring the ways learning disabilities might impact employment (Madaus, Gerber, \& Price, 2008). Employers also need to know about the different types of disabilities and how they may impact the workplace. Madaus, Gerber, and Price, 2003 noted that employers want more information about learning disabilities and their effects on employment. ADA informational sessions should include this.

Resources and Supports for Adults with Disabilities

Study participants indicated that the impact of the disability becomes greater in adulthood because of the lack of support services. Secondary and post-secondary institutions must provide information on the resources available to students after they exit these institutions. Programming should include the type of resources available and how to access the resources for support. 


\section{Sensitivity to Disability}

The results of this study indicate that individuals with learning disabilities are severely impacted by the negative words and actions of others. The words of counselors, parents, and educators about the participants' capabilities angered the participants and negatively influenced their self-esteem. Continued effort must be made to inform parents, counselors, educators, and others about the impact of these negative words. Additionally, during the explanation of test results, psychologists and other evaluators should report not only the weaknesses such as low achievement scores but also positive possibilities for the evaluated individual. Another area for exploration is the provision of mentors-especially mentors who have achieved despite a learning disability_-for students identified with learning disabilities. The recognition that success is possible and others have shared similar experiences may balance the effects of negative comments from others. The negative actions were related to pull-out programs and the lack of choices participants had. Demystification about the usefulness of services may lessen the negative impact of pull-out. Participating in shared decision-making during the Individual Education Plan and Transition Plan processes may provide individuals with disability a stronger sense of control over their lives and reduce the negative impact of the action of others.

Elementary, secondary and post-secondary institutions have a responsibility to implement these recommendations. From the moment students with learning disabilities are diagnosed, they must be informed of not only their weaknesses but their strengths. Evaluators must help students to understand that there is a purpose for the interventions they are receiving. Both the home and school should encourage 
students with learning disabilities to constantly reevaluate their personal growth and goals by using the steps of demystification described by Levine. Pairing students with mentors who have similar disabilities would provide the student with successful role models as well as persons who understand the academic, emotional, and social issues that accompany the disability. Students should be encouraged to participate in developing their Individual Education Plan from a very early age by being given choices concerning their instruction. Schools must also provide professional development that includes success stories from those who have received services. These development opportunities must be provided to parents as well. Too many times, parents and teachers are not aware of the long-term impact of our actions. As the student moves to secondary school, information about the Americans with Disabilities Act, self-advocacy, goal-setting, and transition must increase. Students need to become comfortable explaining their disabilities and asking for accommodations. They need to know how, when, and to whom they should disclose. Students also must be knowledgeable about the community resources that will support them in adulthood.

For those students who enter post-secondary education, knowing how to disclose their disabilities and what accommodations are provided under the law remains critical to their receiving appropriate services. To assist with the transition to the work world, students would benefit from internships and employment related to future careers. Practice with interviewing and disability disclosure as well as up-todate information about the Americans with Disabilities Act will assist students with learning disabilities to make more informed decisions about the disclosure process. 
The recommendations suggested by this study require more sensitivity to the impact of labeling and pull-out programming on students with disabilities as well as earlier and more strategic planning for the transition of students into adulthood.

\section{Limitations of the Study}

Because of the nature of qualitative research, the findings of this study illustrate the collective stories of the participants. These stories and the findings discussed may be similar to the stories of other adults with learning disabilities, but they cannot be generalized across all individuals with learning disabilities.

One of the research questions of the study addressed self-disclosure. Some participants were identified as non-disclosers although the very act of agreeing to participate in this study required them to disclose their learning disability to the researcher. The number of returned responses to participate in the study was small. Perhaps the unwillingness to disclose the disability to a researcher they did not know prohibited potential participants from responding. A second reason may account for the small number of returned responses. Requests for participants went through the director of a high school special education department and the director of a college disability services. Each had access to addresses of former students, but there was not guarantee that the addresses were current.

Although the study attempted to broaden the participant base to include adults with disabilities who did not attend college, no such individual responded to the invitation to participate. Research suggests that individuals who do not attend college have more severe disabilities than those who do (Minskoff, Hawks, Steidle \& Hoffman, 1989). 


\section{Implications for Future Research}

Future research might examine the best ways of providing a level of knowledge and comfort about disclosing learning disabilities and asking for accommodations in the workplace. One of the participants who partially disclosed his learning disability switched jobs several months after our interview and discussed this during the member-check. Although he is having workplace difficulties directly resulting from his learning disability, he will not disclose his disability and ask for accommodations. He believes that the disclosure might provide ammunition for his dismissal so he wants to "fly under the radar."

Research concerning the self-disclosure of learning disabilities in the personal lives of adults with learning disabilities needs expanded. Little research (qualitative or quantitative) on disclosure of learning disabilities focused on participants' personal lives. Previous studies have indicated that non-disclosers expend much energy on concealing their disabilities from others. The participants in this study did not conceal their disabilities from their spouses of significant others. At the time of the interviews, none of the participants had children. Will they disclose to their children? Will disclosure to others provide more opportunities for successful integration into community and social activities?

Finally, with the emphasis on inclusion as a service delivery model, studies need to be conducted to assess the effectiveness of the inclusive classroom on demystification, reframing, and self-determination. When and where these processes will occur and which educators are best prepared to facilitate them must be examined. 


\section{Conclusion}

The ten participants in this study told stories that reflected their lifetime struggles with learning disabilities. The stories are filled with frustration, sadness, uncertainty, self-questioning, self-discovery, and contentment. The participants displayed both the frustrations and victories of living with learning disabilities. The learning disabilities impacted the participants' academic work, their social lives, their home lives, and their beliefs in themselves. For the participants, their life journeys enabled them to decipher their perceptions of their learning disabilities. These journeys were reflected in the stages or reframing of the learning disability. Many struggled with minimizing or concealing their learning disabilities because they wanted to be "normal." This study showed the importance of the demystification of a learning disability since many of the participants questioned their intelligence and remembered feeling dumb or stupid when they were younger. For the few who acknowledged their learning disabilities, they already saw themselves as "normal." Their learning disabilities were just a small part of their identities. These participants believed that they had to inform others of the true meaning of a learning disability so that the negative misconceptions about intelligence were discounted. 


\section{References}

Anderson, P.L., \& Kasmierski, S. (1995). Learning disabilities, employment discrimination, and the ADA. Journal of Learning Disabilities, 28(4), 196204.

Barton, R.S., \& Fuhrmann, B.S. (1994). Counseling and psychotherapy for adults with learning disabilities. In P.J. Gerber \& H.B. Reiff (Eds.), Learning disabilities in adulthood: Persisting problems and evolving issues (pp. 82-92). Boston: Andover Medical Publishers.

Bassett, D.S., Polloway, E.A., \& Patton, J.R. (1994). Learning disabilities: Perspectives on adult development. In P.J. Gerber \& H.B. Reiff (Eds.), Learning disabilities in adulthood: Persisting problems and evolving issues (pp. 10-19). Boston: Andover Medical Publishers.

Brown, D.S. (1994). Personal perspectives_-problems and promises: Adults with learning disabilities in the past and present. In P.J. Gerber \& H.B. Reiff (Eds.), Learning disabilities in adulthood: Persisting problems and evolving issues (pp. 46-51). Boston: Andover Medical Publishers.

Buchanan, M., \& Wolf, J.S. (1986). A comprehensive study of learning disabled adults. Journal of Learning Disabilities, 19(1), 34-38.

Corley, M.A., \& Taymans, J.M. (2002). Adults with learning disabilities: A review of the literature. In J. Comings, B. Garner, \& C. Smith (Eds.), The Annual Review of Adult Learning and Literacy (pp. 44-83). San Francisco: JosseyBass.

Field, S., \& Hoffman, A. (1994). Development of a model for self-determination. Career Development for Exceptional Individuals, 17, 159-169.

Field, S., Price, L., \& Patton, J.R. (2003). Epilogue. Remedial and Special Education, 24(6), 380-382.

Frauenheim, J.G., \& Heckerl, J.R. (1983). A longitudinal study of psychological and achievement test performance in severe dyslexic adults. Journal of Learning Disabilities, 16(6), 339-347.

Gerber, P.J., \& Reiff, H.B. (1991). Speaking for themselves: Ethnographic interviews with adults with learning disabilities. Ann Arbor: University of Michigan Press.

Gerber, P.J. (1994). Researching adults with learning disabilities from an adultdevelopment perspective. Journal of Learning Disabilities, 27(1), 6-9.

Gerber, P.J. (2003). Adults with learning disabilities redux. Remedial and Special Education, 24(6), 324-327. 
Gerber, P.J., \& Ginsberg,R.J. (1990). Identifying alterable patterns in employment success for highly successful adults with learning disabilities. (National Institute on Disability and Rehabilitation Research. Grant \# H133G80500). Washington DC: United States Department of Education Office of Special Education and Rehabilitation Services.

Gerber, P.J., Ginsberg, R., \& Reiff, H.B. (1992). Identifying Alterable Patterns in Employment Success for Highly Successful Adults with Learning Disabilities. Journal of Learning Disabilities, 25(8), 475-487.

Gerber, P.J., \& Price, L.A. (2003). Persons with learning disabilities in the workplace: What we know so far in the Americans with Disabilities Act era. Learning Disabilities Research and Practice, 18(2), 132-136.

Gerber, P.J., Reiff, H.B., \& Ginsberg, R. (1996). Reframing the learning disabilities experience. Journal of Learning Disabilities, 29(1), 98-101.

Gerber, P.J., Schnieders, C.A., Paradise, L.V., Reiff, H.B., Ginsberg, R.J., \& Popp, P.A. (1990). Persisting problems of adults with learning disabilities: Self-reported comparisons from their school-age and adult years. Journal of Learning Disabilities, 23(9), 570-573.

Ginsberg, R., Gerber, P.J., \& Reiff, H.B. (1994). Employment success for adults with learning disabilities. In P.J. Gerber \& H.B. Reiff (Eds.), Learning disabilities in adulthood: Persisting problems and evolving issues (pp. 204-213). Boston: Andover Medical Publishers.

Goffman, E. (1964). Stigma: Notes on the management of spoiled identity. Englewood Cliffs, NJ: Prentice Hall, Inc.

Goodman, N.C. (1987). Girls with learning disabilities and their sisters: How are they faring in adulthood? Journal of Clinical Child Psychology, 16(4), 290-300.

Greenbaum, B., Graham, S., \& Scales, W. (1996). Adults with learning disabilities: Occupational and social status after college. Journal of Learning Disabilities, 29(2), 167-173.

Grigal, M., Neubert, D.A., Moon, M.S., \& Graham, S. (2003). Self-determination for students with disabilities: Views of parents and teachers. Exceptional Children, 70(1), 97-112.

Harlan, S.L., \& Robert, P.M. (1998). The social construction of disability in organizations: Why employers resist reasonable accommodations. Work and Occupations, 25(4), 397-435. 
Higgins, E.L., Raskind, M.H., Goldberg, R.J., Herman, K.L. (2002). Stages of acceptance of a learning disability: The impact of labeling. Learning Disability Quarterly, 25, 3-18.

Hitching, W.E., Retish, P., \& Horvath, M. (2005). Academic preparation of adolescents with disabilities for postsecondary education. Career Development for Exceptional Individuals, 28(1), 26-35.

Hitchings, W.E., Luzzo, D.A., Ristow, R., Horvath, M., Retish, P., \& Tanners, A. (2001). The career development needs of college students with learning disabilities: In their own words. Learning Disabilities Research and Practice, 16(1), 8-17.

Hoffman, F.J., Sheldon, K.L., Minskoff, E.H., Sautter, S.W., Steidle, E.F., Baker D.P, et al. (1987). Needs of learning disabled adults. Journal of Learning Disabilities, 20 (1), 3-57.

Jones, E. E., Farina, A., Hastorf, A.H., Markus, H., Miller, D.T., \& Scott, R. A. (1984). Social stigma: The psychology of marked relationships. New York: W. H. Freeman and Company.

Kakela, M., \& Witte, R. (2000). Self-disclosure of college graduates with learning disabilities. Learning Disabilities: A Multidisciplinary Journal, 10, 25-31.

Kavale, K.A., \& Forness, S.R. (1996). Learning disability grows up: Rehabilitation issues for individuals with learning disabilities. Journal of Rehabilitation, 62(1), 34-41.

Kohler, P.D., \& Field, S. (2003). Transition-focused education: Foundation for the future. The Journal of Special Education, 37(2), 174-183.

Lerner, J. (2003). Learning disabilities: Theories, diagnosis, and teaching strategies $\left(9^{\text {th }}\right.$ ed.). Boston: Houghton Mifflin Company.

Levine, M.D. (1994). Educational care: A system for understanding and helping children with learning problems at home and in school. Cambridge, MA: Educators Publishing Service, Inc.

Lewandowski, L., \& Arcangelo, K. (1994). The social adjustment and self-conceptof adults with learning disabilities. Journal of Learning Disabilities, 27(9),598-605.

Lincoln, Y., \& Guba, E.G. (1985). Naturalistic inquiry. Thousand Oaks, CA: Sage Publications.

Link, B.G., \& Pheloan, J.C. (2001). Conceptualizing stigma. Annual Review of Sociology, 27, 363-385. 
Madaus, J.W. (2006). Improving the transition to career for college students with learning disabilities: Suggestions from graduates. Journal on Postsecondary Education and Disability, 19(1), 85-93.

Madaus, J.W., Foley, T.E., McGuire, J.M., Ruban, L.M. (2002). Employment selfdisclosure of postsecondary graduates with learning disabilities: Rates and rationales. Journal of Learning Disabilities. 35(4), 364-369.

Madaus, J.W., Gerber, P.J., \& Price, L.A. (2008). Adults with learning disabilities in the workforce: Lessons for secondary transition programs. Learning Disabilities Research and Practice, 23(3), 148-153.

Madaus, J.W., Ruban, L.M., Foley, T.E. \& McGuire, J.M. (2003). Attributes contributing to the employment satisfaction of university graduates with learning disabilities. Learning Disability Quarterly, 26(3), 159-170.

Malcolm, C.B., Polatajko H.J., \& Simons, J. (1990). A descriptive study of adults with suspected learning disabilities. Journal of Learning Disabilities, 23(8), 58-520.

McLaughlin, M.E., Bell, M.P., \& Stringer, D.Y. (2004). Stigma and acceptance of persons with disabilities: Understudied aspects of workforce diversity. Group \& Organization Management, 29(3), 302-333.

McNulty, M.A. (2003). Dyslexia and the life course. Journal of Learning Disabilities, 36(4), 363-381.

Miles, M., \& Huberman, M. (1994). Qualitative data analysis. Thousand Oaks, CA: Sage.

Minskoff E.H., Hawks, R. Steidle, E.F., \& Hoffmann, F.J. (1989). A homogeneous group of persons with learning disabilities: Adults with severe learning disabilities in vocational rehabilitation. Journal of Learning Disabilities, 22(8), 521-528.

Minskoff, E.H., Sautter, S.W., Hoffman, F.J., \& Hawks, R., (1987). Employer attitudes toward hiring the learning disabled. Journal of Learning Disabilities, 20(1), 5357.

Olney, M.F., Brockelman, K.F., Kennedy, J., \& Newsom, M.A. (2004). Do you have a disability? A population-based test of acceptance, denial, and adjustment among adults with disabilities in the U.S. Journal of Rehabilitation, 70(1), 4-9.

Patton, M.Q. (2002). Qualitative research and evaluation methods ( $3^{\text {rd }}$ ed.). Thousand Oaks, CA: Sage Publications. 
Patton, J.R,. \& Polloway, E.A. (1992). Learning disabilities: The challenge of adulthood. Journal of Learning Disabilities, 25(7), 10-415.

Price, L.A., Gerber, P.J., \& Mulligan, R. (2003). The Americans with Disabilities Act and adults with learning disabilities as employees: Realities of the workplace. Remedial and Special Education, 24(6), 350-358.

Price, L.A., Gerber, P.J., \& Mulligan, R. (2007). Adults with learning disabilities and the underutilization of the Americans with Disabilities Act. Remedial and Special Education, 28(6), 240-344.

Price, L., \& Patton, J.R. (2003). A new world order: Connecting adult developmental theory to learning disabilities. Remedial and Special Education, 24(6), 328338.

Raskind, M.H. (1994). Assistive technology for adults with learning disabilities: A rationale for use. In P.J. Gerber \& H.B. Reiff (Eds.), Learning disabilities in adulthood: Persisting problems and evolving issues (pp. 152-162). Boston: Andover Medical Publishers.

Raskind, M.H., Goldberg, R.J., Higgins, E.L., \& Herman, K.L. (1999). Patterns of change and predictors of success in individuals with learning disabilities: Results from a twenty-year longitudinal study. Learning Disabilities Research and Practice, 14(1), 35-49.

Reiff, H. B., Gerber, P. J., \& Ginsberg, R. (1997). Exceeding expectations: Successful adults with learning disabilities. Austin, TX: Pro-Ed.

Reiff, H.B., \& Gerber, P.J. (1994). Social/emotional and daily living issues for adults with learning disabilities. In P.J. Gerber \& H.B. Reiff (Eds.), Learning disabilities in adulthood: Persisting problems and evolving issues (pp. 72-81). Boston: Andover Medical Publishers.

Ross-Gordon, J.M., Plotts, C.A., Joesel, J.N., \& Wells, R. (2003). Assessment of adult learning disabilities: Multiple perspectives. Adult Basic Eduction, 13(3), 131-145.

Rubin, H.J., \& Rubin, I.S. (1995). Qualitative interviewing: The art of hearing data. Thousand Oaks, CA: Sage Publishers.

Ryan, G.W., \& Bernard, R. (2003). Data management and analysis methods. In Denzin, N.K. \& Lincoln, Y.S. (Eds.), Collecting and interpreting qualitative materials (259-309). Thousand Oaks, CA: Sage Publications. 
Scheid, T.L. (2005). Stigma as a barrier to employment: Mental disability and the Americans with Disabilities Act. International Journal of Law and Psychiatry, 28, 670-690.

Shessel, I., \& Reiff, H.B. (1999). Experiences of adults with learning disabilities: Positive and negative impacts and outcomes. Learning Disability Quarterly, 22(4), 305-316.

Stake, R.E. (2000). Case studies. In Denzin, N.K., \& Lincoln, Y.S. (Eds). Handbook of qualitative research (pp. 435-454). Thousand Oaks, CA: Sage Publications.

Valle, J.W., Solis, S., Volpitta, D., \& Conner, D. (2004). The disability closet: Teachers with learning disabilities evaluate the risks and benefits of "coming out." Equity \& Excellence in Education, 37(1), 4-17.

Vaughn, S., \& Klingner, J.K. (1998). Students' perceptions of inclusion and resource room settings. The Journal of Special Education, 32(2), 79-88.

Vogel, S., \& Forness, S. (1992). Social functioning in adults with learning disabilities. School Psychology Review, 21(3), 375-386.

White, W.J. (1992). The postschool adjustment of persons with learning disabilities: Current status and future projections. Journal of Learning Disabilities, 25(7), 448-456.

White, W.J. (1985). Perspectives on the education and training of learning disabled adults. Learning Disability Quarterly, 8, 231-236.

White, W.J. (1983). Education and Training of the Adult LD: Goals, Models, Issues, and Implications. Washington, D.C.: National Institute of Handicapped Research.

White, W.J., Alley, G.R., Deshler, D.D., Shumaker, J.B., Warner, M.M., \& Clark, F.L. (1982). Are there learning disabilities after high school? Exceptional Children, 49, 273-274.

White, W.J., \& Polson, C.J. (1999a). Accommodations for adults with disabilities in adult basic education centers. Adult Basic Education, 9(2), 90-103.

White, W.J., \& Polson, C.J. (1999b). Adults with disabilities in adult basic education centers. Adult Basic Education, 9(1), 36-45.

Yin, R.K. (2003). Case study research: Design and methods ( $5^{\text {th }}$ ed.). Thousand Oaks, CA: Sage Publications. 
Appendix A

Interview Protocol

\section{AM INTERVIEWING ADULTS WITH LEARNING DISABILITIES ABOUT HOW THEY HAVE COME TO UNDERSTAND THEIR LEARNING DISABILITIES AND HOW THEY COPE WITH THEIR DISABILITIES IN THEIR PERSONAL AND PROFESSIONAL LIVES.}

1. Tell me a little about yourself.

- Age

- When and where did you attend elementary school/high school/college?

- What types of classes did you take in high school/college?

- Did you graduate from high school/college?

- What kind of special education services/support services did you receive?

- What types of jobs have you held?

o Part-time, full-time

o How long at each one?

o Performance evaluations

o Any raises?

- Are you employed now? Doing what? For how long?

2. Describe your learning disability.

- Strengths

- Weaknesses or areas of concern

3. What do you feel when I say "learning disability?" Why?

- How did you feel during school

- How do you feel in adulthood 
4. Describe the first time you remember the words, "learning disability" used in reference to you.

- What was your reaction to this?

- How did you feel?

5. Describe the circumstances around the diagnosis of your learning disability.

- How

- When

- why your learning

6. How has your learning disability impacted your life either in positive or negative ways?

- Socially

- Emotionally

- Educationally

- Vocationally

- In your family?

7. Does it continue to impact your life (if not discussed in answer)?

- If yes, in what ways?

- If no, why not?

8. What supports have helped you to deal with your learning disability?

- People

- Services

- Activities

- Assistive technology

9. How do you approach a new situation where your learning disability may be a factor?

- Social

- Educational

- Vocational

10. Describe what you would in these situations.

- Avoid

- Pass

- Live up to expectations

- Self-disclose

- Other 
11. Under what conditions (when and why) would you disclose your learning disability?

- Professional

- Personal

12. Have you ever asked for accommodations in the workplace? Why or why not?

- If yes, would you do so in the future?

13. What can you tell me about the Americans with Disabilities Act?

14. Describe the most significant/memorable events in your life that had to do with your learning disability.

- In school

- In adulthood

15. Describe how others have reacted to your learning disability.

- Personal life (family and friends)

- Professional life (supervisors, peers)

- Education (teachers, classmates, coaches, advisors)

16. How do other people's reactions influence how you choose to deal with your learning disability?

- Avoid

- Pass

- Live up to expectations

- Self-disclose

17. I will be interviewing other people for this study. Is there anything else that I should ask about that I did not ask?

18. Is there anything else that you would like to add? 


\section{Appendix B}

Sample Responses for Member Checks of the Interview Summaries

“The summary is pretty much 'dead on.' It is kind of funny to revisit the interview. Recently, I have changed jobs and now I'm doing a lot more, but my life has calmed down a lot so I am not as frustrated. I am all about using technology to give myself a little control over this thing. It [the interview] was pretty accurate. I still feel like I am competing with myself to overcome [the disability]."

"First of all, I was crying-all three times I read it. I had never seen my life on paper like that. Like, I have always told my story, but I have never seen it written so it kind of hit home. I think it was $100 \%$ accurate in how you explained my life. I passed it on to my mother, and she was 'Wow!' It was pretty heavy duty but really accurate and well written."

"For the most part, the summary is very accurate. I am upfront about the challenges that I had to go through to achieve success in life dealing with a learning disability. I know that dealing with a LD is okay and a lot of people have one. I also know that being upfront about your limitations is helpful and that it is possible to get accommodations. I often find myself laughing about the funny mistakes I make writing. I know I am wired different. However, I do find myself using technology to supplement my deficiency in written expression. But I think of this as trying to overcome the LD not hiding it." 
"I just thought, 'This is so like me.' When I got to the end though, I guess, it is just the wording of it, but I felt like I was really lazy-you know, when I talked about not wanting to do jobs that were difficult for me. I am trying to challenge myself so that I can become more independent."

"It was good. It made sense. It absolutely made sense. It accurately portrayed me and the heart of the matter-my continuing to deal with my learning disabilities. I know other people with learning disabilities who feel similar to me, especially about how hard it is in every part of life. Staying organized will always be really difficult for me."

6 "I wish I would have spoken more fluently in the interview. I use technology for help and do put in longer hours to overcome the differences my colleagues take for granted. I do choose carefully who I disclose my disability to and down play its effects, if any, on my performance. In the event that I do disclose my disability, it's usually sparked by situations where a mistake--numeral misplacement or misspelling--was discovered and pointed out. In my profession it seems as though I'm the minority being dyslexic. I can't say I run into many engineers or science related professionals that seem to understand the affliction I face. It's my opinion that it's look upon as vulnerability. You made a good point however, maybe this is something I did carry with me from my school days and the segregation of some classes and the stigma of this perceived by classmates.

With that said, my disability has made me strive to prove to myself and others that I can perform as well as, if not better than, the 
majority. I feel the disability and the support of my wife has made me the successful in my career. So, it's my opinion my disabilities have enhanced my abilities!

I was told you could never get better at it, and I found that the more I write reports, the better my sentence structure and writing gets. My writing has gotten a million times better than it was in the past."

7 "When you wrote about how important what people do and say is to me, you're right. My friends, my boyfriend, and my family have more faith in me than I do in myself. They tell me I can do anything, but I am still afraid to try some things. Everything else was good."

8 "I don't know if I agree with everything. I sound kind of selfish because I don't tell my students, but I don't want them to see me as an easy target. Maybe when I get more comfortable, I might try to talk to a few of them."

$9 \quad$ "Everything you wrote sounds ok. I have been tellin' some other kids about how they need to do good in school because it 's hard in the world. I know that others with LD do good in life but it's hard for me to get a good job because I don't have college. Maybe I should try again." 


\title{
Appendix C
}

Vita

\author{
Christine M. Sampson \\ 257 G.C. and P. Road, Apartment \#1 \\ Wheeling, West Virginia 26003 \\ (304) 233-7294 \\ csampson@bethanywv.edu
}

\section{Education}

October 2008 "Risk and Stigma Management in Higher Education: practical Skills and Policy Guidance for Disability Services and College Personnel" Association on Higher Education and Disability

June 2008 "Students with Asperger's Syndrome" Post-Secondary Institute Training Institute, Portland, ME

August 2004- Doctoral candidate, West Virginia University

August 2009 Dissertation: Life Stories of Selected Adults with Learning Disabilities: How They Come to Understand and Choose to Reveal Their Disabilities

Summer 2005 Learning Strategies Trainer Update, Bridgeport, WV

Fall $2003 \quad$ Learning Strategies Trainer Update, Bridgeport, WV

Winter 2001 Learning Strategies Trainer Update, Bridgeport, WV

Summer 2000 History Alive! Level One Training and Certification, Richmond VA

Spring 2000 Lindamood-Bell Training, Phonemic Awareness and Visualization, San Luis Obispo, CA

Summer 1999 Wilson Language Training, multi-sensory teaching for severe language disabilities, Cleveland, $\mathrm{OH}$

Summer 1998 "The Master Student” student retention program, Baltimore, MD

Summer 1987 Strategies Intervention Model Training for Trainers, University of Kansas, Lawrence, KS

1978-Present Advanced coursework in Special Education and Educational Leadership Studies

1974-1978 M.A., Special Education (Learning Disabilities K-12), West Virginia University, Morgantown, WV

1973-1974 Endorsement: Mental Retardation, West Liberty State College, West Liberty, WV

1967-1971 B.A. Education (English, Speech, Language Arts 5-12), West Liberty State College, West Liberty, WV 


\section{Professional Experience}

June 2006- BETHANY COLLEGE, Bethany, WV

Present Director, McCann Learning Center

Administer all aspects of the McCann Learning Center including Fundamental Studies, the Program for Academic and Social Success, the Writing Center, and Disability Services.

July 2005- BETHANY COLLEGE, Bethany, WV

June 2006 Assistant Professor, Teaching and Social Services

Teach Professional Education and Special Education courses; advise students; participate in committee work; provide service learning opportunities; other duties as assigned.

January 1999- WHEELING JESUIT UNIVERSITY, Wheeling, WV

June 2005 Assistant Professor, Teacher Preparation Program

Develop and teach Professional Education and Special Education courses; write and administer grants; advise students; participate in committee work; collaborate with outside agencies; advocate for individuals with disabilities.

Summer 2002 OHIO DEPARTMENT OF EDUCATION, Columbus, OH Assistant Director for School Reform and Federal Programs

Collected and analyzed data relevant to No Child Left Behind (NCLB); represented the Office of School Reform and Federal Programs as we began the redesign of the Education Management Information System (EMIS) to reflect the standards of NCLB; summarized for stakeholders research related to NCLB.

$1994-2000$

SAMPSON EDUCATION SERVICES, Wheeling, WV

Proprietor

Instructed students with learning difficulties in a 1:1 or small group setting; collaborated with schools and home; provided workshops for parents and teachers on such topics as Attention Deficit Disorders, inclusion, cooperative learning, learning disabilities, legal issues, and advocacy.

1987-1996

BETHANY COLLEGE, Bethany, WV

1994-1996 Assistant Professor of Professional Studies and Field Placement Coordinator. Taught upper level education courses as listed below; advised students; coordinated field placements; established relationships with urban schools for multicultural placements; supervised early field experiences and student teaching.

1994-1992 Director of Academic Services (Center for Academic Success, Special Advising, Media Center, and Developmental Studies). Developed, implemented, and evaluated programs within the division; prepared and monitored budget; fostered institutional/community partnerships; procured and monitored grants; advocated ADA provisions and 504 regulations; taught special education courses as listed below.

1990-1992 Instructor in Education and Director of Special Advising. Taught Human Development I/II, Introduction to the Exceptional Learner, Educating the Specific Learning Disabled Student, Assessment for Learning Disabilities, Methods for Specific Learning 
Disabilities, Early and Middle Childhood, and Working with Students in the Mainstream; supervised student teachers; wrote grants; advised students.

1987-1990 Director of Special Advising and Lecturer in Education. Developed, marketed, monitored all aspects of Special Advising (a comprehensive support program for students with learning disabilities and attention deficit disorders); taught education courses; coordinated study skills program/orientation program for high-risk students.

1984-1999 WEST VIRGINIA UNIVERSITY, Morgantown, WV

1986-1996 Adjunct Instructor. Taught graduate courses in Special Education; supervised student teachers completing M.A. in Special Education.

1984-1986 Instructor. Supervised student teachers completing coursework for M.A. in Special Education.

1984-1985 Graduate Research Assistant. Developed job acquisition and work adjustment strategies to assist mildly handicapped students with the transition from the school setting to successful employment.

$1974-1983$

OHIO COUNTY SCHOOLS, Wheeling, WV

1980-1983 Learning Disabilities Teacher, Bridge Street Junior High School. Developed and implemented model team teaching program to facilitate the full integration of students with disabilities into the mainstream. Program awarded West Virginia Department of Education Outstanding Special Education Program, 1983.

Summer 1980Director, Summer Learning Disabilities Program. Coordinated and supervised the first academic summer program for students with learning disabilities. Site selected by West Virginia University as a practicum site.

1978-1980 Learning Disabilities Resource Teacher, Elm Grove Elementary School. Instructed students with learning disabilities; assessed students' abilities and achievement levels; modified curriculum and instructional methods; in-serviced staff and ancillary personnel; collaborated with teachers, and consulted with parents/guardians of students receiving special education services.

1977-1978 Individual Education Program (IEP) Coordinator. Performed diagnostic assessments of all students referred for/enrolled in special education; conducted Placement Advisory Committee meetings; in-serviced county-wide staff on methods, materials, assessment tools, observation techniques, IEP writing, legal issues are related to special education, and conferencing techniques; coordinated observations, materials, and meetings for Special Education On-Site Review Team.

1976-1977 Department Chairperson, Special Education, Wheeling Park High School. Coordinated and supervised special education teachers and ancillary special education staff; administered guarantees of PL 94-142; collaborated with teachers and students to provide optimal learning experiences; instructed a basic skills/tutorial non-categorical resource room.

1974-1976 Learning Disabilities Teacher, Wheeling High School. Began West Virginia's first high-school level program for students with learning disabilities; integrated instructional program designs to expand programming for Wheeling Park High School; designed and presented awareness and transition in-services for department heads of the consolidating high school staffs. 


\section{Presentations}

Try Another Way, presentation for Diocese of Charleston-Wheeling, Wheeling, WV (August 2005)

Web D.I.G.s, a two-day technology workshop for K-4 teachers, Doddridge County, WV (August 2004)

Service Learning: The Ultimate Win-Win Partnership, Council for Exceptional Children International Convention, New Orleans, LA (April 2004).

A Journey to Africa, Technology, Reading, and Learning Disabilities Conference, San Francisco, CA (January 2004)

A Statewide Study of the Perceptions of Special Education Teachers, West Virginia Council for Exceptional Children, Morgantown, WV (November 2003).

Integrating Technology in the Classroom, a one-day workshop for West Virginia Technology Integration Specialists, Charleston, WV (Summer 2003).

A Statewide Study of the Perspectives of Special Education Teachers, Council for Exceptional Children International Convention, Seattle, WA (March 2003)

What to Do When What You're Doing Isn't Working, a three-day workshop for third-fifth grade teachers, Ohio County Schools, WV (November 2002)

Multiple Intelligences in the Classroom, Ritchie County, WV (August 2002)

LINCS and Word Identification Learning Strategies, Ohio County Schools, WV (August 2002).

A Journey to Africa, West Virginia Council for the Social Studies and the Appalachian Geographers, Pipestem State Park, WV (2001).

Multisensory Language Instruction, Marshall County, WV (Fall 2001)

\section{Professional Organizations}

AHEAD

NADE 